\title{
THE ART OF
}

PORTRAIT PAINTING 


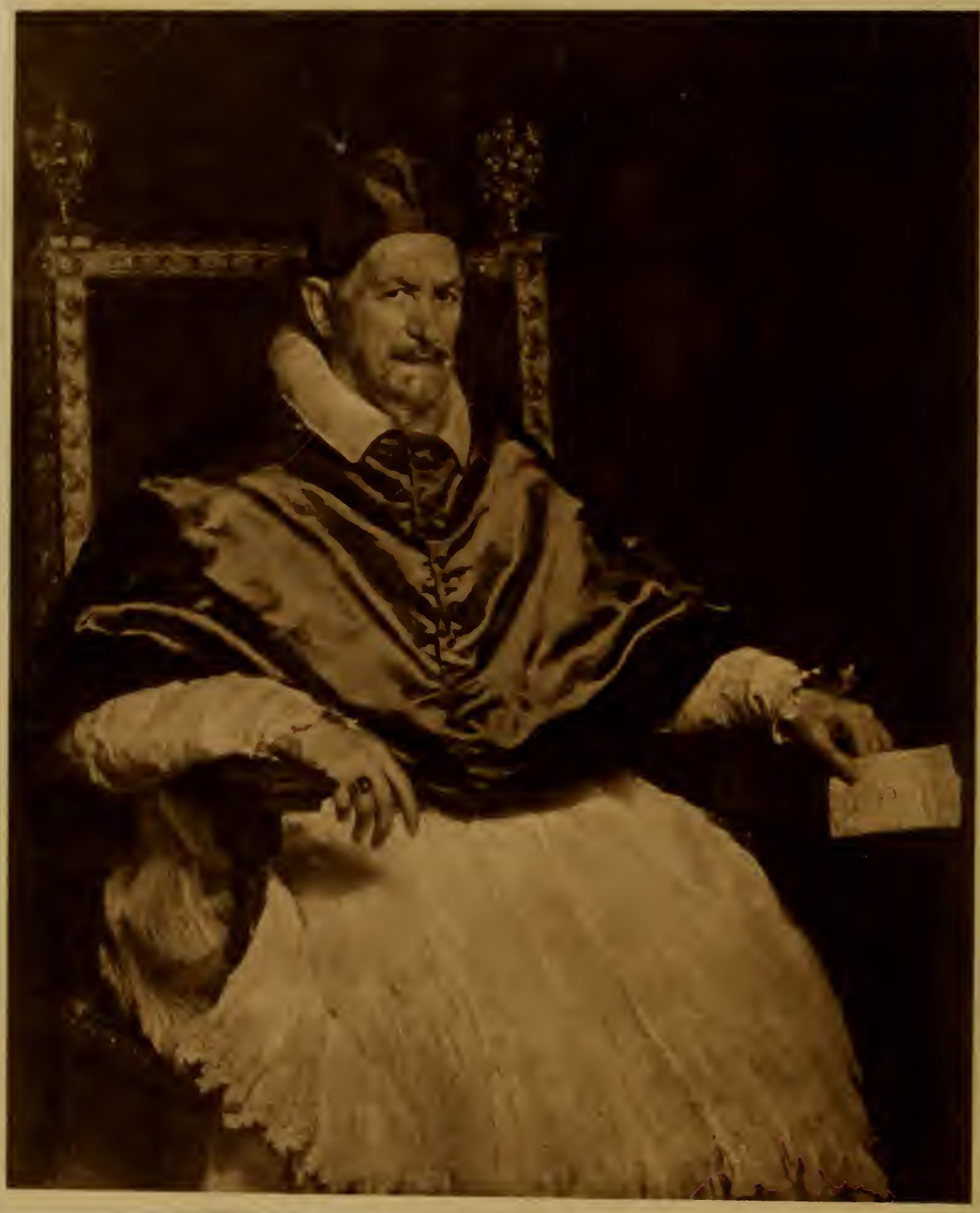


Q. Geoffey W. Saw

1904. 




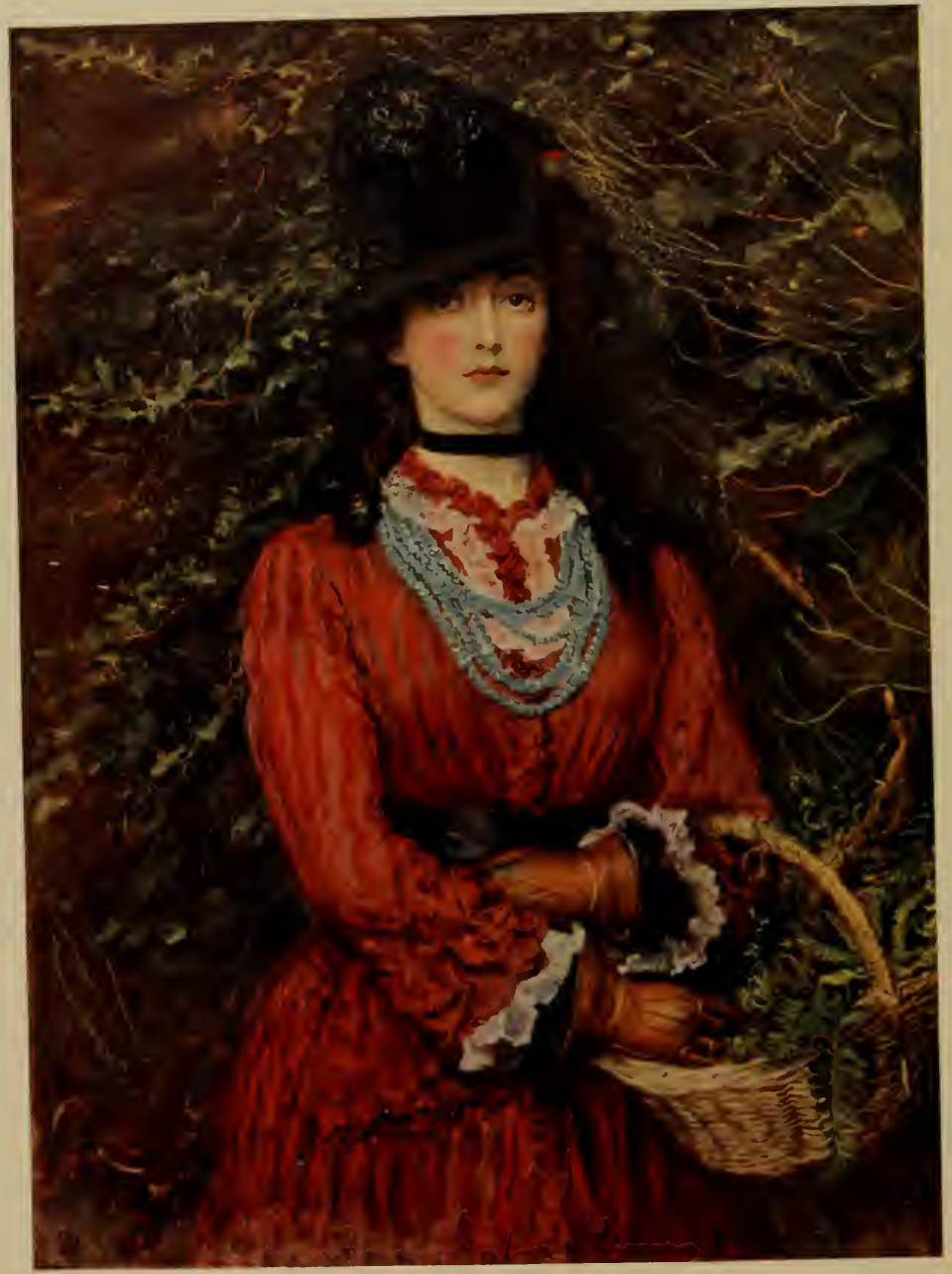


MISS EVELEEN TENNANT (MRS. FREDERIC W. H. MYERS).

BY SIR J. E. MILlais, BART, P.R.A.

By permission of Mrs. Tennant. 



\section{THE ART OF \\ PORTRAIT PAINTING}

BY

\section{THE HON. JOHN COLLIER}

Vice-President of the Society of Portrait Painters

Author of "A Primer of Art" and "A Manual of Oil Painting"

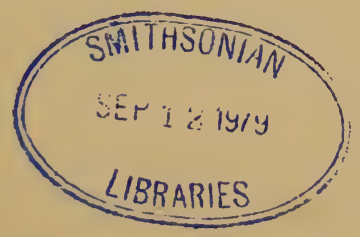

WITH FORTY-ONE ILLUSTRATIONS

IN COLOUR AND HALF-TONE

CASSELL AND COMPANY, LIMITED

LONDON, PARIS, NEW YORK AND MELBOURNE

MCMV. ALL RIGHTS RESERVED 



\section{PREFACE.}

I HAVE to thank Sir James Knowles for his kind permission to reproduce in the historical section of this work the substance of an article on "Portrait Painting in its Historical Aspects," which appeared in The Nineteenth Century some ten years ago (this, again, was founded on a lecture delivered at the Royal Institution).

My thanks are also due to Mr. Edwin Bale, for whose counsel in helping me to select the illustrations and for whose care and patience in supervising the reproductions I cannot be sufficiently grateful.

On Mr. Bale's advice I have tried the experiment of reproducing some of the pictures by the three-colour process-a method which has been very much improved of late. I was a little nervous about this, but I think the results have fully justified the step.

Colour is such an important element in portraiture that where it is possible to give a fairly truthful suggestion of it in a reproduction it is surely worth while to do so. Of course some pictures lend themselves much better to reproduction than others, but most of those that I am able to give are extraordinarily faithful to the originals.

This little work has no pretensions to be an exhaustive treatise. There are many omissions-many eminent names have been left out, especially amongst the modern artists; but as far as it goes I trust it will be found accurate and helpful. 



\section{CONTENTS.}

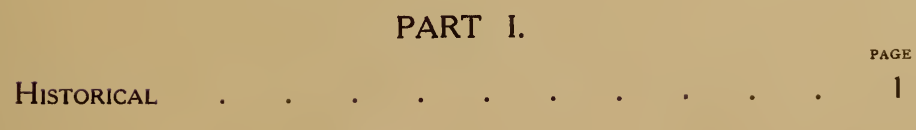

PART II.

Aims and Mẹthods of the Great Masters . . . 36

PART III.

The Practice of Portrait Painting . . . . . 77 



\section{LIST OF ILLUSTRATIONS.}

Bastien-Lepage, J. . . "My Grandfather" . . . . . . Plate No. 36

Cooper, Samuel . . . General Monk, Duke of Albemarle . . " , ,40

Gainsborough, T., R.A. . Mrs. Sheridan and Mrs. Tickell ("The Misses

Linley "). Colour . . . . . " , 15

Mrs. Robinson ("Perdita "). . . . . . " , 28

Ghirlandajo . . . . The Birth of John the Baptist . . . . " " 2

Giotto . . . . Head of Dante . . . . . . " , 1

Hals, Frans . . . . The Company of St. George, 1627 . . . " , 8

Dr. Albert Van Nierop. Colour . . . . , , 26

Holbein, Hans _ . . Hubert Morett . . . . . . . " " 20

Reskemeer, a Cornish Gentleman . . . . . , 21

George Gisse. Colour . . . . . . „2 22

Holl, Frank, R.A. . . The Duke of Cleveland . . ‘ . . " „19

Lavery, John, R.S.A. . . Portrait in Grey and Blue. Colour . . . " " 35

Leonardo da Vinci . . The Gioconda (Monna Lisa) . . . . " " 3

Millais, Sir J. E., Bart., P.R.A. Miss Eveleen Tennant (Mrs. F. W. H. Myers). Colour Frontispiece

Rt. Hon. W. E. Gladstone . . . . . Plate No. 30

John Ruskin . . . . . . . ” , 18

Moroni, Giambattista . . Portrait of a Tailor. Colour . . . . „ „ 5

Orchardson, W. Q., R.A. Viscount Peel. Colour . . . . . " 33

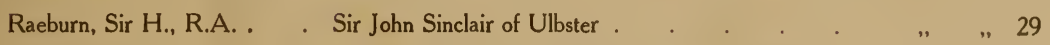

Rafael, Sanzio . . . Leo X., with Cardinals Giulio de' Medici and Ludovico de' Rossi . . . . . . , 4

Rembrandt van Ryn . . The Lesson in Anatomy . . . . . " " 10

Central Figures from "The Night Watch" . . . , II

The Syndics of the Clothworkers' Guild . . . , 12 
Reynolds, Sir J., P.R.A. . Mrs. Siddons as "The Tragic Muse." Colour . Plate No. 16 Dr. Johnson . . . . . . . . . . . 38

Romney, George . . . . "The Parson's Daughter." Colour . . . . . " " 17

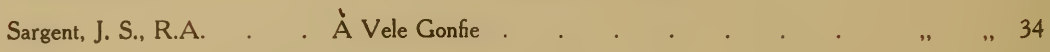

Titian

- La Bella . . . . . . . . . . . 6

L'Homme au Gant . . . . . . . . . . 23

Ariosto. Colour . . . . . . . . " 24

Van der Helst, B. . Banquet of the Civic Guard to Celebrate the Peace

of Munster . . . . . . . . . . . 9

Vandyke, Sir A. . . . Maria Luisa de Tassis Colour . . . . . " " 13

Philip Lord Wharton . . . . . . . " , 27

Van Eyck, Jan . . . Jan Arnolfini, of Lucca, and his Wife Colour . $\quad$ " 7

Velasquez . . . . Central Figures from "The Surrender of Breda" . . . " 14

Las Meninas . . . . . . . . 25

The Jester (Pablillos of Valladolid) . . . . . . . 37

Watts, G. F., O.M., R.A. . Miss Alice Prinsep (Mrs. Stracey-Clitherow) Colour _ , „ 32

Whistler, J. McN. . . Miss Alexander. Colour . . . . . . . . 31

Wright, Joseph, of Derby "An Experiment with the Air-Pump " . . . . . . . 39 


\section{THE}

\section{ART OF PORTRAIT PAINTING.}

part I.

\section{HIST ORICAL.}

7 HE whole of modern art has been so much influenced by that of the Greeks and Romans that it is obviously necessary in any discussion of the history of portrait painting to consider what portraiture was like in classical times.

The prior art of Egypt may be left aside. To quote MM. Perrot and Chipiez, "Painting never became an independent and self-sufficing art in Egypt. It was commonly used to complete sculpturesque effects, and it never freed itself from this subordination." In fact, it had its origin in the painted bas-relief, and it never advanced beyond the process of filling in an outline with flat tints. Obviously this can never give us portrait painting in the true sense of the term, and it is with this branch of portraiture only that I am here concerned.

Classical art has aroused such unbounded enthusiasm, and has been investigated with such loving care, that in spite of its remoteness we really know a great deal about it-much more, indeed, than we know of the art of the Middle Ages. But there are very serious gaps in our information; and it is precisely in the present subject that one of these gaps occurs.

We can form a very good idea of what classical painting in general was like from the remains at Pompeii, for although they 
belong to a comparatively debased period, they are certainly an echo of the finest Greek art. That is to say, the best Greek painting was like that, only a great deal better. But it is a very curious thing that there is practically no portraiture amongst the Pompeian remains. The nearest approach to it is in the great mosaic of the battle of Issus, where the principal figure is certainly meant for Alexander; but it is a very conventional rendering, and, being in mosaic, can only give a vague idea of what a painted portrait was like. So that we can take it that there is no direct evidence bearing on our subject until we come to the funeral portraits of the late Roman period, found in the Fayoum. These are so debased in style that I am afraid they cannot help us much, though I will refer to them further on.

Nevertheless, although direct evidence is wanting, we can form from analogy with the other arts a fairly definite idea of the characteristics of classical portraits. There is little doubt that in the best period of Greek art they were very good indeed. In one particular, that of rendering the essential dignity of the human face and figure, I think it is likely that they have never been equalled. This quality is found again in the best periods of Italian art, though probably in a lesser degree, but it has been generally deficient in the work of even the finest painters of other nations.

Among the leading characteristics would be, in the first place, great restraint. There were no very powerful effects of light and shade. Although some classical painters obtained renown for their mastery over chiaroscuro, yet we may be sure that it fell far short of the boldness and resourcefulness of Velasquez and of Rembrandt. Violent gestures, strained attitudes, forced expressions, would assuredly be absent. They were very sparingly used even in subject pictures; for portraits they would be considered quite inadmissible. Neither the face nor the figure would be shown in positions that require foreshortening. It is one of the most curious 
generalisations to be made from the paintings and mosaics at Pompeii that there is hardly any foreshortening of human figures; at the most there are a few limbs treated in this way.

The execution would never be rough or coarse; even when slight it would not look unfinished. The colouring would be bright and admirably harmonious.

To modern eyes these portraits might seem a little lacking in character. That is to say, the touch of caricature that we are gradually getting to think essential to a speaking likeness would certainly be absent. The person would be represented at his best, and would often be slightly idealised. Even when an ugly person was faithfully portrayed (and some painters had the reputation of not extenuating defects) there would be a certain suave play of line which would go far to redeem this ugliness. A Greek of the best time must have had a feeling for the gracefulness of a delicately modulated curve that would give a sense of beauty to everything he touched.

So that portraiture amongst the Greeks was at its best a most harmonious and dignified art, more beautiful probably than it has ever been since-at its worst still, harmonious and decorative, but rather tame and lacking in character.

No doubt it degenerated somewhat when it got into the hands of the Romans. Their artists, indeed, were mostly Greeks, but they were influenced by the inferior taste of their patrons. Do we not read of a colossal portrait of Nero, I 20 feet high? It stood in a garden, and must have been one of the most monstrous of sky-signs. Then the exuberance of Roman demands would induce a hasty and mechanical production. We hear, for instance, that Varro had a gallery containing no fewer than 700 portraits. And so the age of shoddy set in, until the fashionable artist became a mere manufacturer of graceful inanities.

And here we come at last on direct evidence as to what was 
the popular taste in portraiture in the second and third centuries of the Christian era. The likenesses of the dead found in the GræcoRoman cemetery of the Fayoum must not, of course, be regarded as good specimens of the art of the time. They were, no doubt, hastily executed by very inferior practitioners, but they show the prevailing fashion for all that.

It is very curious how nearly they resemble the fashionable portraiture of a very different period-that of the early Victorian era; they have so many of the characteristics of that interesting though extremely debased form of art. The eyes are too big, the noses too long, the nostrils too narrow, the mouth too small, the face too oval, the neck too thin and long, the shoulders too sloping. These likenesses of the early Christian times seem strangely familiar when one thinks of the books of beauty of some fifty years ago.

And then this style became gradually less and less human, until it developed into Byzantine formalism, such as we see in the celebrated mosaic at Ravenna, representing Justinian and Theodora-a work of the sixth century.

After this we lose our art for a time, for portrait painting, as we understand it, can hardly be said to have existed during the early Middle Ages.

We first get a glimpse of it again when Italian painting revived in the person of Giotto. This great innovator was born in 1276 , and died in 1336. His influence on art can hardly be overrated, although his master Cimabue had started the revival to which Giotto gave so remarkable an impetus. To quote Vasari : " $\mathrm{He}$ became so good an imitator of nature that he banished the rude Greek manner, restoring art to the better path adhered to in modern times, and introducing the custom of accurately draving living persons from nature, which had not been used for more than 200 years." Nor, indeed, for much longer. 


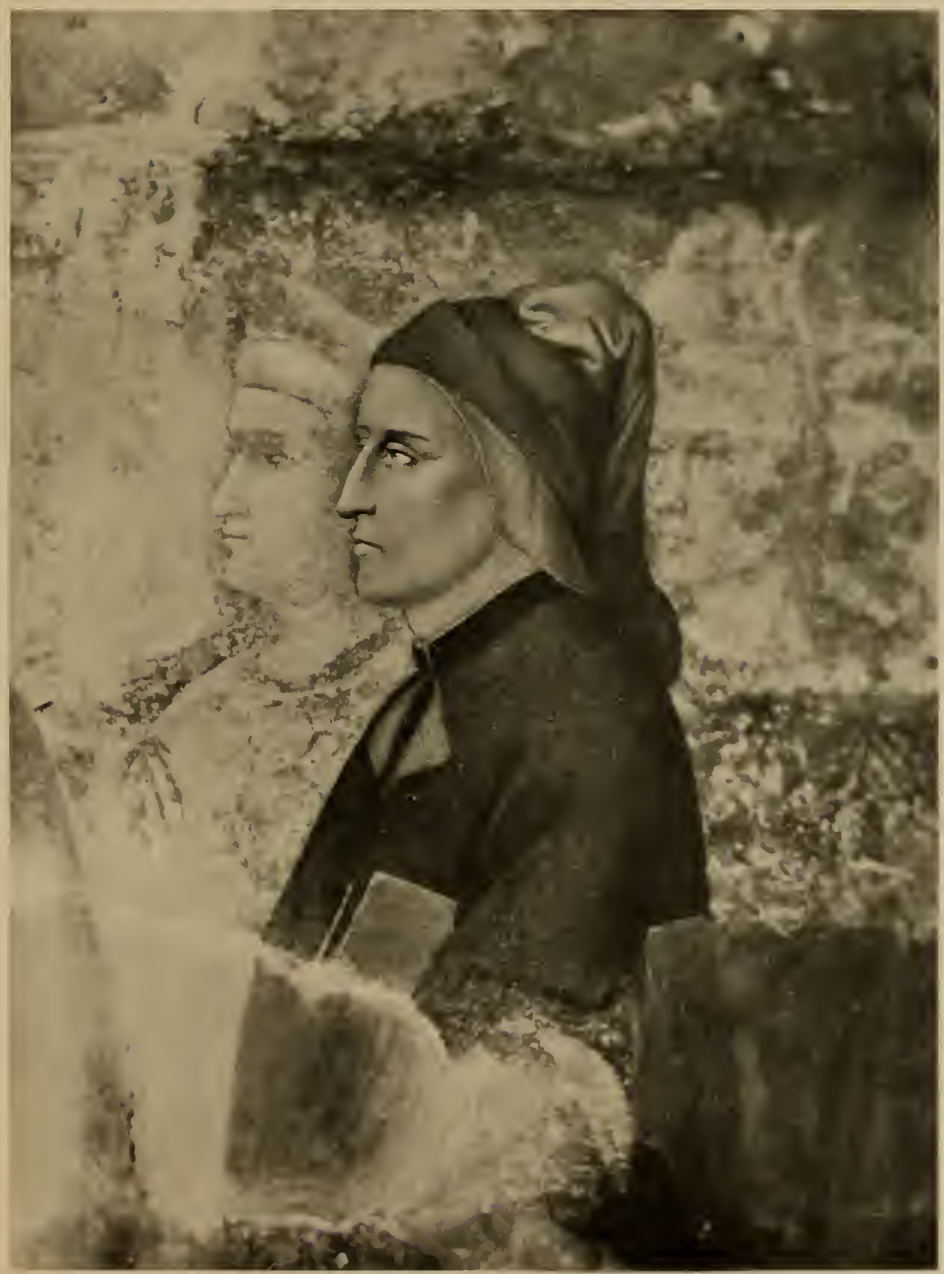

HEAD OF DANTE.

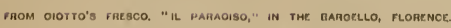

Plate 1.

From a l'hotograph by Aluari, Florence. 



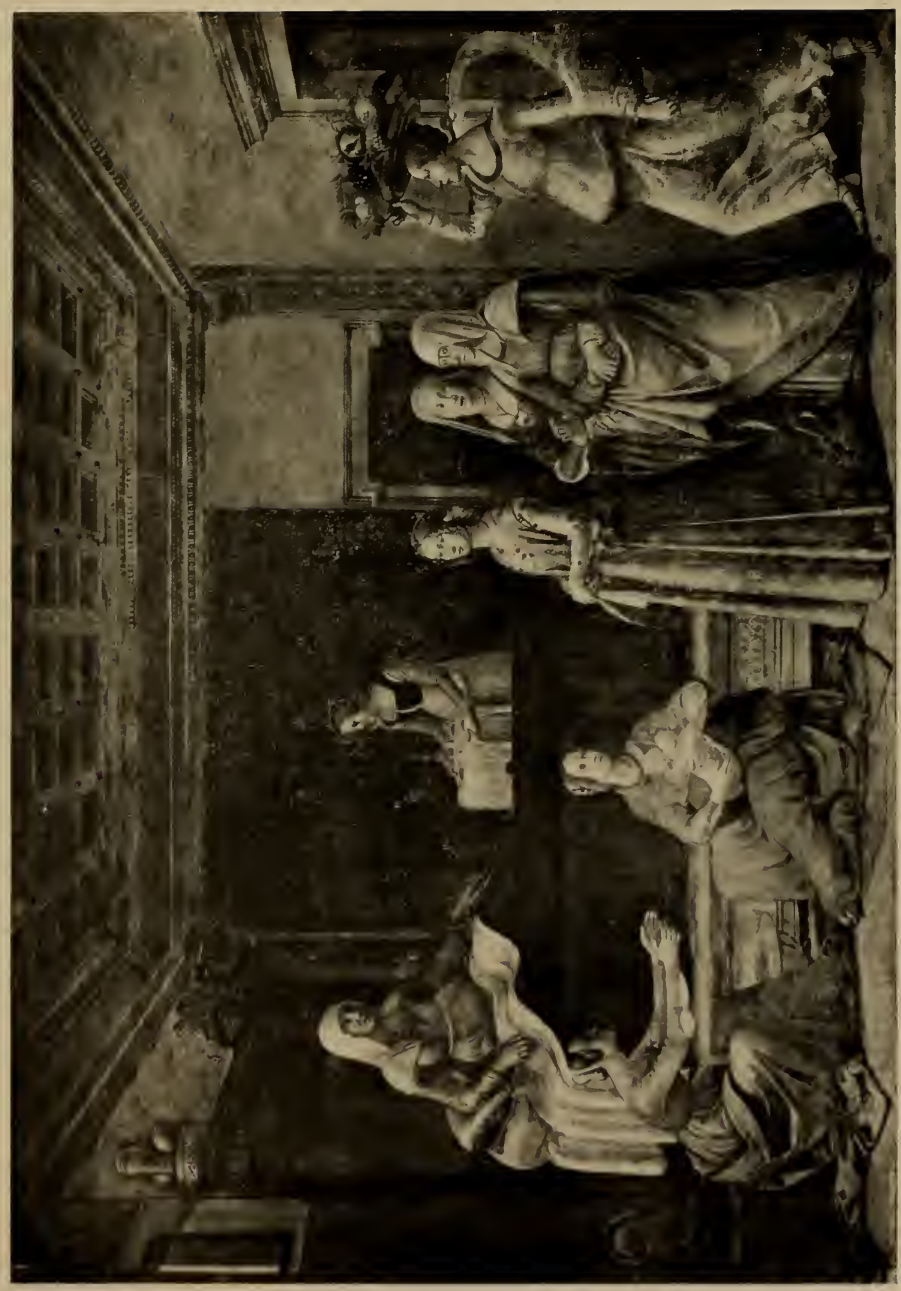

व
$\frac{0}{2}$

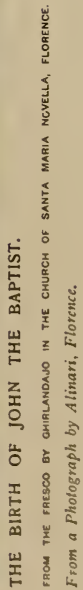



Of course, however ardent an admirer of nature a man may be, the bondage of convention is far too strong to be broken in one lifetime. To his contemporaries Giotto was an audacious realist, probably a brutal realist, or even worse, in the language of the art critics of the day. To us, his work, though vigorous, is strangely stiff and formal. His ardent study of nature led him to introduce portraits of his friends into his imaginative works. In the chapel of the Bargello at Florence, the lower portion of the great fresco of "Paradise" is filled by a procession of citizens, amongst whom is Dante with others of Giotto's friends. This very interesting work was discovered in 1840 beneath a coat of whitewash. It is much damaged, and has been extensively repainted, but in spite of this we can gain from it a very clear idea of what the great Dante looked like. (Plate I.)

The next decided advance in Italian art was due to Masaccio.

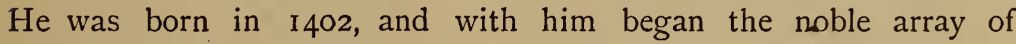
fifteenth-century masters, who, to many people (though not to myself), are more fascinating than the great painters of the sixteenth century. As usual, the advance was made by a more strict adherence to nature, and, as usual, the increase of realism produced a leaning towards portraiture. It was Masaccio who developed the practice, first tentatively introduced by Giotto, of grouping a crowd of spectators, composed of the painter's friends and acquaintances, in the midst of the historical scenes he was depicting. This practice was continued with great success by most of the fifteenth-century masters, such as Filippo and Filippino Lippi, Benozzo Gozzoli, and especially Ghirlandajo. In the picture that I reproduce by this latter master of the birth of St. John the Baptist, the beautiful figure in the foreground is a portrait of Ginevra de' Benci. (Plate 2.) At the same time they had hardly arrived at the modern conception of portraiture; that is, a picture which depends for its interest on the likeness of an individual. 
The modern practice of individual portraiture seems to have sprung up, naturally enough, with the popularity of easel pictures, and this, again, was much influenced by the introduction of oilpainting.

Whether Antonello of Messina really acquired the art from the Van Eycks or from Lucas of Leyden, as some have conjectured, is very doubtful, but it was certainly he who introduced the new process into Venice, whence it spread all over Italy.

We have now come to the full development of the art of painting that sprang up towards the close of the fifteenth century, and which was chiefly embodied in four great men, Leonardo, Rafael, Michel-Angelo, and Titian. All of these were great portrait painters in the true sense of the term, with the exception of Michel-Angelo, who seldom condescended to easel pictures and who never worked in oil.

The great advance made by the sixteenth-century painters over the pre-Rafaelites was in the much fuller utilisation of the resources of chiaroscuro. Up to this time the colours used were mostly clear and light, and only so much shading was introduced as was necessary to give relief to the figures. The value of shadow in itself was hardly appreciated; in fact, the whole conception of painting was to show everything as far as possible in a full light.

The great innovator in this matter was Leonardo. Being, as he was, as much a man of science as a painter, the problems of light and shade interested him in both capacities, and he investigated them in something of the modern spirit. By the aid of the knowledge thus acquired, he succeeded in giving to his figures a roundness and a relief that had been hitherto unknown. In fact, he carried it so far that they are sometimes over-modelled.

The extraordinary thing about Leonardo is that with his restless activity and length of years he produced so little. Indeed, of all great artists, he is almost the solitary example of unproduc- 


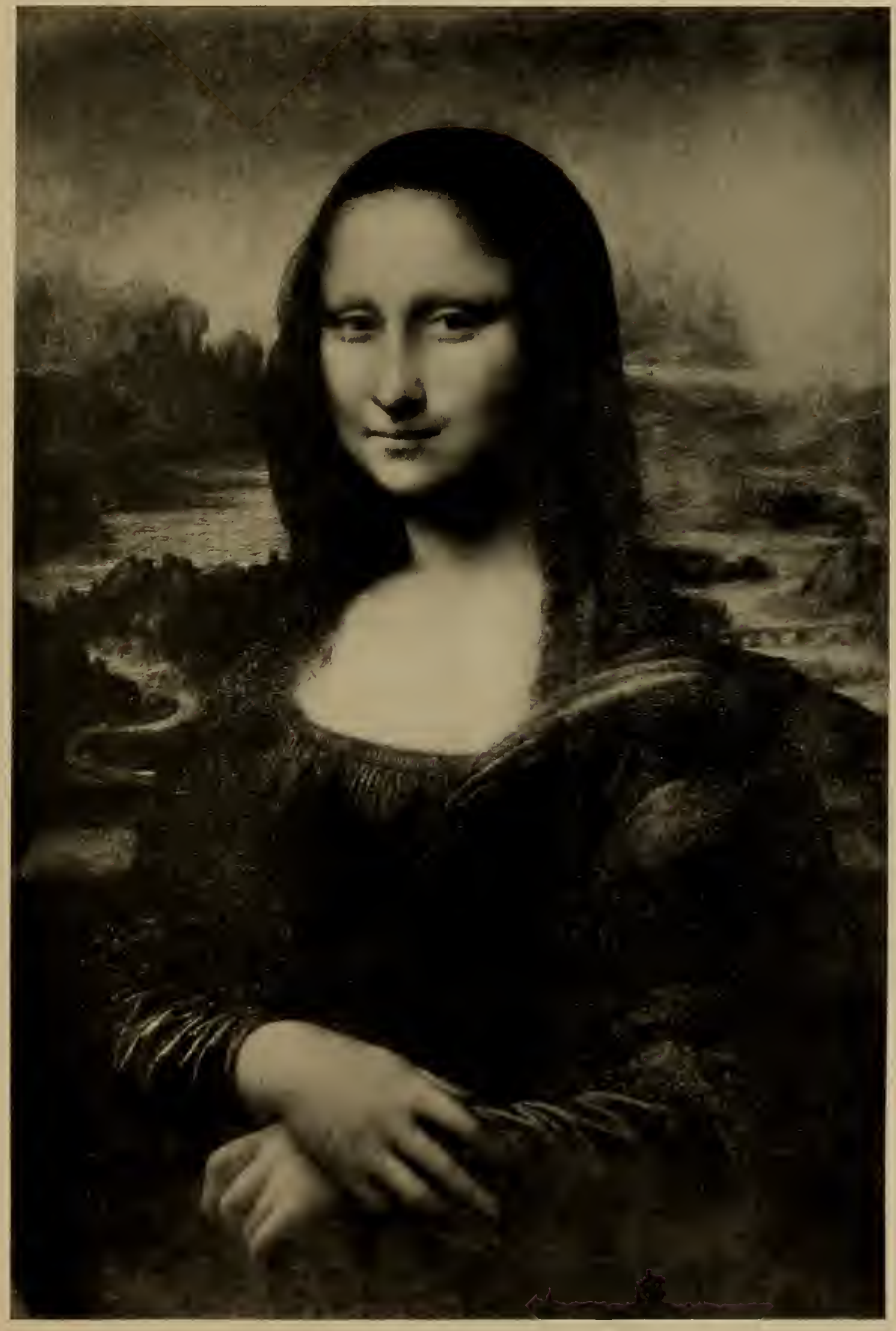

THE GIOCONDA (MONNA LISA).

BY LEONARDO DA VINCI.

Plate 3.

IN THE LOUVRr. 


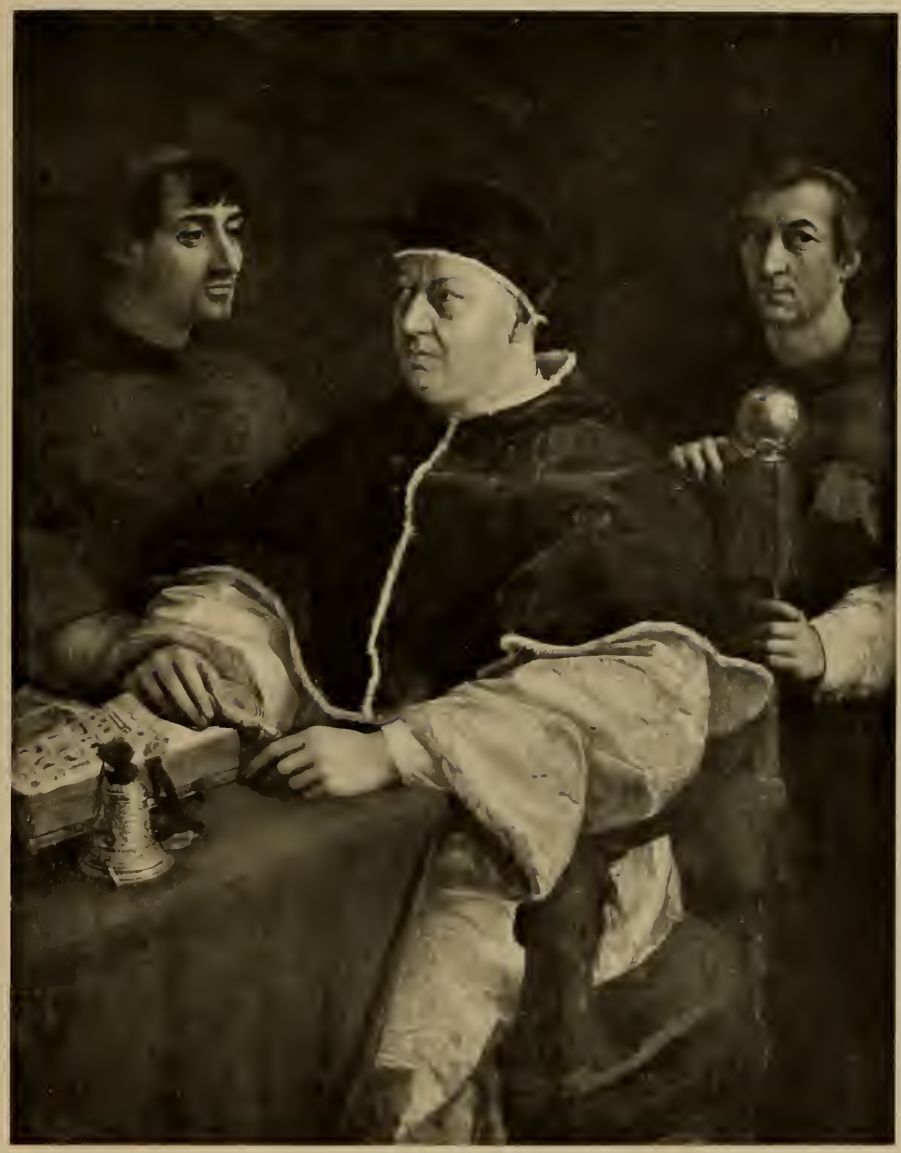

LEO X., WITH CARDiNalS GIULIO DE' MEdiCI AND LUDOVICO DE' ROSSI. BY RAFAEL.

Plate 4.

IN TKE PITTI PALACE, FLORENCE.

from a Photograph by Alinari, Florence. 

tiveness. All others (except possibly Giorgione) have been very prolific, some of them far too prolific.

Fortunately for our purpose, one of the few works of the master that are absolutely authentic, and at the same time fairly well preserved, is the celebrated "Monna Lisa" at the Louvre. The colour of the face has faded a good deal, owing, no doubt, to his pernicious habit of glazing thinly over a preparation in monochrome, but the exquisite modelling remains. The delicacy of this modelling and the subtlety of the expression have never been surpassed. It is one of the finest examples of highly finished and elaborate portraiture that exist. (Plate 3.)

Rafael also was a very fine portrait painter. Indeed, to those who, like myself, get rather tired of the mannered grace of his religious pictures, there is something very refreshing in the manly vigour and simplicity of his portraits. Take, for instance, the celebrated group of Pope Leo X. with the Cardinals Giulio de' Medici and Ludovico de' Rossi. This is an admirable example of thorough workmanship and acute characterisation. (Plate 4.)

But the portrait painter amongst the great Italian artists of the Renaissance was undoubtedly Titian. That is to say, he devoted more of his energies to this branch of art than either Rafael or Leonardo. Taken all round, I am inclined to consider Titian as the greatest painter who has ever lived, though not the greatest portrait painter. It was hardly possible for Titian, with his very elaborate technique, with his habit of keeping pictures by him for years, retouching and retouching until they attained their final perfection, to give to his portraits the intense vitality that Velasquez and Rembrandt obtained by their much more summary methods. But setting aside a certain lack of spontaneity, Titian's male portraits, with their wonderful dignity and their rich but sober colouring, can hold their own with those of any other master. His female portraits are apt to be stiff. 
It is odd how many fine painters appear to have suffered from this lack of ease in the rendering of their female sitters. It was owing, I believe, to the extreme gorgeousness of the clothes that the ladies always insisted on putting on for their portraits. The men, leading perforce a more active life, suffered less from this disability. The female portraits of Velasquez are an extreme example of this tyranny of clothes. Even Vandyke, with all his mannered grace, was seldom able to get his women into anything like the easy attitudes that distinguish his men. And certainly the Italian portraits of the best time are very disappointing in this respect. In the National Gallery there is a very striking example of this failing. Amongst the numerous fine portraits by Moroni, there is one of a lady in a red dress, sitting in a chair in a most uncomfortable position, which is an extraordinary contrast to the easy and unaffected attitudes of the men. Again, in the same gallery there is the magnificent female portrait by Bordone, which in spite of, or rather because of, its magnificence is as stiff and awkward as possible. We find another very marked example in one of the most celebrated of Titian's portraits-the one in the Pitti Palace commonly called "La Bella." (Plate 6.)

It is in many ways a charming picture, but why could he not have given it the ease and grace of the draped figure in his "Sacred and Profane Love"? Because there, as in other subject pictures, he was able to modify the costume a little to suit his artistic tastes, whilst "La Bella" would have perished sooner than allow the slightest alterations in her uncomfortable finery. I may mention that the head has been a good deal repainted.

As an example of the much greater ease that Titian displayed in his male portraits I have reproduced the celebrated "Homme au Gant" of the Louvre-a much more satisfactory work than "La Bella," in spite of the decorative qualities of the latter picture. 

Plate 5.

\section{PORTRAIT OF A TAILOR.}

BY MORONI, IN THE NATIONAL GALLERY, LONDON. 


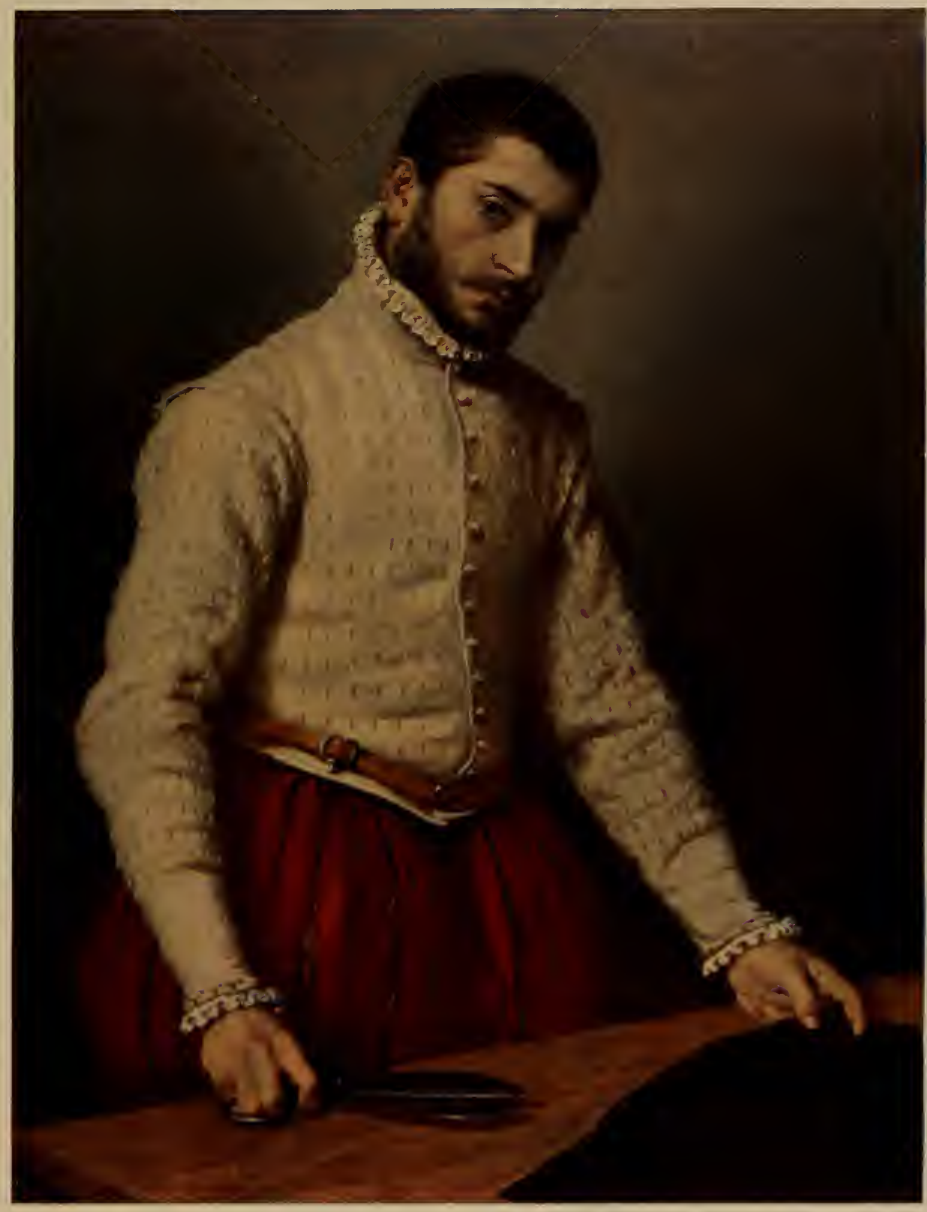





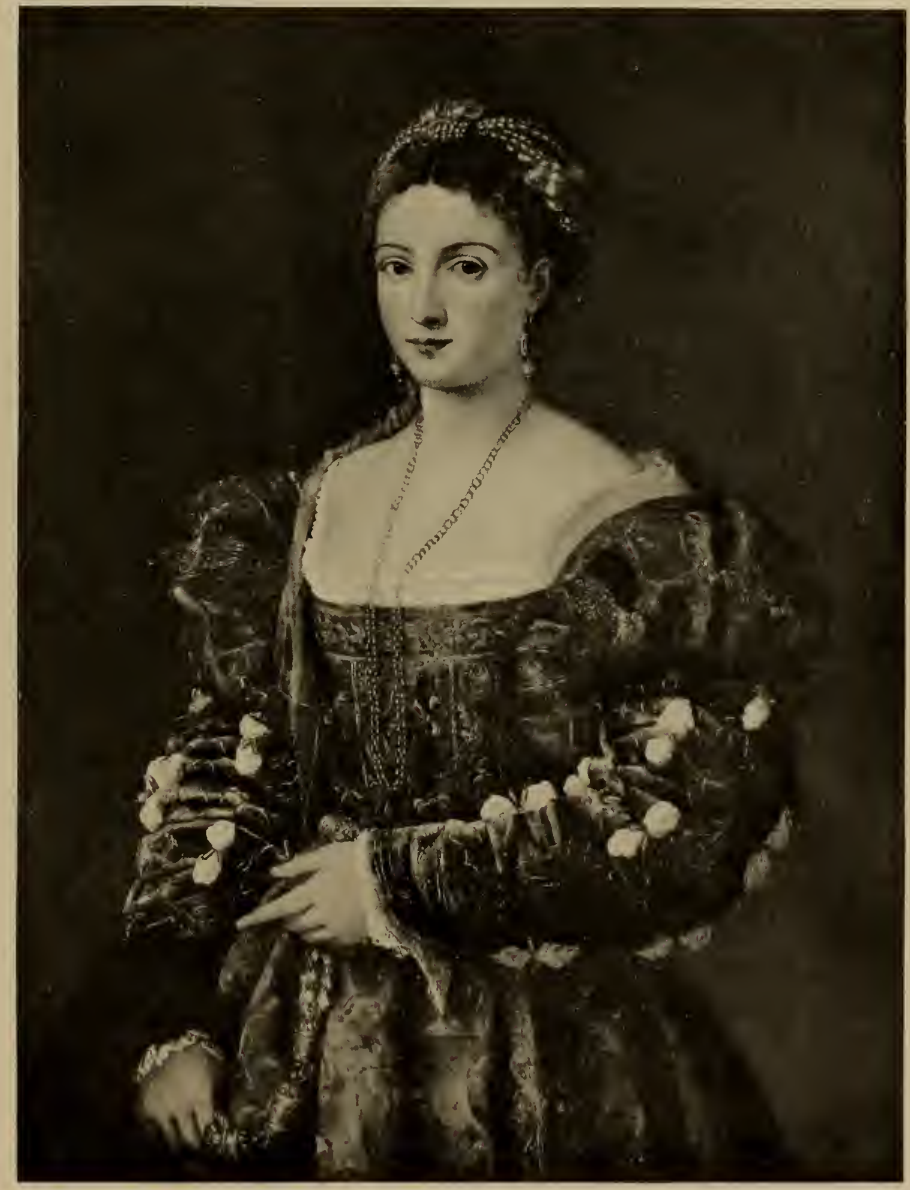

LA BELLA.

BY TITIAN.

Plate 6.

in the PITTI PALACE, FLoREnOE.

From a l'hotographt by E. Alinari, Florcnce. 

The painter above mentioned, Moroni, is about the first example that we come to of the specialised portraitist, such as we know him in modern times-that is, a man whose chief business is the painting of portraits, and whose other work, if he does any, is comparatively unimportant. Moroni's subject pictures are quite uninteresting and have fallen into merited oblivion, but as a specialist he takes a very high rank. The celebrated "Tailor" in our National Gallery is an admirable example of his skill. (Plate 5.)

Its great quality is a certain refined and dignified simplicity. The pose and expression are perfectly natural; the colouring is a harmony in grey, the background is a plain tone, and there are no accessories beyond the scissors he is holding in his hand and a small piece of drapery on the table. The execution is smooth, but not tame. Altogether a wonderfully fine example of portraiture pure and simple.

But then what a charming person to paint-really we poor moderns are rather severely handicapped!. Where shall we find sitters like this amongst our tailors-or elsewhere?

We must now leave the Italian school, although of course there are many admirable portrait painters, especially amongst the Venetians, whom I have left unnoticed. The great characteristic of this school is the feeling for human beauty and human dignity; no doubt this feeling was still greater in classical art, but, with this exception, it has never been manifested to anything like the same extent by any other school of painting. Dignity is to be found in Spanish art, but certainly not beauty of face or figure, and the Flemish and Dutch schools, until we come to Vandyke, were strikingly deficient in both dignity and beauty. Vandyke approached the Italian ideal, but more as an imitator than with real conviction; and the great English school of the eighteenth century showed a wonderful feeling for grace and charm of a somewhat 
flimsy and superficial order, but certainly fell far short of the robust and magnificent types of the great Italian masters.

It is an interesting inquiry why it is that the non-Italian schools are so deficient in the feeling for human beauty. It is only in Italy that we find a really fine ideal. The other nations, however admirable their schools of painting may be, are all far below her in that one quality. As to the cause of this I have little doubt that, at the time of the Renaissance, the Italian was the handsomest race in Europe, so that the painters had better models to choose from; but what was probably of greater importance was that the classical influence never entirely died out, and also that Italy was full of the remains of ancient art.

We will now turn to the early Flemish school, to which a special interest attaches, as, according to tradition, the Van Eyck family were the inventors of oil-painting.

There were three members of the family who were renowned artists-Hubert, his younger brother John, and his sister Margaret. Vasari ascribes the invention to John. Of course, this has been hotly disputed, and many learned works have been written on the subject, mostly made in Germany.

However that may be, it is John who claims our attention now, for, amongst other things, he was a very remarkable portrait painter. We have in the National Gallery an admirable specimen of his skill. It is a small picture of a merchant and his wife, done with an exquisiteness of minute finish that is quite unsurpassable. (Plate 7.)

Unlike the Moroni, it is very rich in all kinds of accessories, wonderfully painted. The two figures have an immense amount of character, but, considered as human beings, they are appallingly hideous. One reflccts at once how much more beauty would have been shown in an Italian picture of the same date, and is inclined to put it down to the natural ugliness of the Flemish race, when 

Plate 7.

JAN ARNOLFINI, OF LUCCA, AND HIS WIFE. BY JaN VAN EYCK, IN THE NATIONAL Gallery, LONDON. 


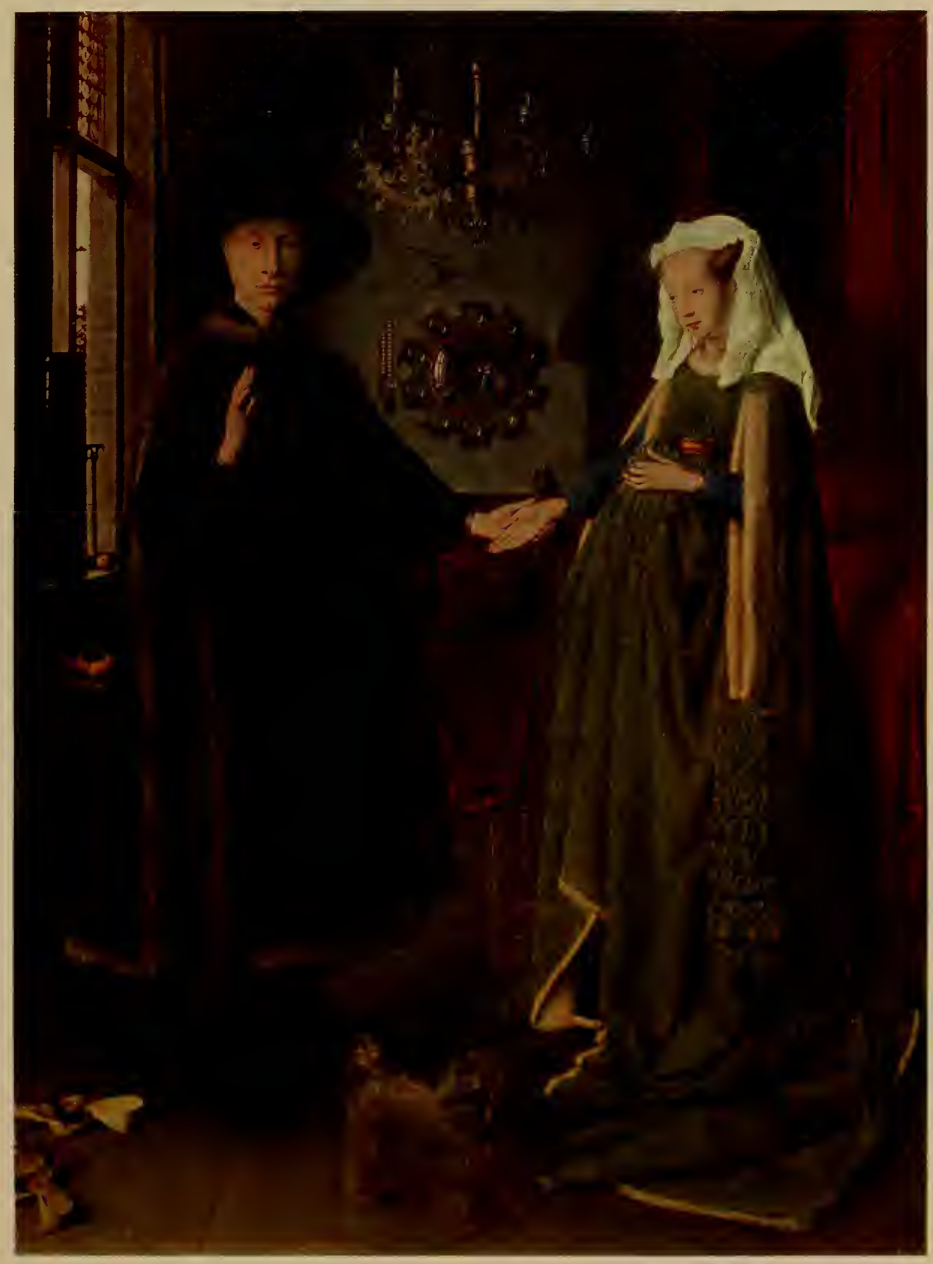



these speculations are suddenly cut short by the discovery that these people are Italians-a certain Arnolfini of Lucca and his wife. They may have been, of course, exceptionally ugly Italians, but I cannot help thinking that the ugliness resides a good deal in the Flemish way of looking at them. A very fine portrait for all that, and, as usual with the Van Eycks, time has had but little effect on its vivid pigments. The invention of oil-painting seems to have been complete at its first inception; the successors of the Van Eycks have never bettered the process.

The great Holbein seems, as regards his method, a direct descendant of these Flemish masters, although he belongs to a different school-the German. He also was a member of an artistic family. His father and (probably) his grandfather before him were called Hans Holbein, and were noted painters. Hans Holbein, the younger, was born at Augsburg in 1494, or thereabouts.

In 1526 he visited England, where he was received into the family of Sir Thomas More, to whom he brought an introduction from Erasmus. He soon was appointed Court painter to Henry the Eighth, and became the fashionable portrait painter of the day.

There is one well-known anecdote concerning him that has always troubled me. It is said that he was sent to paint the portrait of Anne of Cleves, and that he so flattered the likeness that Henry proposed to the lady on the strength of it, but was bitterly disappointed when he saw the original. Now, it is very difficult to believe that Holbein ever flattered anybody; his portraits show him to be the most uncompromising of realists, and bear the stamp of the most minute and subtle accuracy. They are not lovely as a rule, but then human beings are not lovely as a rule. Not being an Italian, he may have missed some of the essential beauty of his sitters, but his portraits are never grotesque and are often dignified. Their chief characteristic is the look of absolute and unrelenting truth. 
The next school of portraiture to be considered-the Dutchis perhaps, as a school, the greatest of all. At the head of it stands Rembrandt; but there were a great number of portrait painters of high merit, and there was a general encouragement of portraiture that must have helped materially to bring out the latent talent of the artists. It was in Holland that the practice sprang up of painting great portrait groups: the mayor and aldermen of a town, the syndics of a guild, or a company of archers or arquebusiers making merry-which, indeed, seems to have been their chief occupation. These portrait groups involved problems of extreme difficulty, and the way in which these difficulties were overcome by the Dutch masters excites the admiring wonder of every modern artist.

The first really great name that occurs in Dutch painting is Frans Hals. He was born in 1584 and died in 1666. His work can be properly studied only at Haarlem, where there are a number of his great portrait groups, representing mostly companies of arquebusiers. (Plate 8.) These were a sort of volunteers, who, in Hals's time, existed less for purposes of national defence than for friendly jollification-something like our Foresters and Oddfellows, but of a higher social grade.

These groups at Haarlem are distinguished by a most extraordinary vivacity. The men seem to be all talking and laughing in a most animated manner; their gestures and attitudes are wonderfully life-like; the composition is varied and skilful, and the general play of colour is delightfully fresh and vivid.

But still I do not put Frans Hals quite in the first rank of portrait painters. He has alivays been famed for his essentially painter-like qualities, but I am firmly of opinion that this is a mistake. He can brush in a costume or a background with great dash and vigour, but his flesh-painting-and this is, after all, the 


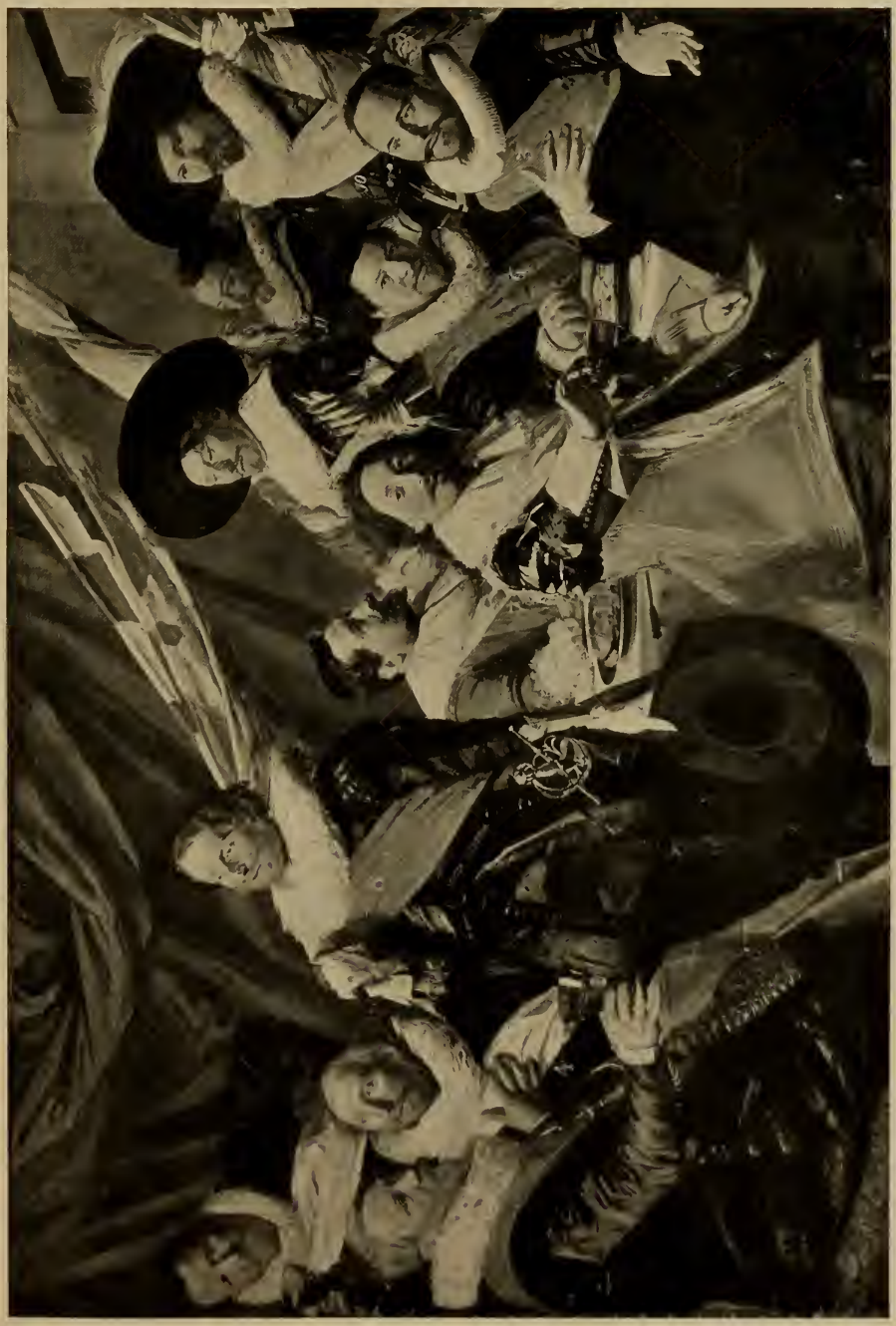

$\frac{1}{2}$

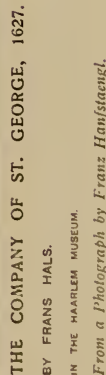





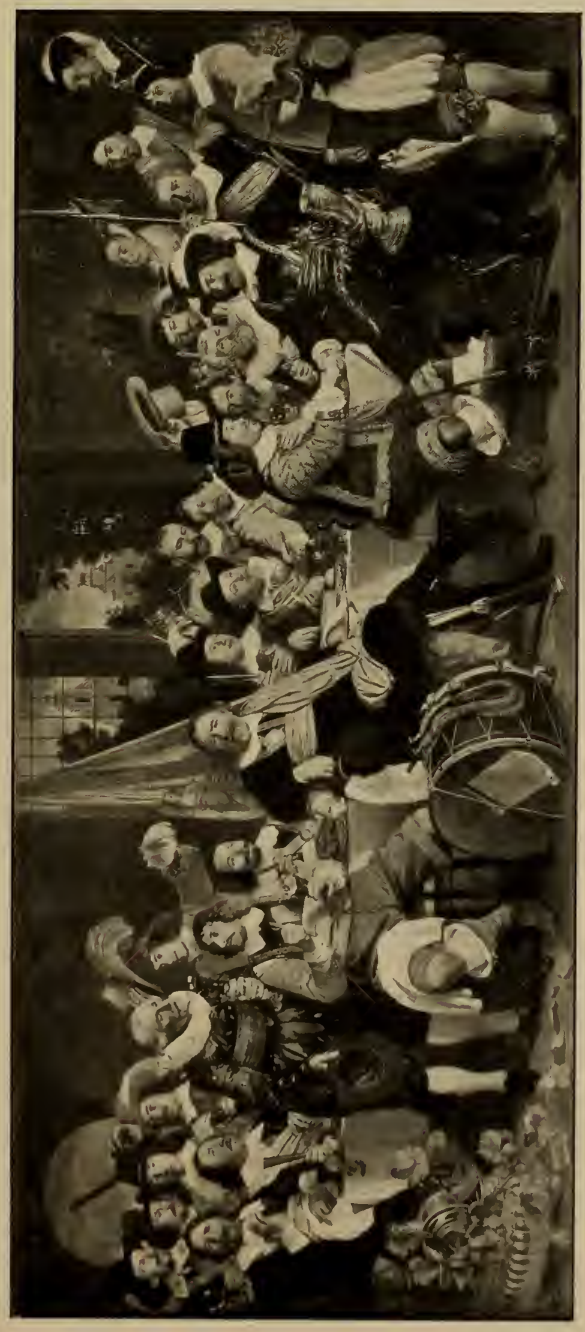

0
$\frac{1}{2}$
$\frac{8}{2}$

岌禽

$\stackrel{\vec{v}}{\infty}$

离崫

벙

암 离

会

र्य

雚

प्र

폰

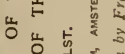

出之䠌

岁方 I

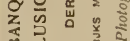

ब

崖各方焉 

real test-is distinctly inferior. In his heads he is more of a draughtsman than a painter; it is to his marvellous draughtsmanship that he owes the animated expressions for which he is so justly famous. Of course the painting is vigorous enough, but vigorous painting is not necessarily good painting. Nor do I complain of its being sketchy. Rembrandt's latest work may also be called sketchy, but it is full of the most subtle truth; whercas Hals's heads are not quite true either in colour or texture, and they are certainly not subtle.

But, for all that, no one has ever put more life into an expression.

As a contrast we will take the work of Van der Helst, who was a little later in date, as he was born in I6r3. His chef-d"curre is "The Banquet of the Civic Guard on the Solemnisation of the Peace of Munster," now in the museum of Amsterdam. It is an immense picture, containing twenty-five figures of the size of life. (Plate 9.)

All these figures and the numberless accessories display a high degree of finish. Nothing is scamped, nothing is sacrificed. There is not a tumbler nor a piece of bread that is not admirably well painted, and yet the whole is harmonious and well balanced. The miracle of it is that such a high level of achievement has been kept up without faltering throughout the whole of this immense picture. Every head is admirable in character; every figure is well posed and finely drawn. But perhaps the most extraordinary part of the picture is the hands.

There is nothing in which even the greatest painters more often fail than in the hands, and yet here we have them in a great variety of positions, all faultlessly drawn and painted, and with so much individual character that it has been said of them that if they were cut off and thrown in a heap one could select with ease the hands that fitted each of the heads. When we 
come to painters like Vandyke, who gave everybody the same hands, or like Sir Joshua and Gainsborough, who seldom drew them even decently, we shall be able to appreciate at its just value this great achievement of Van der Helst.

Lest my enthusiasm for this picture may seem excessive I may mention that Sir Joshua Reynolds, of all people, pronounced it "perhaps the finest picture of portraits in the world, comprehending more of those qualities which make a perfect portrait than any other I have ever seen." I do not go as far as this, for the flesh-painting is not nearly as fine as Rembrandt's, and the colouring, although good, is not that of a born colourist. Also I feel the want of concentration in the treatment. There is a certain monotony in the uniform emphasis on all the figures. Nevertheless, I think that in certain qualities, and those very important ones, this picture has never been beaten.

I must add that in no other work that I have seen of his has Van der Helst ever approached this high level. There is another large group at Amsterdam which is distinctly inferior; and his single figures are, as a rule, tame and uninteresting.

In point of time Rembrandt comes between the two painters I have just described, for he was born at Leyden probably in 1606 or 1607 .

To the best of my judgment, he and Velasquez are the greatest portrait painters who have ever lived, but I should give the palm to Velasquez.

Like that of most great artists, Rembrandt's work underwent a gradual evolution. His early style is rather smooth, and, although broad in treatment, is marked by great delicacy of detail. Then he gradually adopted a freer style of execution, which developed into the very rough and comparatively coarse method of his later years. But in each style he was admirable.

The celebrated "Lesson in Anatomy" at the Hague is the 


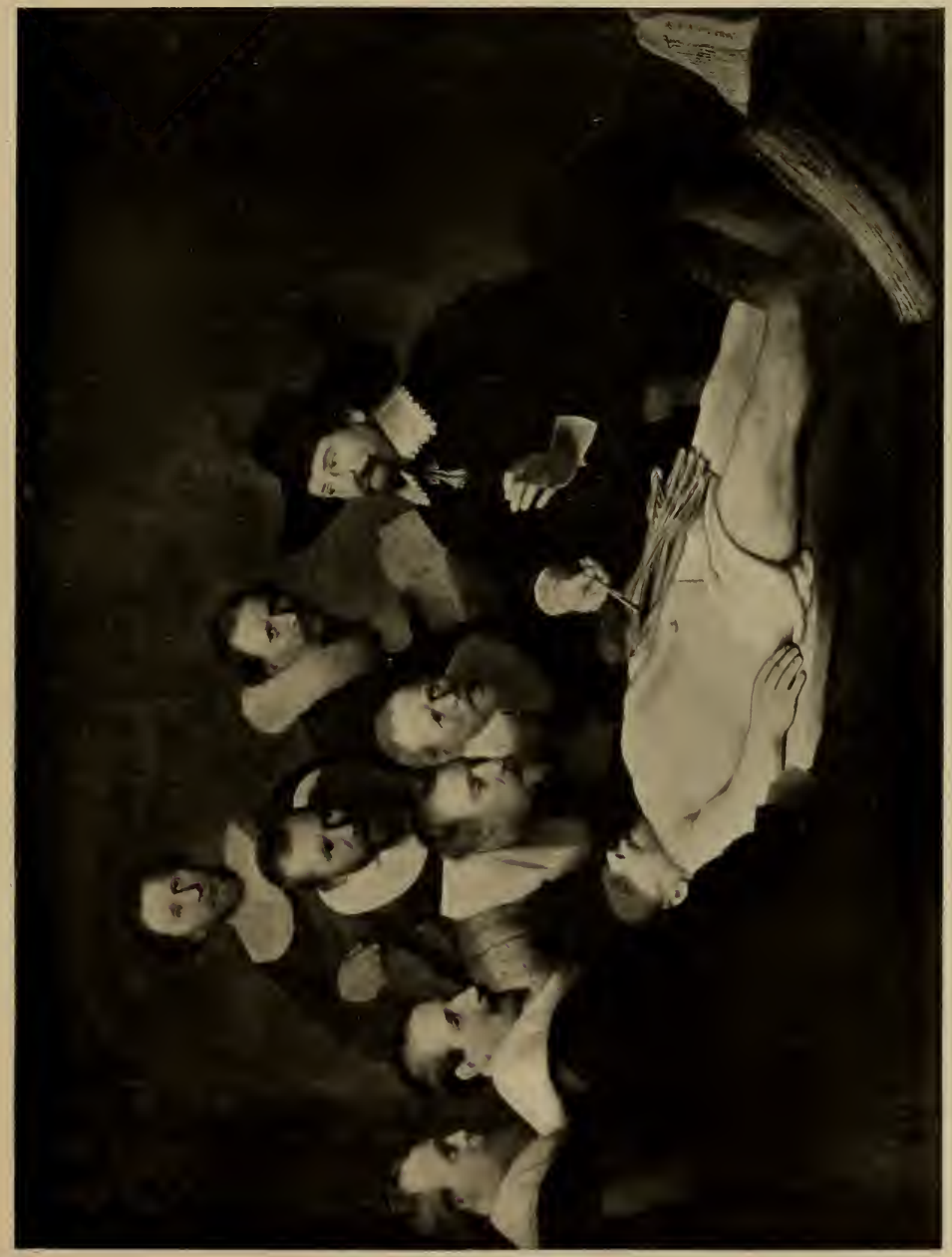

$\frac{2}{\frac{2}{2}}$

\begin{tabular}{ll}
1 \\
\multicolumn{2}{c|}{}
\end{tabular} 



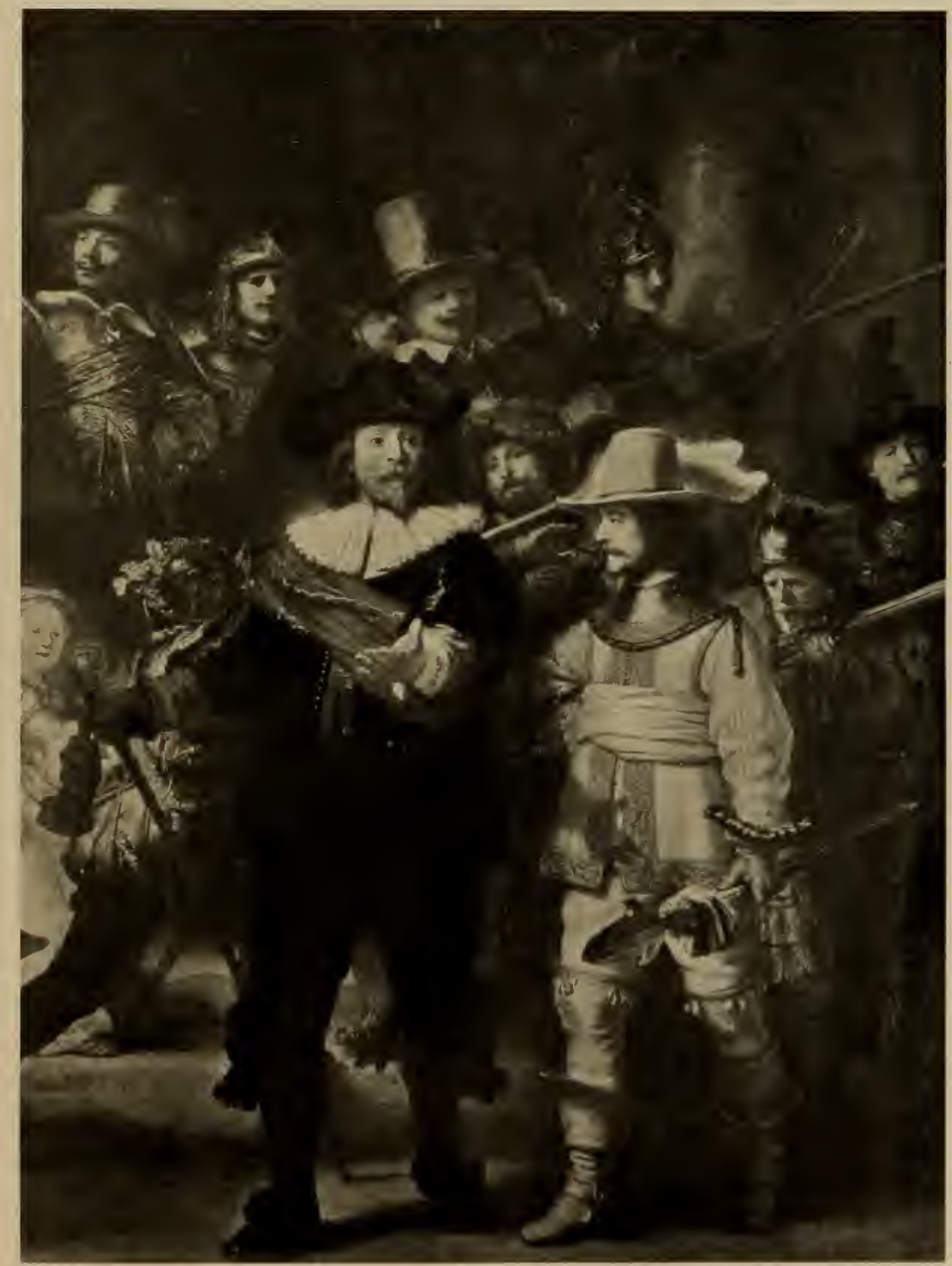

CENTRAL FIGURES FROM "THE NIGHT WATCH."

BY REMBRANDT.

Flate 11

IN THE RIJKB MUSEUM, AMETERDAM,

From a Plotograph by Franz IIanfstacngl. 

finest extant example of his earlier style. (Plate Io.) It was painted in 1632, when he was about twenty-five.

We find in it, already fully developed, his mastery over light and shade; but it is scarcely so skilful in arrangement as some of his later works.

What is very noteworthy in this early work is that the heads, although smoothly painted, are quite as vigorous as in his later and much rougher style. Of course, the reason is (though this is often overlooked) that vigour of effect depends on truth of tone and strength of light and shade, and not on thickness and roughness of paint.

Rembrandt's later style was finer than his earlier because it gave more truly the impression of texture; also the work was done more rapidly and with more ease. Consequently it was more masterly-but it was not more effective.

It is this essential truth and vigour that, to my mind, constitute Rembrandt's chief claim to be one of the two greatest portrait painters of the world. For his mastery over chiaroscuro I think he has been overpraised. This mastery he undoubtedly had, and in many of his pictures it is used most worthily to enhance the general effect, but in others it is employed in an exaggerated and unnatural manner, and degenerates into something very like a trick.

For instance, the wonderful picture which used to be called "The Night Watch" got its misnomer by reason of the excessive darkness of its shadows. It certainly does look very like a night effect, but, as a matter of fact, it was meant for daylight, and indeed for actual sunlight, as witness the definite shadow thrown by the hand of the principal figure. (Plate I I.)

It is true that the picture may have darkened a good deal, but we know from contemporary records that it was always very low in tone. Samuel Van Hoogstraten, Rembrandt's pupil, says of it: 
"It is so picturesque, so beautiful in its arrangement, and so powerful, that, by its side, in the opinion of many, other canvases look like playing-cards. Nevertheless" (he goes on to say) "I could have wished a little more light." And I wish it too. Hoogstraten's praise is not nearly warm enough for its picturesque qualities; the heads are splendid, the composition is admirable, and the colouring extremely rich and harmonious, but I feel very strongly that the light and shade are forced and artificial to the last degree, and that good honest daylight, to say nothing of sunlight, is far too fine in itself to be played tricks with in this way.

A much simpler and more natural picture is that of "The Syndics of the Clothworkers' Guild," also at Amsterdam. (Plate 12.)

This was painted in $166 \mathrm{I}$, when Rembrandt was in the fulness of his powers. It is simply a representation of five respectable merchants seated round a table with their servant waiting on them. The heads are magnificent, the lighting is simple and consistent, and the colour is as fine a combination of rich red, golden grey, and black as one could wish to see. The grouping, too, is wonderful in its quiet effectiveness. But yet, to my prosaic mind, there is one undoubted drawback: the perspective is perfectly insane. The table, covered with a red cloth (which is as fine a mass of one colour as I have ever seen in a picture), is obviously looked at from below-for we do not see the top of it. Yet the heads are certainly not looked at from below, and the lines of the woodwork behind them are absolutely inconsistent with this view of the table.

Many people, especially of the superior order, will say that it does not matter in the least-I think it does matter, but that nevertheless this is one of the finest portrait groups in the world.

Many of Rembrandt's isolated portraits are equally masterly, but I have dwelt on these groups as the painting of combined 


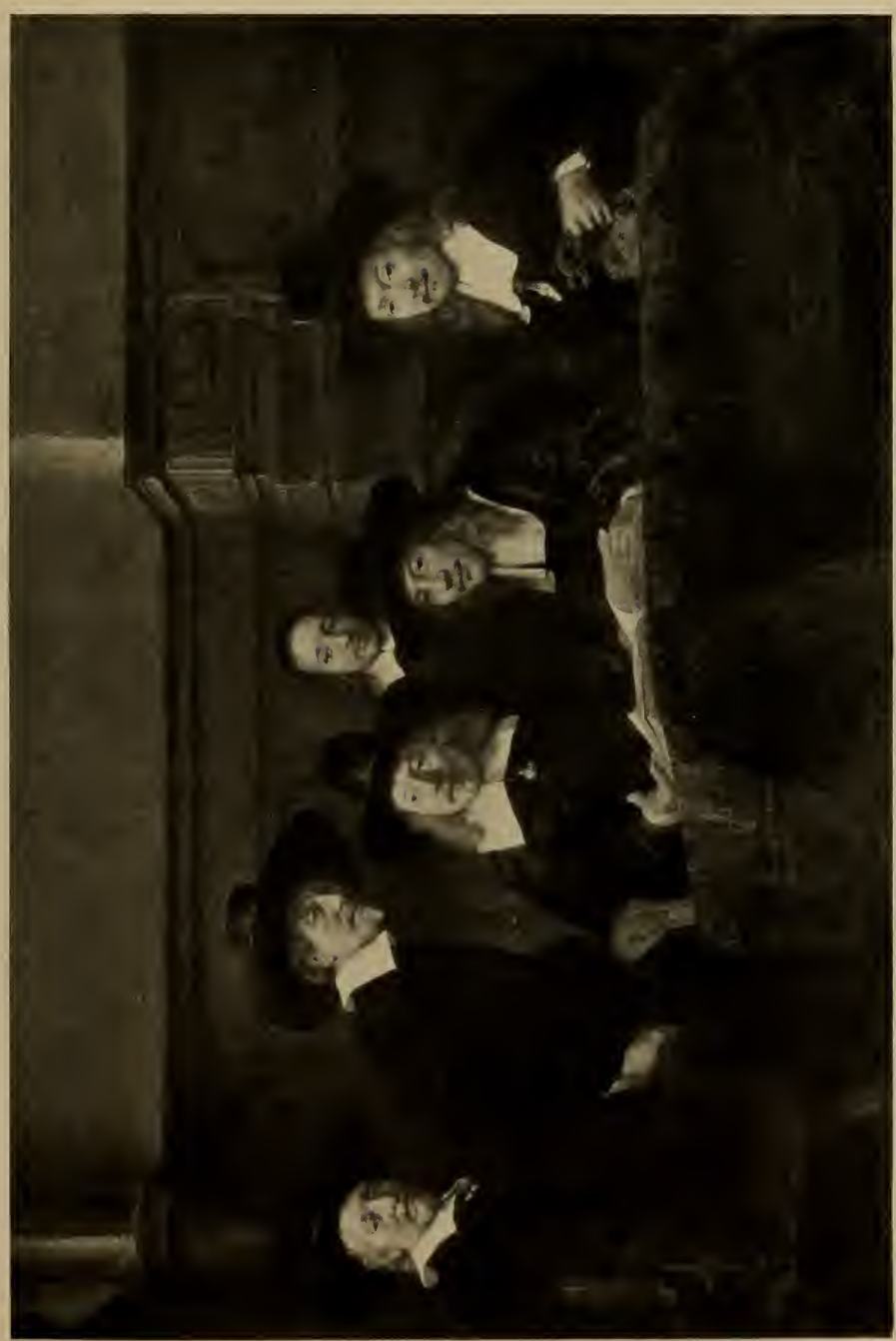

$\frac{\text { จ }}{\frac{8}{2}}$

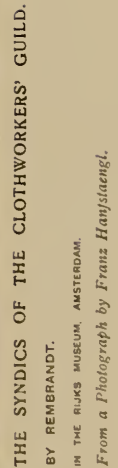



portraits is much more difficult than the painting of single figures, and there are far fewer artists who have succeeded in it.

I have already expressed my opinion that the one rival of Rembrandt is Velasquez. Indeed, I am distinctly inclined to put the Spaniard above the Dutchman.

The former, although a master of chiaroscuro, did not play the same tricks with it as the latter. His colouring too, although not so alluring as his rival's, is free from that artificial golden-brown tone which gives to many of Rembrandt's pictures a touch of mannerism. On the other hand, Velasquez was so far influenced by the excessive formality of his courtly surroundings that his portraits are often a little stiff. From this Rembrandt was absolutely free.

Velasquez was born in 1599, so he was Rembrandt's senior by eight years. Unlike Holland, Spain could not boast in his time of a large and flourishing school of portrait painters. Good portraits were produced by Murillo and others, but the great Spanish school of portraiture may be said to begin and end with Velasquez.

Like Rembrandt, he gradually worked up to the masterly and summary handling that distinguishes his later style through an early period which was characterised by great precision and some hardness. Indeed, it may be laid down as a general law in painting (a law to which I should like to call the attention of my friends the Impressionists) that the only way to arrive at a really masterly sketchiness is to do a great deal of preliminary work in a very precise and careful style. Even when the method of Velasquez was most rapid and summary, it never degenerated into carelessness; indeed, he was one of the few Court painters who have been able to resist the deteriorating influences of their surroundings. Holbein was another; they were no doubt both of them men of very exceptional character.

These surroundings, however, although they did not degrade 
the man, have certainly endangered his reputation as a painter, for the constant demand for replicas of his royal portraits necessitated his setting up a workshop, where these replicas were produced by his assistants. Although he never did careless work himself, yet he made himself responsible for a great deal of work that was done by inferior hands. It is this question of the workshop that makes it so difficult to be sure of the genuineness of any reputed work of the master. For instance, there was an exhibition at the New Gallery in 1895 in which were about forty pictures assigned to Velasquez, but I think most good judges would say that not more than six or seven of them at the outside were by his hand.

That Velasquez, when he had a good chance, could manage a portrait group as well even as the great Dutch painters can be seen from the magnificent picture of "The Surrender of Breda," commonly called "The Lances," which is one of the great ornaments of the Prado Gallery at Madrid. This is something half-way between a portrait piece and an historical painting, and is of the highest excellence in either aspect. The composition is original and striking to the last degree. None but the boldest genius could have ventured on the line of spears that rise up into the sky on the right-hand half of the picture. But the success of this startling arrangement is so obvious that from it the picture has obtained its popular title. And from the point of view of portraiture nothing can excel the dignity and distinction of the principal figure-the Marquess of Spinola, receiving with a magnificent courtesy the keys of the fortress from the vanquished General, Justin de Nassau. (Plate 14.)

A more strictly portrait group and an even more remarkable achievement from the technical point of view is "Las Meninas," in which the painter is represented at work in his studio; but this I will discuss in a later chapter. 

Plate 18.

MARIA LUISA DE TASSES.

BY VANDYKE, IN THE LICHTENSTEIN GALLERY, VIENNA. 


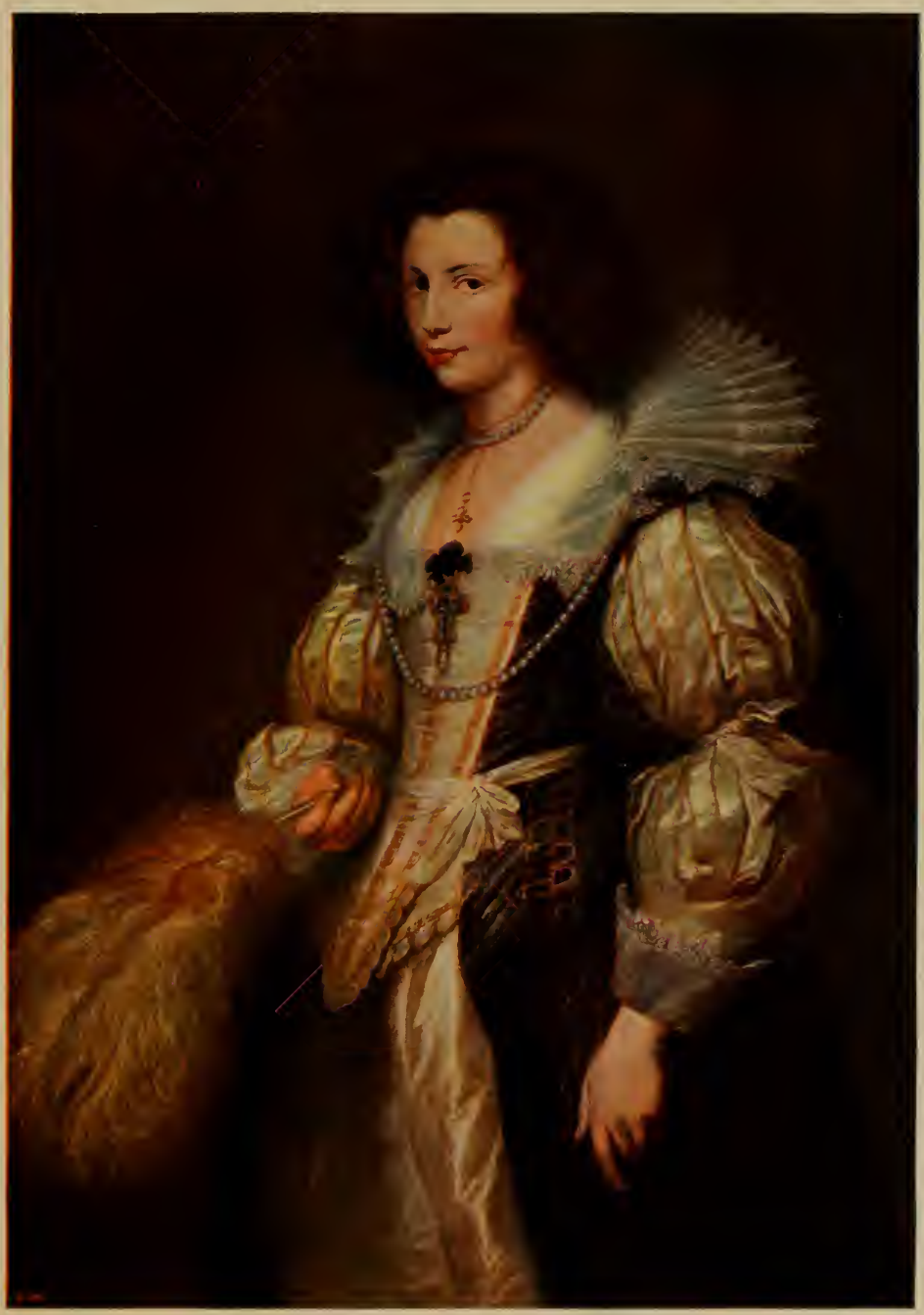





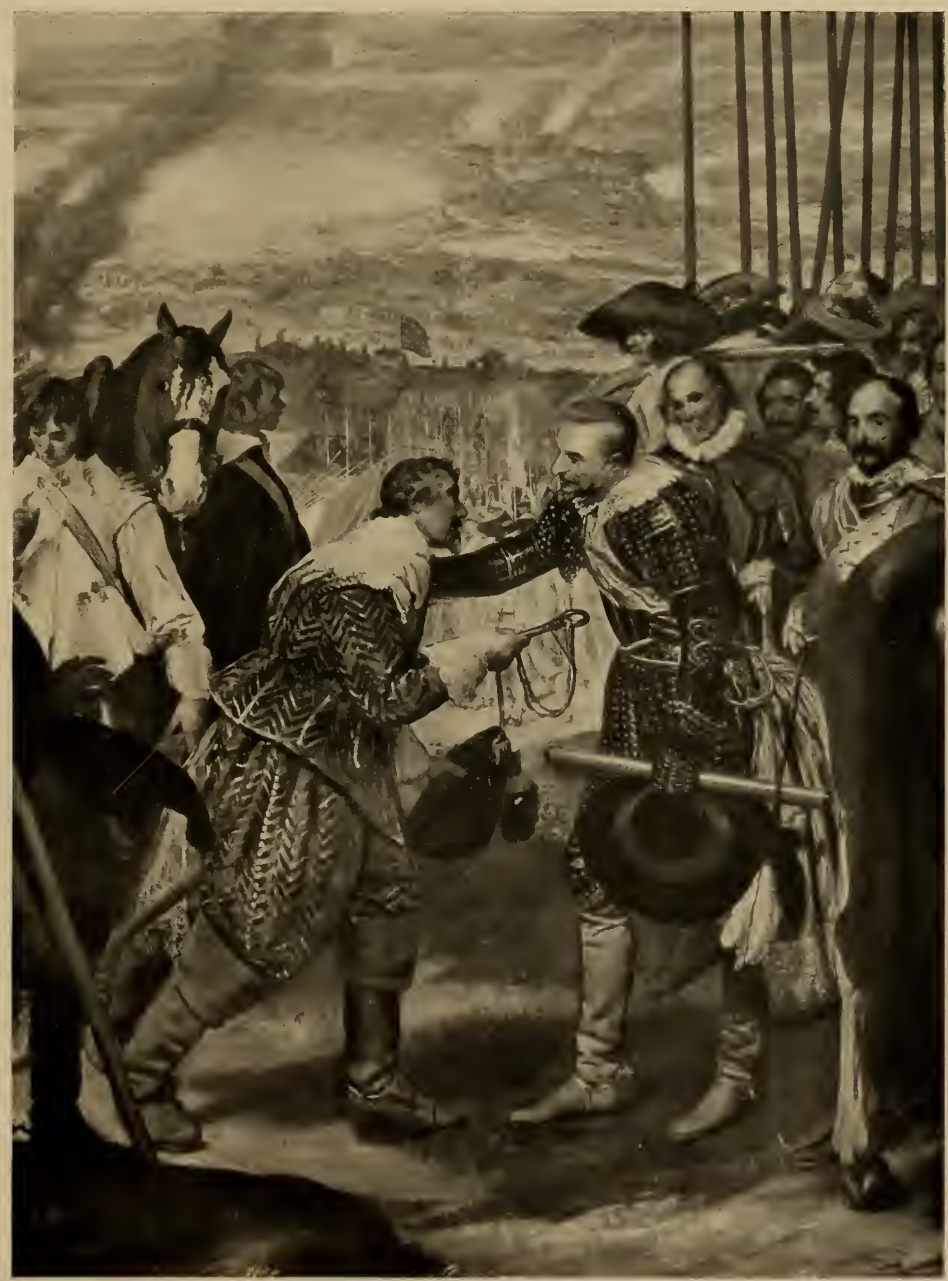

CENTRAL FIGURES FROM "THE SURRENDER OF BREDA."

BY VELASQUEZ.

Plate 14.

IN THE PAADD, MADRID.

From a Photograph by Brasn, Parts. 

We will return now to the Flemish School as embodied in Vandyke-a man of great talent, but who, I consider, has had an unfortunate influence on Art.

He was born at Antwerp in 1599-the same year as Velasquez. He became the pupil of Rubens, a bad master for a youth gifted with such a fatal facility as Vandyke. Fortunately for himself, he took a journey to Italy when he was quite a young man, and, conceiving a warm admiration for Titian and the other great Italian painters, he adopted a style much finer than the sloppy exuberance of his master, whom I have always regarded as a strangely overrated painter.

Vandyke's best portraits were painted during his stay in Italy, and after his return to his native land, whilst he was still under the influence of his Italian studies. He was not a Court painter then, and was not pushed to too rapid production by popularity and extravagance.

Unlike most of his predecessors and contemporaries, Vandyke paid great attention to female portraiture. Perhaps the best example of his skill is the beautiful portrait of a young lady of Antwerp, Maria Luisa de Tassis, in the Lichtenstein Gallery, Vienna. (Plate I3.)

In 1632 he settled in England, where his success was immediate. In that same year he was knighted, and was appointed painter to Charles the First. He died in the winter of I64I, at the early age of forty-two.

His productiveness during this short period was extraordinary, and, I may add, lamentable. He was a weak man, and very extravagant, so that his studio became at last a mere manufactory of mannered and superficial portraits.

Of course it takes a great deal to destroy such very remarkable gifts as those with which Vandyke was endowed, so that during the worst fever of this over-production he still painted occasional 
masterpieces. But the stamp of mannerism lay heavily on most of his work. There is a distinct lack of individuality; many of his portraits have a strong family likeness; in the poorer specimens the colouring became weak and the handling mechanical.

It was the beginning of a decadence which became more marked in his followers as it passed from Sir Peter Lely to Sir Godfrey Kneller.

For a long time the chief painters in England were imported foreigners; and it is a very remarkable thing that in a country that had hitherto suffered from such a striking lack of native talent, there should spring up suddenly, in the middle of the eighteenth century, a truly British school of painting, with three men of undoubted genius at the head of it.

Reynolds was born in 1723, Gainsborough in 1727, Romney in 1734 .

Reynolds died in 1792, outliving Gainsborough by four years; Romney died only four years later than Reynolds-so that for a long period they were all working side by side. And although there were interesting differences in their methods, they all had the same conception of portraiture. It was a kind of revival of the best traditions of Vandyke, and, it must be added, of some of the worst also.

They were all three pre-eminently successful with women. Indeed, for the first time since the classical epoch had female portraiture completely emancipated itself from the tyranny of stiff clothes and of consequently stiff attitudes. They all three gave the special charm and grace of womanhood in a way which has never been seen before or since-not even, I believe, in those classical times when they had a far higher ideal of feminine beauty.

The male portraits are on the whole less satisfactory. Now and then they attain a very high level, especially in the work of Sir Joshua, who was distinctly the manliest painter of the three; 

Plate 15.

MRS. SHERIDAN AND MRS. TICKELL (THE MISSES LINLEY). BY THOMAS GAINSBOROUGH, R.A., IN THE DULWICH GALLERY. 


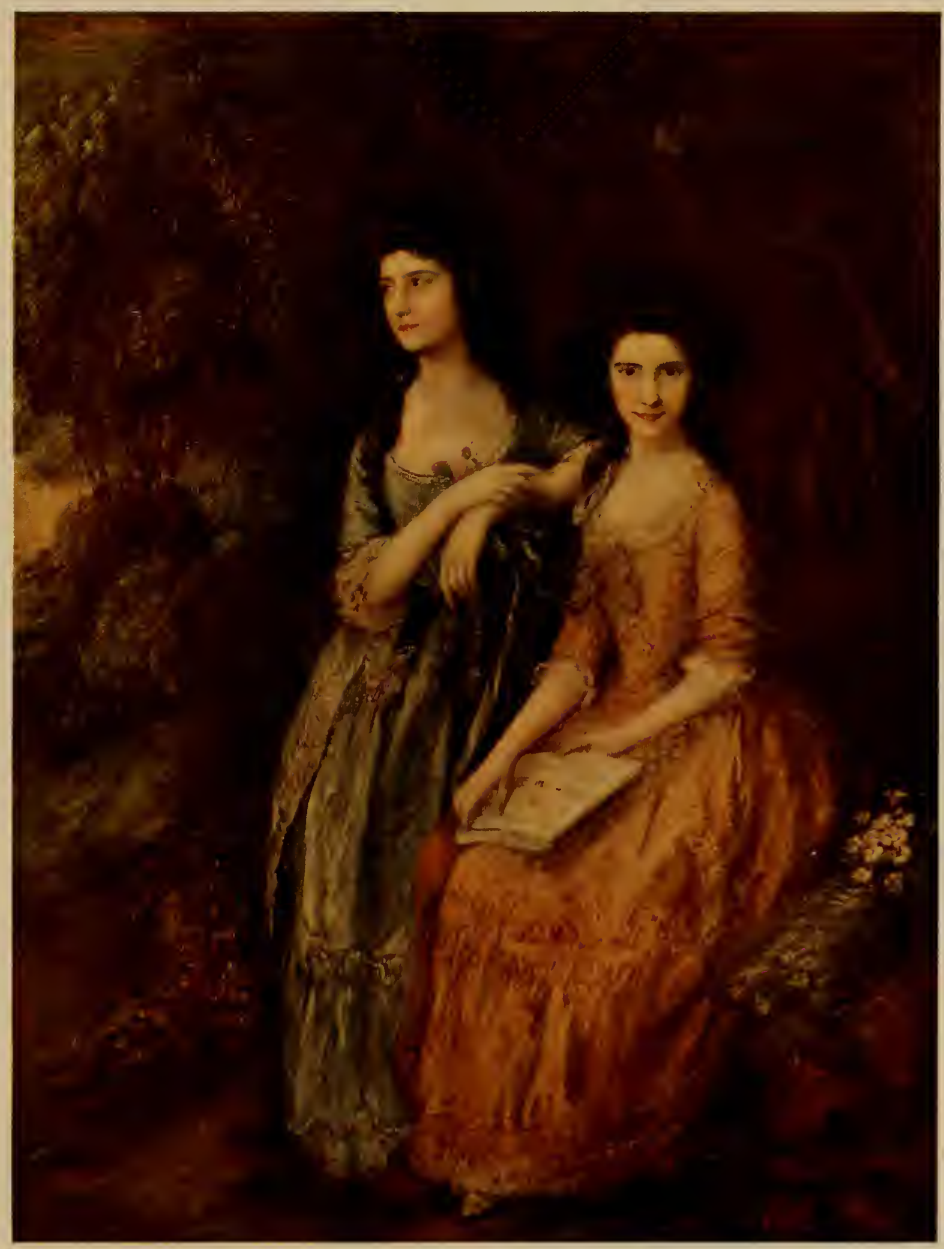



but the weaker examples, which are very numerous, fall far below the standard of the great masters. No amount of grace and charm will compensate for the absence of a body beneath the fine clothes, for hands that are so weak and sketchy as to be almost non-existent-in short, for a general lack of firm and vigorous drawing.

Like Vandyke, they were all three immensely prolific-Sir Joshua, who was a very methodical man, has left us his notebooks with a careful record of his various sitters. From them we learn that in the year 1758, when he was thirty-five years of age, he painted no fewer than 150 portraits.

This was his best year as regards numbers, but there were 148 in the following year, and he kept up an average of about 120 for a long period.

Gainsborough and Romney hardly equalled his enormous productiveness, but, judged by modern standards, their output also would be considered prodigious.

Of course, the question immediately arises, how was it possible to go on painting good pictures at such a rate as this? The answer, to my mind, is simple enough-it was not possible. When they had sitters that pleased them, or when, for one reason or another, they put out their full strength, these men of genius produced admirable pictures, and from these pictures they have deservedly gained their great reputation. But their average work was very slight, and, in fact, scamped, and their poorest work was very poor indeed; ill-drawn, conventional in attitude and expression, and with very little of the individuality that makes a good portrait. Like Vandyke, they were spoilt by becoming the fashion. It was the manufactory over again.

Gainsborough is the most unequal of the three. A really poor Gainsborough-and there are many of them-is an abominably ill-drawn, flimsy caricature of humanity, but at his best 
he carries the essential charm of the school further than either of his rivals. They were all fine colourists, but he was the finest. He was also, I think, the most original of the three.

The group of the Linley sisters, which is one of the chief ornaments of the Dulwich Gallery, is a very characteristic Gainsborough. (Plate I5.) The heads are delightful; it is difficult to imagine a more sympathetic rendering of two charming young women. The arrangement is simple and pleasing, with all the grace and hardly any of the affectation that usually distinguish the school. The background is skilfully conventional, and the colour is quietly harmonious. On the other hand, the drawing is very poor-the hands and arms being even worse than usual.

As a contrast, I give the splendid "Mrs. Siddons as the Tragic Muse," from the same gallery. (Plate 16.)

This is a fine example of the robuster art of Sir Joshua Reynolds. It is much better drawn than the Gainsborough (though not impeccable in this respect), and has a strength and vigour quite beyond the scope of either of Sir Joshua's great rivals.

The colouring reminds one of a fine Rembrandt-a harmony in golden-brown. Gainsborough's colouring is essentially cool, whereas Sir Joshua's feeling was always for warm tones.

I say but little about Romney, as he is distinctly less interesting than the other two; yet he also produced an occasional masterpiece.

Many of his numerous portraits of Lady Hamilton are endowed with a wonderful fascination, whilst the little head in the National Gallery called "The Parson's Daughter" is quite an epitome of the merits of the school. (Plate I7.) It is extraordinarily empty. There is hardly any modelling, the eyes, nostrils, and mouth just touched in with a few strokes of the brush-the 

Plate 16.

MRS. SIDDONS AS "THE TRAGIC MUSE."

BY SIR JOSHUA REYNOLDS, P.R.A., IN THE DULWICH GALLERY. 


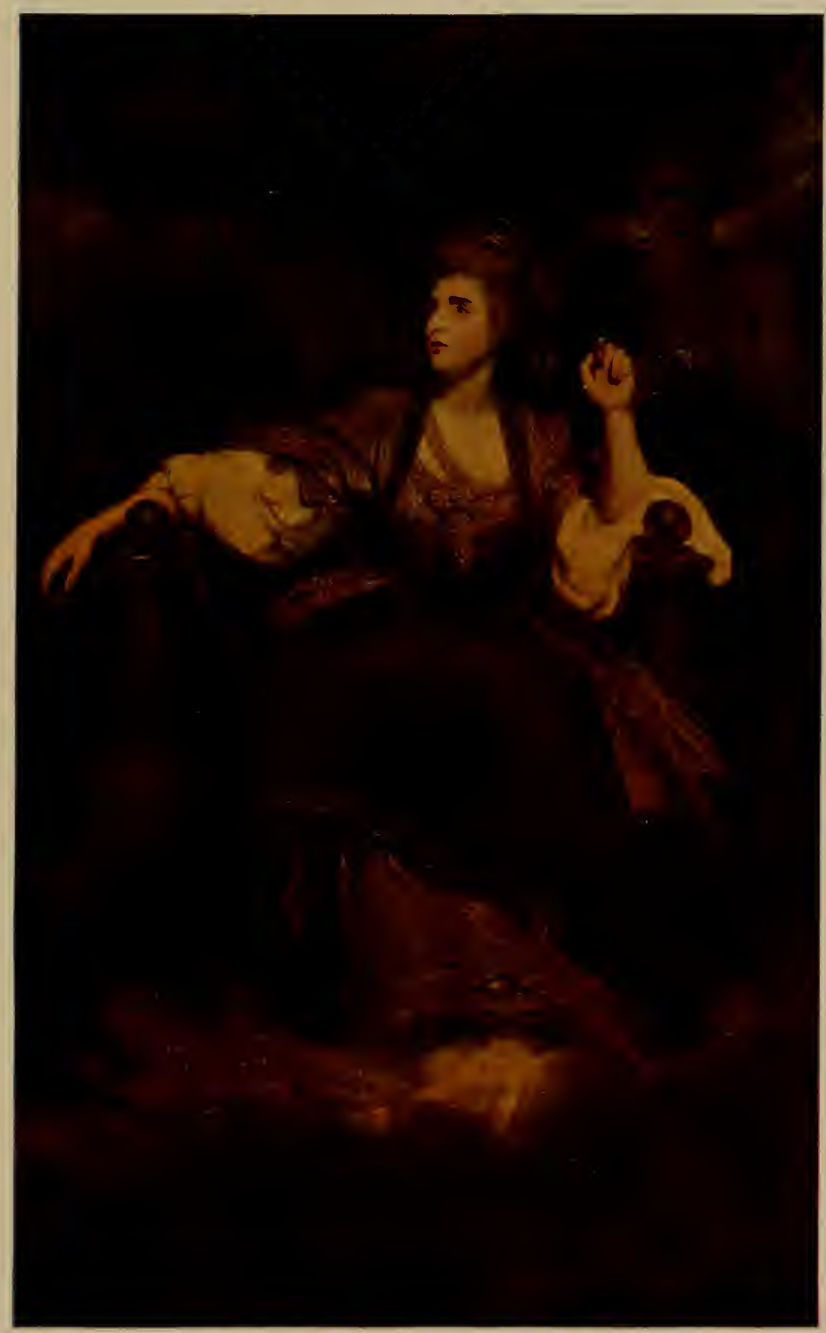



whole thing is so slight in painting that the canvas scarce seems covered. And yet all the essential charm is there. It is really miraculous that so much can be suggested by such slight means. This is an undoubted masterpiece.

Sir Joshua's "Dr. Johnson" (Plate $3^{8}$ ) is one of the best examples of what he could achieve in male portraiture. Neither Gainsborough nor Romney can touch him here.

There is, for once, no touch of convention. Indeed, the Doctor hardly lends himself to it. The character of the heavy, uncouth, intellectual head has been rendered in the most masterly manner, with, as usual, an extraordinary economy of means. Perhaps this economy is carried a little too far. Rembrandt would have given us more, and so would Velasquez. But still, as regards the head, all the essentials are there. The hand, as usual, is abominable.

With all its drawbacks, this is perhaps the most charming school of portraiture that has ever existed.

I say "most charming" advisedly, but assuredly not the greatest. Reynolds, Gainsborough, and Romney lived in too artificial an age to produce the highest art, but this very artificiality gives a dainty grace that is in some ways more attractive than the robust truthfulness of the greatest schools of painting. It is precisely in this quality of truthfulness that the work of these exquisite artists falls short. They flattered their sitters abominably. Then their productiveness was so immense that in all but their finest work they scamped everything but the head. Indeed, they adopted the fatal practice of having draperies, backgrounds, and even hands painted for them by their assistants, generally without the presence of the sitters. The male portraits have more individuality than the female, so they do not display the same tendency to conform to a type. In general, it may be said of them that the faces are apt to be a little fatuous, and are mostly very well nourished, and 
that the older men seem to be fortunate in avoiding wrinkles. But the women seem to be all of one family, the members of which are not often handsome, and are never quite plain. They seldom look very intellectual, but then they seldom look foolish, and they generally have a particular charm of expression that makes one forget that their features are not really fine and that their bodies are mostly very poor and weedy. They all look moderately good, and seem very lively and good-tempered.

They all have to conform to an ideal type-full of grace and charm. But grace and charm are not everything. I maintain that an ideal of womanhood founded almost exclusively on these two qualities is but a poor ideal.

And not only is their ideal a very flimsy one, but the way in which they allowed it to swallow up the individuality of their sitters is fatal to the highest portraiture. Were none of their innumerable female sitters ever broad-shouldered? Had they none of them big firm mouths and square jaws? They cannot all have been slim and dainty. Had none of them the magnificent robust type of the Venus of Milo or of the women of Titian?

Indeed, we may go further. Some of them must have been fat. Do we ever find a fat woman in the painting of this school? And some of them must have been short and squat, and some of them must have been downright ugly. But we never see them. I am aware that there is the most uncanny power of adaptation in the female form to the prevailing fashion, but it is not unlimited. For instance, it is now the fashion for women to be tall, and it is remarkable how many of them contrive to be in the fashion; but there are exceptions. In these charming portraits there seem to be practically no exceptions to the prevailing type. Decidedly there must have been a great lack of sincerity in these courtly painters, and I must repeat that for the highest portraiture sincerity is an essential. 

Plate 17.

THE PARSONS DAUGHTER. BY GEORGE ROMNEY, IN THE NATIONAL GALLERY, LONDON. 


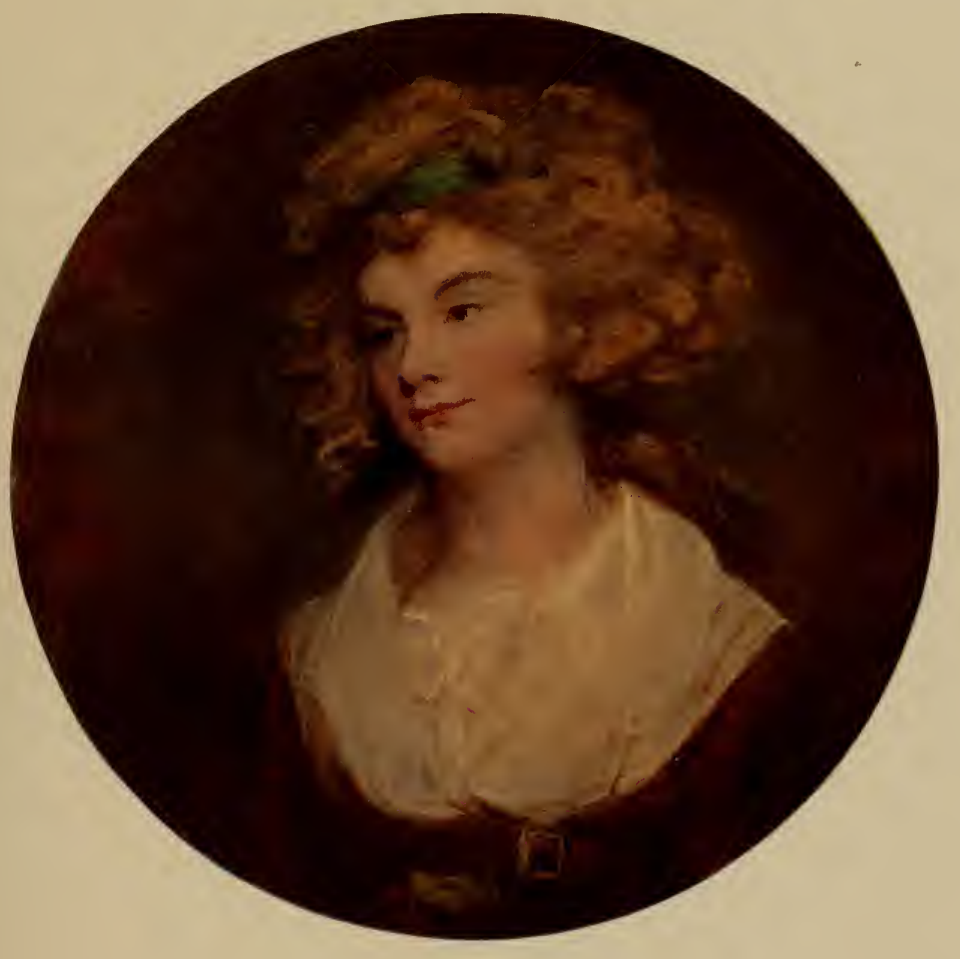



This is the last of the great epochs of portrait painting. About the same time, or rather a little earlier, there arose a school in France with somewhat the same aims and characteristics, but, on the whole, very inferior to ours. They differed from the English school in not being chiefly portrait painters, but they had the same feeling for the charm of a very artificial femininity set in a background of equally artificial landscape. The women of the English painters, however, are far more attractive than the soulless minxes who disport themselves so coquettishly in the French canvases of the period.

To return to Great Britain: the tradition of Sir Joshua was carried on by such excellent painters as Northcote and Hoppner and to a less extent by a much greater painter than either of these-Sir Henry Raeburn-a man of marked originality who, although he remained more or less a follower of the conventions of the British school in his design and in his light and shade, yet broke away from them completely in his technique. In this he reminds one of Frans Hals, and of those moderns who follow the Halsian methods. Raeburn was a singularly direct painter, and absolutely forsook the devious ways by which Sir Joshua obtained his wonderful results.

He lived and worked entirely in Scotland, which, no doubt, is the reason why he had so little influence on English art. Indeed, it is only quite of late years that the English public has become alive to his merits. I shall return to his technique in a later chapter. I only wish to put on record here my opinion that in his limited way he was one of the most masterly of painters.

Unfortunately the most popular follower of Sir Joshua was Sir Thomas Lawrence, in whose hands the great tradition became vulgarised. The type is, if anything, more artificial, but the charm, except in the very best of his pictures, has fled. They are painted with an extraordinary ability of a very tricky and flashy 
kind. And then we gradually descend to the mere inanities of the early Victorian Era.

And now we come to the moderns. About them I had much rather be silent. I am a man of peace, and, all unworthy though it be, I still hold my life dear. But at any risk I must venture on this perilous field, for, after all, it is modern work that should interest us most. Before coming to personalities I must say a few words as to the general tendency of modern portraiture.

In the first place it is very varied and highly experimental. We are always trying new effects of light and shade, new methods of handling, new harmonies of colour, to say nothing of new discords. And this, I think, is good in the main. The tendency in all art to convention is so strong and so fatal when yielded to, that this wholesale seeking after new methods is, I believe, a wholesome sign. But there should be some moderation in it. We are ready enough to condemn the seeking after novelty for mere novelty's sake in the fashions of female dress. We talk of the silliness and vulgarity of this restless love of change, but we forget that a similar feeling in art is just as vulgar. It should be no recommendation for a style of painting to be new if it be not good also. This may sound a very obvious truism, but it needs enforcing, for all that. I have not yet in modern art come across a portrait of a gentleman standing on his head, but I have no doubt I shall do so.

Then, again, I am old fogey enough to consider that a portrait ought to resemble the person it is meant for. I am aware that many of my brother artists will consider this a mere antiquated prejudice, and I am willing to concede that I have perhaps stated the principle a little too strongly, but this I must adhere to-that a portrait ought at least to resemble a human being.

But I must now leave the comparatively safe ground of 


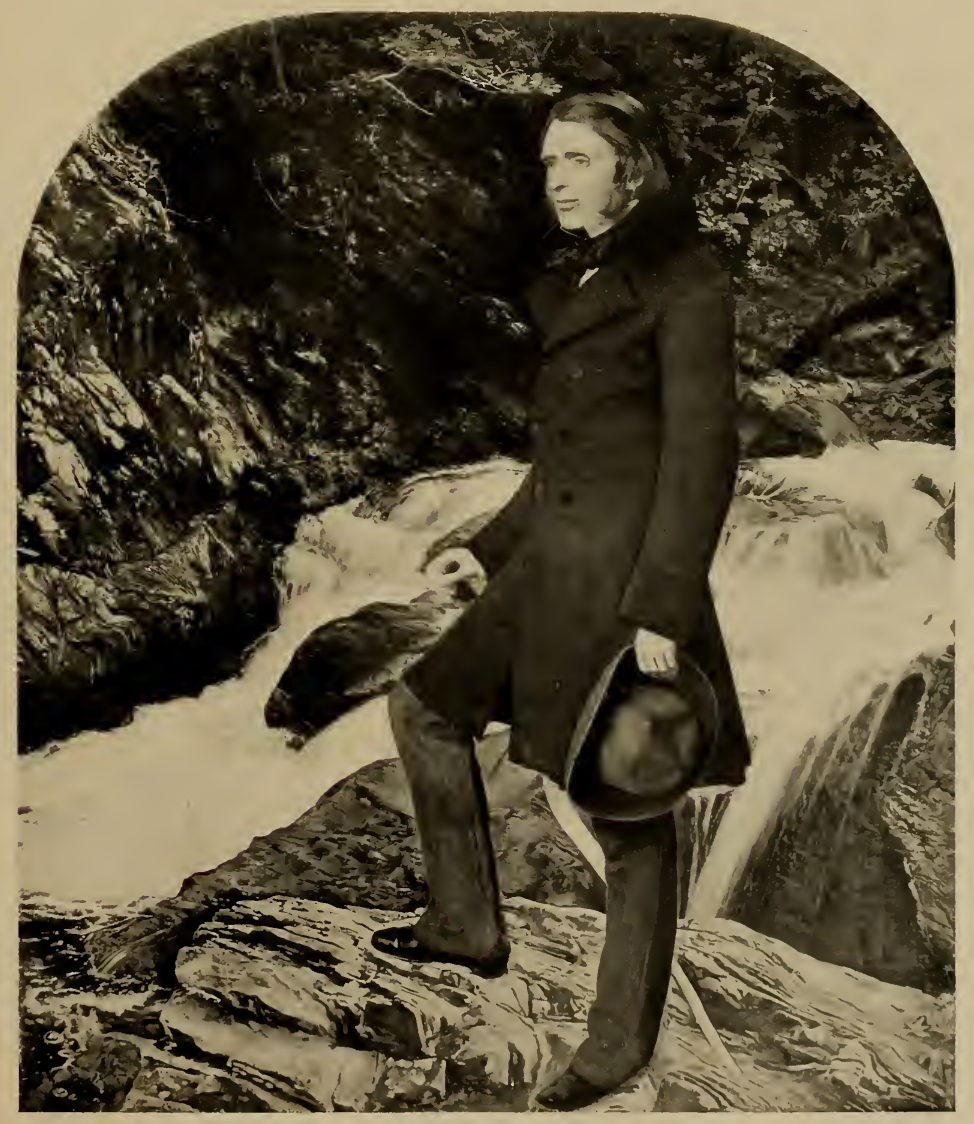

JOHN RUSKIN.

BY SIR J. E. MILLAIS BART., P.R.A.

Plate 18 ,

oY PERMISSION OF MISS ACLAND. 

generalities and treat of modern portraiture as practised by a few representative artists.

The founder of modern portraiture, at any rate in Great Britain, is certainly Millais. This great artist was a realist, and he broke once and for ever with the mannered grace and essential artificiality of the great school of the eighteenth century. Millais was one of the most original of painters; in his early days he was influenced by the other pre-Rafaelites, but his middle and later styles are entirely his own. Not necessarily the better for that, but undoubtedly more original, and his portrait work falls almost entirely into these two periods-and, unfortunately, chiefly into the latter. I say unfortunately, as his latest style is not his best. It is often careless, and I would willingly exchange some of his dashing impressions of fashionable beauties for a few careful studies such as the little figure of Ruskin, which is one of the few portraits of the early period. (Plate i 8 ).

This is a masterpiece of pre-Rafaelite art, and might, if he had persevered in this line, have set a fashion that would have been of the utmost value at the present day. But. Millais's work, even at its sloppiest, was always natural and unconventional. It had extraordinary variety; indeed, he is almost the only portrait painter of whom it can be said that his pictures display no family likeness. Even Rembrandt is not quite free from this reproach.

Millais broke with tradition in another respect which is of the utmost importance for the welfare of our art. He dispensed entirely with the army of assistants that had hitherto been the mainstay of the fashionable portrait painter. His work is all his own, and this break with a bad tradition has, so far, been a lasting one. There has been no revival of this pernicious practice-at any rate in Great Britain.

I will discuss the peculiarities of Millais's style in a later chapter; for the present it is enough to point out that it is 
characterised by great vivacity of colour and expression, by immense variety, and by a resolute avoidance of convention.

As a contrast I will cite the work of Frank Holl, who, on the whole, was the most serious rival to Millais in portraiture. Holl's work was essentially mannered; his scheme of colour was monotonous, and there was rarely much vivacity in the expression-but in his way he was a very fine painter. He had a sureness of method and a power over his limited convention that remind one of the great masters. The vigour of his handling and the strength of his light and shade are such that other portraits look flimsy and unreal by the side of his. His sitters generally look intellectual and nearly always dignified. In fact, his was a singularly robust and distinguished convention. But convention it was. The backgrounds are nearly always dark brown; with this he makes a pleasant though monotonous harmony by painting the black coats of his sitters a blue-green. They are often sitting in a green leather chair, and if they have white hair, which is not unusual with them, as his speciality was painting old men, this white hair was represented with a strong blue tinge. (Plate I9). When I add that the figures are often over life-size it will be seen how large a part convention plays in the work of Frank Holl. On the other hand, Millais's colouring was, as I have mentioned, extraordinarily varied-indeed, often too vivid and kaleidoscopic-and he seems to have looked on every sitter as a fresh problem, not as a creature to be forced into an artistic mould. Millais, too, was equally good at men, women, and children, whereas Holl's portraits were almost exclusively of men, and generally of old men.

For these reasons I regard Millais as by far the greater portrait painter of the two. But as compared with Holl his execution was tentative, and he seemed to know much less what he meant to do and how to do it. In consequence, his failures were more frequent. 


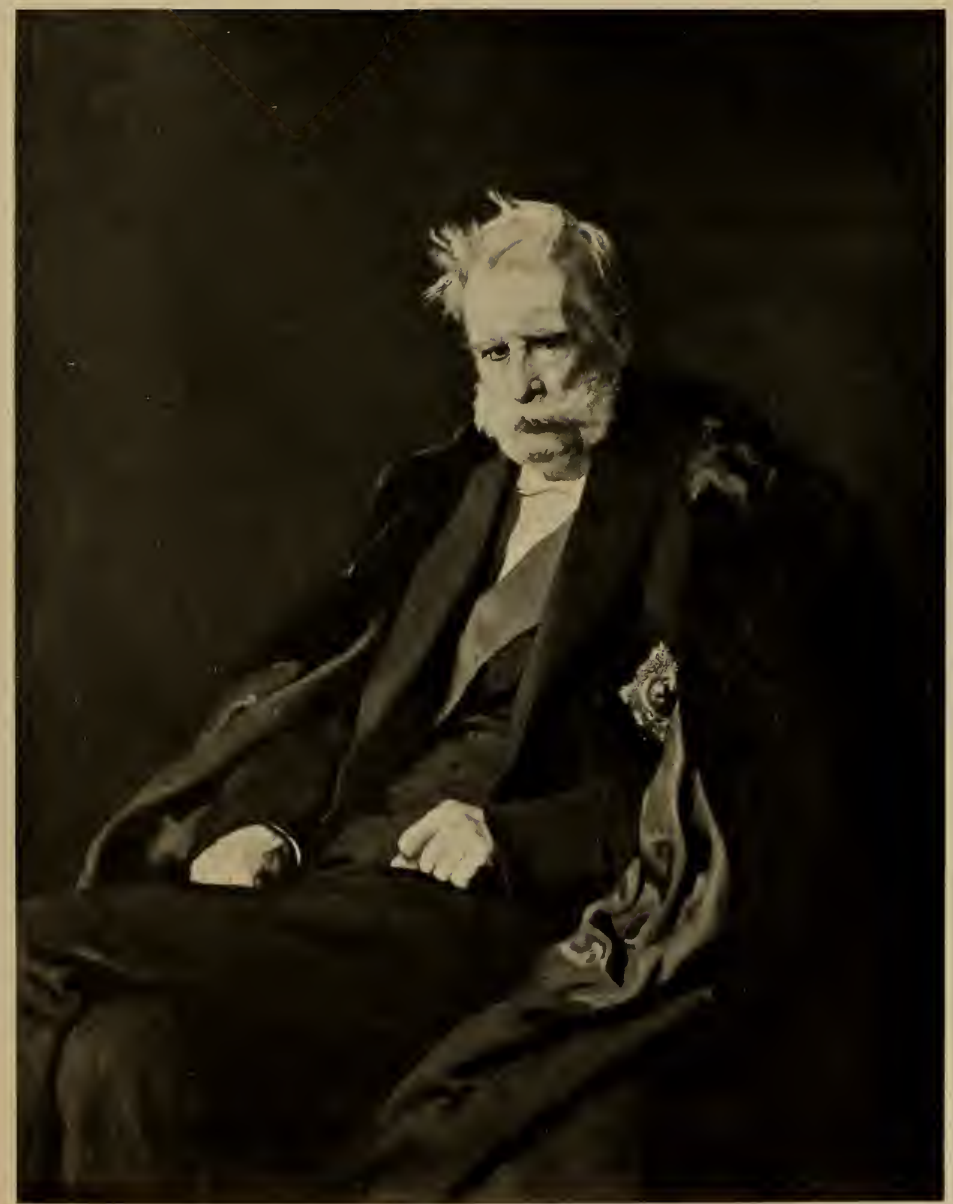

THE DUKE OF CLEVELAND.

BY FRANK HOLL, R.A.

Plate 19. 

One of Millais's besetting sins was lack of simplicity in colouring, especially in flesh-painting. This was a legacy from his pre-Rafaelite days, when the great aim of the brotherhood was to produce an intense vividness by the juxtaposition of small patches of the primary colours instead of mixing the required tone on their palettes. This method is still adopted by some water-colour artists, and there is a little group of painters in France who push it to the furthest limits of extravagance, but with these exceptions the method is now very generally, and I think rightly, discredited. None of the really great colourists have adopted it, and I am quite sure that flesh, at any rate, is much better represented by simple tones, subtly gradated, but not too much broken up.

The leader of the reaction against this method of Millais was undoubtedly Whistler-a man of great originality, whose influence on modern art can hardly be exaggerated. The chief characteristics of his portrait, as of his other work are a great subtlety of tone, harmonious colouring, pitched in a very subdued key, and a simplicity of arrangement that is carried so far at times as to seem to the natural man mere wilful eccentricity.

Nothing more unlike the art of Millais can well be imagined, and it is a very useful protest against some of the tendencies of his school. But there is no denying that it is highly artificial. By some critics Whistler has been compared to Velasquez, and this comparison with another artist is probably the one he would have resented least. It is true that his colouring in its quiet greys does rather resemble the older master, who also (though in a much less degree than Whistler) was fond of simplicity of arrangement. But here, to my mind, the resemblance ceases. Velasquez was essentially a realist. His figures look like good honest flesh and blood; they are solid, they stand out to the eye as real people would; they are vigorous and human. It is said 
that Philip the Fourth took a portrait of an admiral in the painter's studio for the admiral himself, and upbraided him for being away from his duties. This may or may not be true, but at any rate it does not sound at all unlikely. But who could possibly imagine any of Whistler's portraits to be living human beings? They seem like ghosts of people; flat, with little modelling, and no substance. Charming as decorative schemes and subtle harmonies, but very far removed from the frank vigour and absolute naturalness of the work of Velasquez.

It is for this reason that I am not so enthusiastic an admirer of the portraiture of Whistler as it is now fashionable to be. I have always held that a portrait should be immensely like a human being. To me the work of Whistler is nothing of the kind. It is, to use his own expression, a harmony in grey and flesh-colour, or something to that effect, but it is not Mr. Brown or Mrs. Smith. Now it may be replied that it is a much higher form of art than the crude representation of uninteresting people. This it may be, but it is just in this representation, whether crude or otherwise, that portraiture consists, and I am convinced that Velasquez and Rembrandt would be on my side in this controversy. They undoubtedly endeavoured to give a life-like representation of the human beings who sat to them, whether interesting in themselves or not, and it is just this life-likeness of their portraits of the contemporary Browns and Smiths that makes them interesting to us.

Another great figure in English painting has recently passed from us. It is ungracious to have to speak in any kind of disparagement of the work of an artist of such distinction as Watts; but I must record my conviction that as a portrait painter he has been much overrated. Some little of his portrait work, especially of the earlier period, attains a very high level (although rather too reminiscent of the Italian masters), but the great bulk 
of it is disagreeable in execution and often faulty in drawing. It is always dignified and distinguished in style, and at his best Watts was a fine colourist; at his worst the flesh tones are curiously dirty, and the texture extremely unpleasant.

I must now, with some reluctance, turn to living artists. Of them, it is difficult to speak quite frankly without fear or favour, but I will endeavour to do so even at the risk of appearing invidious. I must merely premise that I have no pretension to give an exhaustive account of modern portrait painting, and that the few names I shall mention are chosen chiefly as representing tendencies.

Of the older living painters, Mr. Orchardson stands out, a figure of great distinction, with a very personal method in no way influenced by the prevailing fashions of modern art. A fine though limited colourist, he has a great feeling for decorative arrangement. The prevailing tone is very warm, a sort of golden hue; his blacks are always of a brown tone, not very dark. The backgrounds and clothes are painted thinly, with a somewhat scratchy touch, the shadows being transparent. The flesh tones are very luminous; indeed, the heads often tell out too light against the background. The modelling is somewhat flimsy and superficial, but the expression is always animated and lifelike. The flimsiness and lightness of the touch remind one a little of Gainsborough, but otherwise the method is all Mr. Orchardson's own. In fine, a somewhat limited and not very natural art, but the convention is a very distinguished onenot so vigorous as that of Frank Holl, but much more refined and sympathetic. Unfortunately Mr. Orchardson stands alone; he has no school, no following.

By far the most commanding figure in modern portraiture is Mr. Sargent, and his work is vigorous and life-like enough in all conscience. But he also has a great simplicity of tone and 
handling that probably owes a good deal to the example of Whistler.

Like the older painter, Mr. Sargent is said to have derived his principles and practice chiefly from Velasquez. Indeed, his art has often been compared to that of the great Spaniard. In this instance again I consider the comparison mistaken. To my mind, Mr. Sargent's work is much more reminiscent of Frans Hals. Besides the vigour, there is a subtlety and delicacy of modelling and of handling in Velasquez that I fail to find in the modern master, whose work is not so much modelled as blocked in. It has all the freshness, but also the lack of subtlety of a sketch; like that of Hals, the work is admirably drawn, and painted with a few decided and masterly touches, but they are left almost unmodified, and consequently it is only at a considerable distance that these frank strokes of the brush can be taken for the infinite delicacy of flesh.

This is quite unlike the method of Velasquez, who, even in his latest and most summary work, blended his tones and imitated the texture of flesh with extraordinary subtlety.

Another peculiarity of Mr. Sargent is, that in his intense desire for vividness and vitality, he frequently introduces just a touch of caricature. This undoubtedly helps him to achieve his aim, and gives his portraits their astounding individuality; but I would willingly give up some of the intense characterisation for the dignity and reticence of Velasquez.

I think it probable that Mr. Sargent owes this tendency to over-emphasis to the influence of the French painter Manet, who was a realist of distinctly the brutal order-a man of very original power, though he, in his turn, is said to have been inspired to some extent by that erratic genius, Goya, a Spaniard who flourished towards the end of the eighteenth and the beginning of the nineteenth centuries, and who was, as it were, 
rediscovered by the leaders of the French revolt against Academic traditions which began some forty years ago.

I have compared Mr. Sargent to Frans Hals. I think, as regards technique, this is not an unfair comparison, but I ought to add that the range of $\mathrm{Mr}$. Sargent is infinitely greater than that of the Dutch master. In the first place, Hals was pre-eminently a painter of men-in the whole of his work there are very few young women, and what there are, are singularly unattractive. $\mathrm{He}$ was better at old women, but his forte lies in the life-like portraiture of commonplace men, mostly of middle age.

Now, Mr. Sargent is equally good at men, women, and children. He has much more feeling for feminine beauty than any Dutchman that ever lived, and the scope and variety of his portrait work are quite amazing. $\mathrm{He}$ is also, at his best, a fine and original colourist, and if he has an exceptionally beautiful complexion to paint, can so far modify his summary methods as to give the delicacy of nature in a manner never even attempted by Hals.

When all reserves are made there is no doubt that $\mathrm{Mr}$. Sargent is a master of portraiture. In his own line he is supreme, but I am afraid that his influence on his contemporaries (which of course is very great) has not been for their good. What in him is masterly sketchiness degenerates in some of his followers into mere sloppiness, and, speaking generally, a number of the younger men are endeavouring to copy his facility without going through the long and arduous study by which he has gained it. I have remarked before that there is a general rule that all really masterly work has been preceded by a course of precise and careful study. The early work of Velasquez is very hard; Rembrandt's early portraits are quite highly finished; Millais had the invaluable training of his pre- 
Rafaelite days, before he launched out into the freedom of his middle period-and Mr. Sargent's early studies are no exception to the rule.

There is nothing more dangerous for the young painter than to endeavour to be masterly.

I have already disclaimed any pretence to deal exhaustively with modern portrait painting. The field is far too wide for me to attempt to cover it. So I shall confine myself to the British School, partly for the purpose of concentration, but also because I genuinely believe that portraiture is in a much healthier state here than on the Continent. With regard to the United States, we have annexed two of their best portrait painters, so that anything I have to say of our art will refer to a certain extent to theirs as well.

Amongst the diverse tendencies of British painting, the modern Scottish School stands out with marked individuality. In its wildest developments it represents impressionism gone mad. But in the hands of its ablest exponents it shows a marked dignity and reticence, and a very beautiful sense of colour. It undoubtedly owes a great deal to Whistler, and has many of his qualities, and also some of his defects.

Sir James Guthrie, the President of the Royal Scottish Academy, and Mr. Lavery, who, by the way, is an Irishman by birth, may be taken as the most prominent exponents of the school. To them, as to Whistler, a portrait is first and foremost an arrangement. This gives to their work a certain artificiality, and I cannot help feeling that the human element takes a somewhat subordinate position. With Mr. Lavery in particular the head is often somewhat sacrificed to the delicate tones and harmonies that constitute the arrangement of the picture; and there is such an absence of detail that I have some difficulty, when I look at one of his charming portraits, in realising the 
individuality of the sitter. Each work seems to me like a sketch for a possible masterpiece which never gets itself painted. If it did it would be a masterpiece indeed. As it stands it is a delightful sketch, beautiful but incomplete.

This incompleteness seems to mar much of the clever work that is now being done. It is either a flashy imitation of Sargent, or a low-toned perversion of Whistler. Of course, there is also a certain amount of honest, straightforward, but perhaps somewhat commonplace portraiture being done, but it is out of fashion, especially with the critics. The critics, indeed, are unduly hard on anything that savours of the commonplace. It is surely better to be good and commonplace than bad and eccentric. But the fact is, the poor critics are so bored with the number of pictures that they have to look at that they naturally require rather a high flavour to tickle their jaded palates. I have every sympathy with them, but I think it a little distorts their judgment.

Amongst the youngest of our painters there seems to be a tendency to a harder and more precise style. This is all to the good, and I shall be curious to see if the movement spreads or if it gets submerged in the prevailing torrent of slop.

At any rate, there is no monotony about modern portraiture. It is varied and vigorous if somewhat chaotic, and I have great hopes that out of the chaos will be evolved a school of rational methods and sane ideals. 


\section{Part II.}

\section{THE AIMS AND METHODS OF THE GREAT MASTERS.}

$\mathrm{O}^{\mathrm{F}}$ the half-dozen of the greatest portrait painters of the world Holbein is the earliest, and his methods are certainly the farthest removed from most of our modern practice. It never occurred to him that any part of a picture should be scamped in order either to save trouble or to give more value to the rest. $\mathrm{He}$ could leave out where he thought advisable-for instance, some of his portraits have a quite plain background-but anything that he put into his picture he painted with the utmost care and finish. This was not peculiar to Holbein. It was the theory, and more or less the practice, of all painters up to about the middle of the sixteenth century. There is plenty of bad work amongst the earlier painters, but practically no slovenly work-indeed, no sketchiness of any kind. This theory, that every part of a picture should be well finished, is much decried nowadays, but it is incontestable that a number of masterpieces have been produced on this principle.

I am not upholding it as the only method of painting, or even as the most preferable. Masterpieces have also been produced on the extreme impressionist principle, and a great number of fine works are somewhat betwixt and between. The besetting sin of writers upon art is to be so enamoured of some one school that they cannot see the merits of any other. I think the real philosophy of the matter has been summed up by Mr. Kipling in one of his shorter poems-

"There are nine-and-sixty ways

Of constructing tribal lays,

And every single one of them is right." 


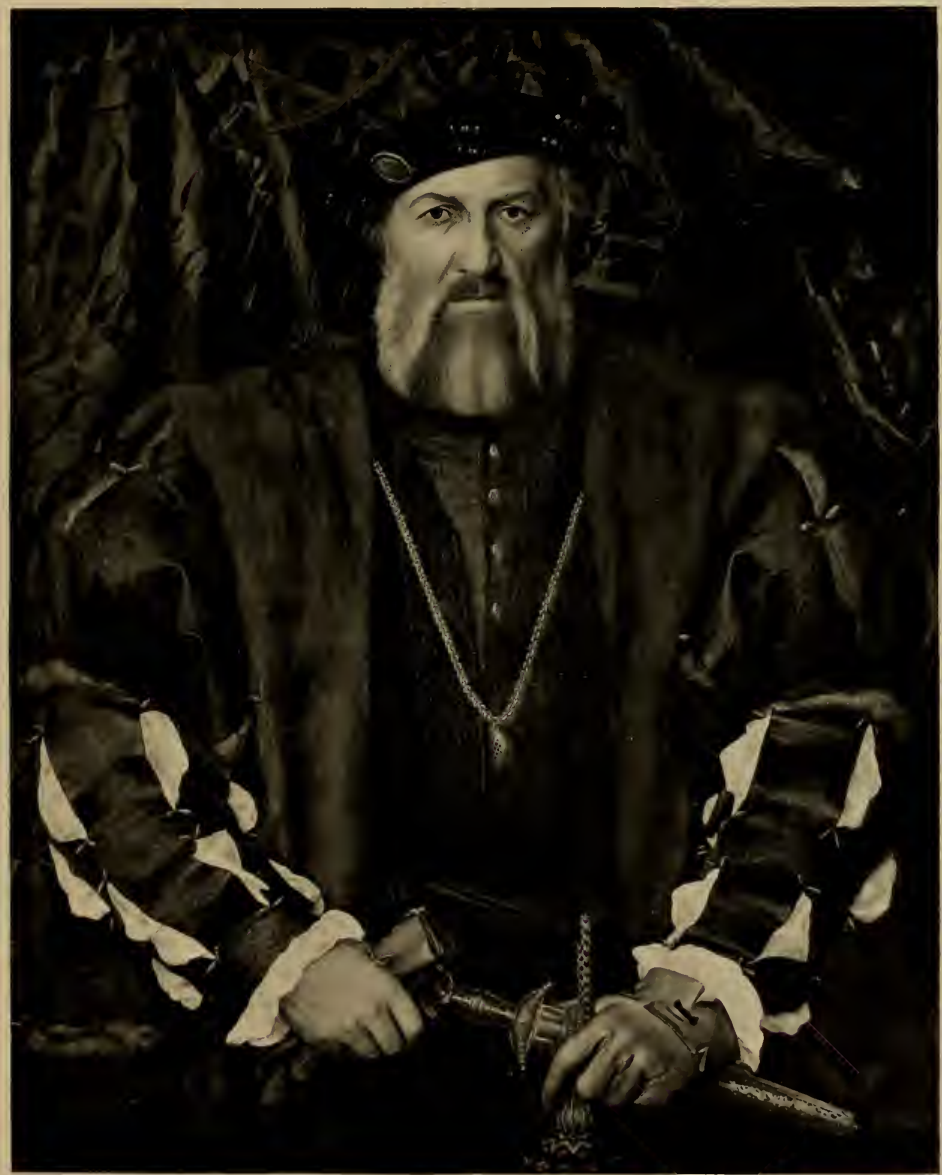

HUBERT MORETT.

BY HOLBEIN.

Plate 20

IN THE DAESOEN GALLERY,

From a Photograph by Franz IIanjstaengl. 



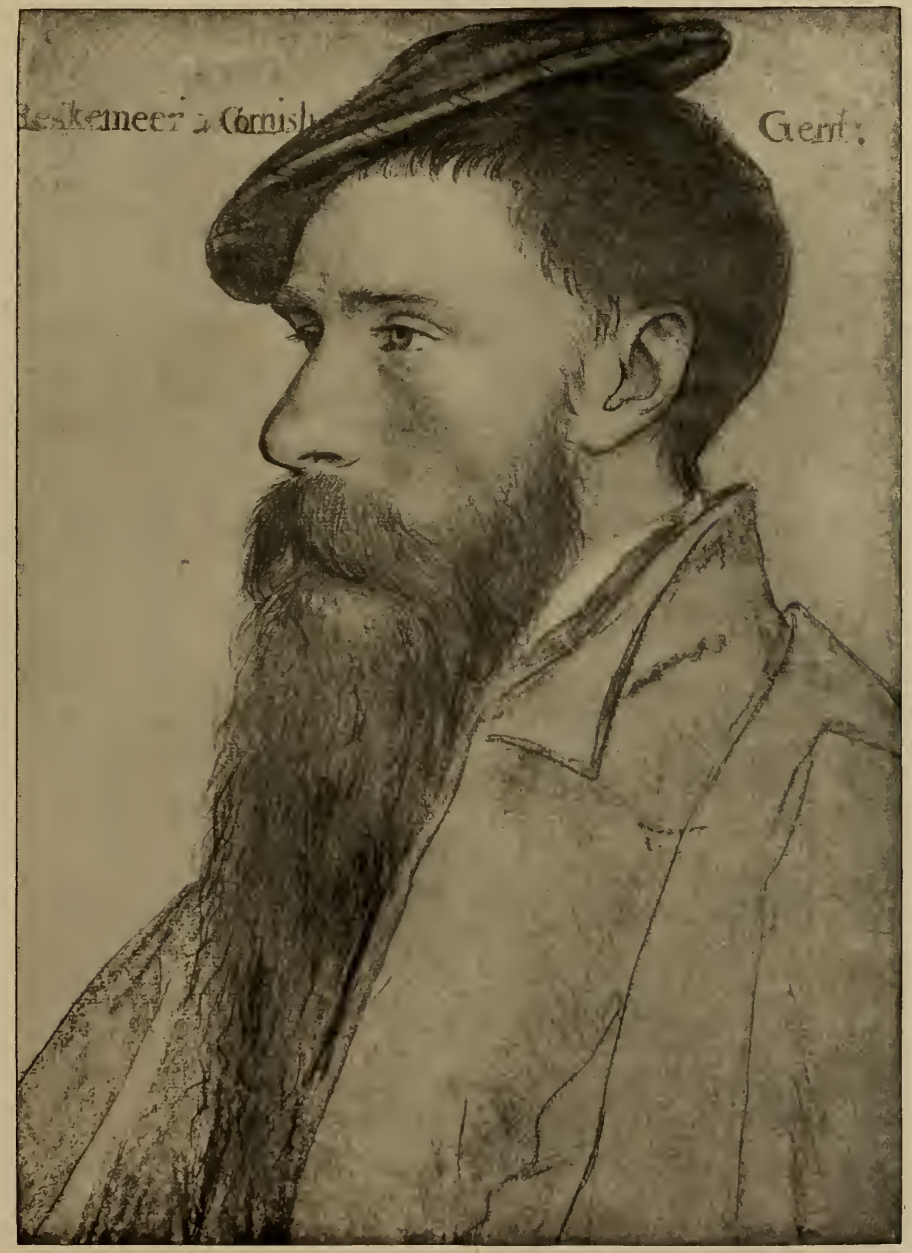

RESKEMEER, A CORNISH GENTLEMAN.

FROM THE DRAWINO BY HOLGEIN, IN THE ROYAL COLLEOTION, WINOSOR,

Plate 21.

From a Photograph by Braun, P'aris. 

But leaving aside for the present the controversial aspects of this question, it is an undoubted historical fact that the masters who may be loosely called pre-Rafaelite finished every part of their pictures, and were generally fond of introducing a good deal of minute detail; and in order to show off this detail their pictures are rather fully illuminated-deep shadows being avoided. With Leonardo and Rafael a subordination of certain parts of the picture begins to take place, but this is effected not by sketchiness of treatment, but by the employment of large masses of shadow, in which the detail is necessarily somewhat lost. This has the result of concentrating the attention on the principal parts of the picture, and generally produces a bolder and less scattered effect; but the careful finish of every part remains the same.

The originator of what is now called "impressionism" was undoubtedly Tintoretto. He was the first great painter who deliberately left parts of his pictures sketchy and unfinished. This was partly the outcome of theory, but it was also partly necessity, as owing to the impetuosity of his nature he began far more work than he could possibly carry out in the -deliberate style of the early masters. Indeed, he is the first painter who ever seems in a hurry-there have been many since his time.

To return to Holbein. He belongs distinctly to the preRafaelites (the real ones, of course, not the English brotherhood who took the name), if not in point of date, at any rate in point of manner. There is practically no subordination of detail in his work, and he mostly avoids large masses of shadow, although he had a considerable mastery over chiaroscuro when he chose. His methods are more those of a draughtsman than of a painter. $\mathrm{He}$ seems to have begun all his portraits by making a separate and very careful drawing upon paper. These drawings are some of his most admirable and characteristic work, and fortunately a number of then survive. There are about eighty in the great 
Windsor collection alone. Most of these have been unfortunately retouched and the outlines strengthened at a later date-probably not by Holbein himself, although by a skilful hand; but they are in sufficiently good preservation to enable us to appreciate the extraordinarily subtle draughtsmanship of the master. (Plate 2r.)

The outlines are studied with the utmost care, and, besides, a very delicate modelling is introduced. Sometimes they are slightly coloured, but they are mostly in monochrome, often with written notes as to the colour by the side.

The drawing was then transferred to the panel or canvas, sometimes by actual tracing. The costume was occasionally altered, but the head always remained the same. Apparently the picture was then laid in from the drawing, making use of the suggestions of modelling and the written notes as to colour. Then we must suppose the picture was finished from the actual sitter, and the details painted very carefully from Nature. But in Holbein's case, as in that of so many other great painters, contemporary records are curiously silent as to the method of work.

In the oil-painting the surface is always smooth, texture being rendered not by inequalities of surface, but by play of light and shade, as in a photograph. This is a very laborious method, and even with Holbein is not quite satisfactory. Undoubtedly his pictures do look too uniformly smooth, and they are a little too hard and cut out in outline. They have, indeed, the natural defects of the method-the drawing somewhat overpowers the painting. On minute observation an actual outline-a thread of paint-can be discerned, even in his latest pictures, and this certainly accentuates the impression of over-hardness. Again, there is a slight want of spontaneity in the expression and attitudes; some, but not all, of his portraits are decidedly stiff. But when all drawbacks have been allowed, how superb is his work ! How subtle, how dignified, and how strong! And how extraordinarily like the sitters it must have been! 
. 



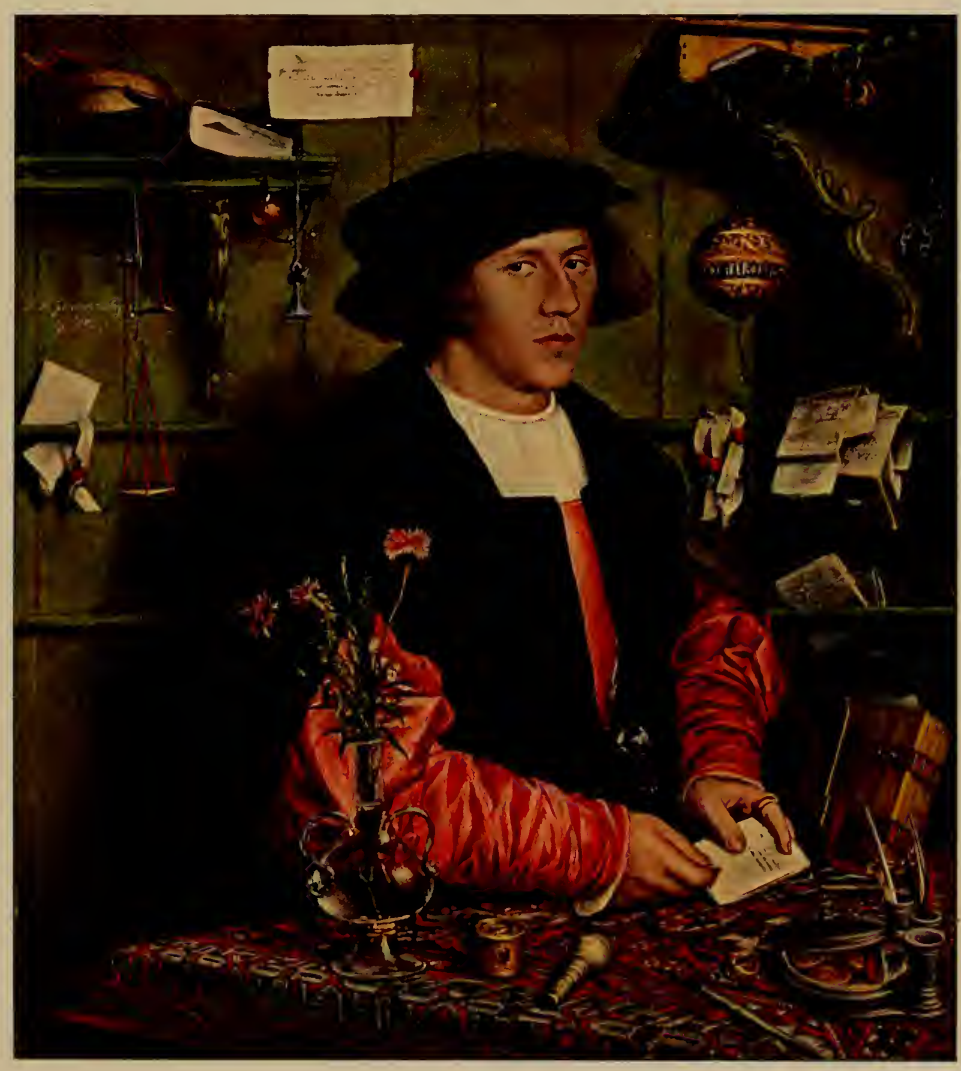



It is said of Sir Joshua Reynolds that a good number of his portraits were returned on his hands as not being like enough to the originals. And this, I think, gives the real note of difference between a painter like Holbein and one like Sir Joshua-both men of genius, but the first one of the most thorough artists that have ever lived, the other a man who painted 150 portraits in a year, who relied on other people to paint his backgrounds and his draperies, and was often so careless and inaccurate that his portraits were quite unlike his sitters. To me there is no manner of doubt as to which produced the higher art; but it is the latter master that we follow more than the former. Indeed, I could think of no better augury for the future of portraiture than a movement of "back to Holbein." There is not much sign of it at present.

As a very characteristic example of our master we will take a portrait, now in the Berlin Gallery, of a young German merchant resident in London-one Gisse. (Plate 22.)

Here we have him in his counting-house, surrounded by the implements of his trade-his pen and ink, his papers, his receipts, his balance, his ball of string, his seal, his account-book -everything he wants for his business, and besides, just for the touch of beauty that it gives, a delicate glass vase with one or two carnations in it. To me all these details help the portrait; not only do they make one understand the man and his surroundings, but they are so painted as to be delightful in themselves: and yet the head maintains its mastery over the whole as it would do in real life. The man is by no means the most interesting of Holbein's sitters, but this is certainly one of the great portraits of the world.

Before I pass on to other artists I should like to dwell a little more on Holbein's extreme care for his outline. He perhaps carried it too far, but, on the other hand, nothing is more common than to neglect it too much. It is frequently said that there are 
no outlines in Nature. This is true enough, literally, but those who say it forget that there are boundaries-wherever a patch of one colour or tone is seen against another colour or tone there is an edge. If the edge is smooth and sharp (as it often is) the boundary of the patch is quite definite, and may be properly indicated by a line-a mathematical line, i.e. length without breadth, would indicate it perfectly. Even if the line is thick enough to be easily visible, its breadth may be so small as not to interfere with the substantial accuracy of the representation. It is the boundary where one patch of colour ends and another begins. Where the form of the boundary is composed of subtle curves, as it mostly is in the human face and figure, it is obviously easier for the hand to follow these curves by a delicate line than by spreading the whole patch of colour up to the boundary and then making it of the right shape. So it will generally be found that the draughtsmen who use the point show greater feeling for the beauty and delicacy of the play of line than the painters who rely mostly on the broad brush. It must be conceded, on the other hand, that the broad brush men have often a truer sense of proportion than the linear draughtsmen. Even Holbein occasionally errs in proportion. It is very curious that he often makes the eyes too small-in direct contrast to the tendency of most artists. In spite of this, Holbein as a draughtsman is almost unsurpassable; as a painter, he leaves more to be desired.

It is said that Tintoretto inscribed over his studio, "The drawing of Michel-Angelo and the colouring of Titian." In the same way, one of the most accomplished of modern artists has told me that his ideal of technique was the drawing of Holbein and the painting of Velasquez. And a very fine ideal too!

This method of accurate draughtsmanship, of smoothness of surface, and of careful detail is to be found more or less in all portraits until the time of Titian, who inclines to a much 


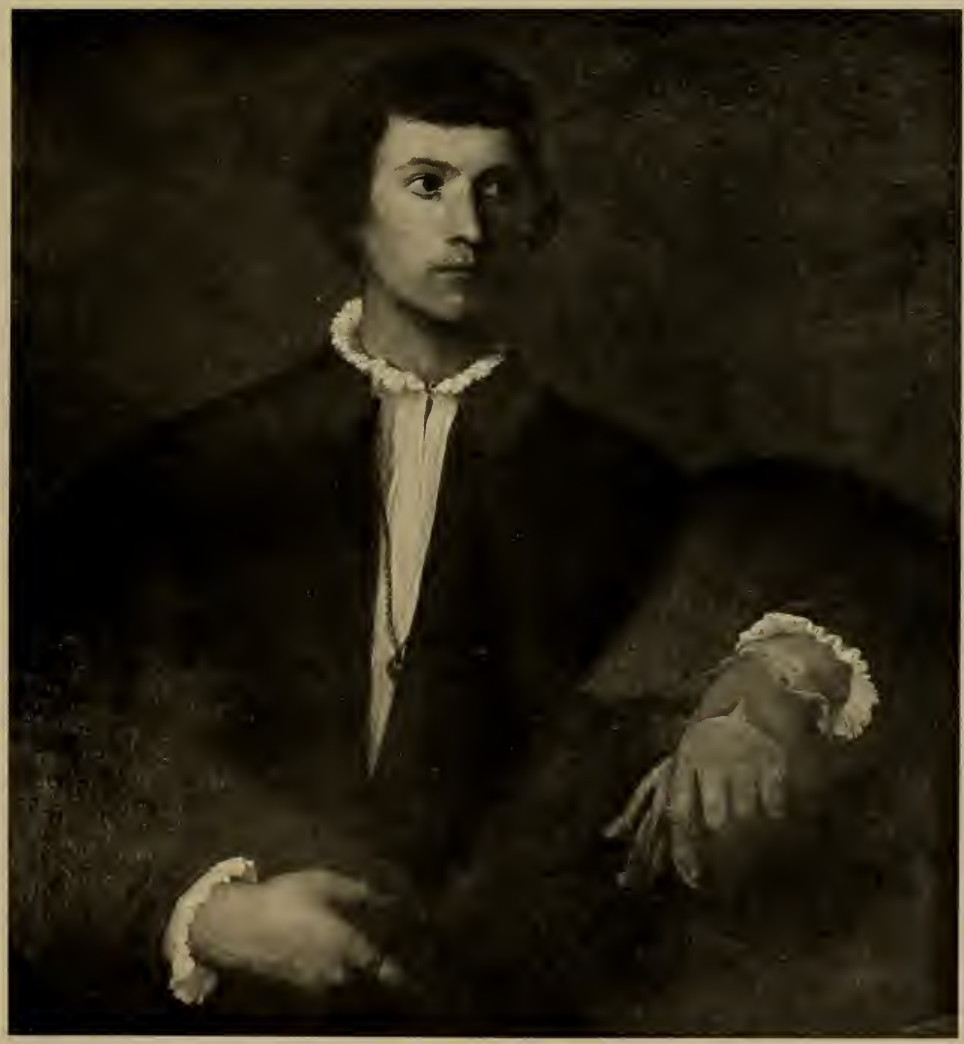

L'HOMME AU GANT.

BY TITIAN.

Plate 23.

IN THE LOUVAE, PAAIS. 

broader treatment and more vigorous handling of the paint. This is still more pronounced in Tintoretto, but there is no real revolution until Rembrandt and Velasquez finally break away from the old traditions, and carry the art of manipulating paint and the rendering of texture by brushwork to the highest level it has ever reached.

I have already mentioned that Titian's method was very elaborate. I will borrow from a very interesting and learned work on "The Graphic Arts" by Hamerton, a résumé of what Boschini tells us with regard to Titian's practice. This Boschini knew the younger Palma, whose father had received instruction from Titian, so it is probable that the tradition handed down by him is not very wide of the mark.

It seems that the pictures were at first laid in very solidly with a simple palette composed of white, black, red, and yellow. There was apparently no blue, but black and white make a bluishgrey which would be sufficient to indicate this colour in the first painting.

Boschini speaks of four pencillings which were done in this way, and then the picture was put aside for several months. When he took it up again he first amended and corrected all the forms. He then finished very laboriously with continual glazings and also with rubbings of opaque colour, frequently applied with the finger instead of with the brush. In this way he is said to have gained the exquisite delicacy and richness of colour in which his paintings surpass all others.

I shall not attempt to criticise a method which has produced perhaps the finest pictures that the world has ever seen, but it has obvious drawbacks for portraiture. Indeed, for this, the method was no doubt somewhat relaxed, or the patience of his sitters would have been too severely tried; but he never attained the freshness and spontaneity of Velasquez and of Rembrandt. 
As a further specimen of Titian's style in portraiture I give a coloured reproduction of the portrait of Ariosto that has been recently added to our National Gallery. (Plate 24.) I do this with some misgivings for the painting of the flesh is certainly not worthy of the master; so some critics have doubted that it is a genuine work-one of them has endeavoured to evade the difficulty by assigning the picture to Giorgione. My orvn belief is that the picture is a genuine Titian, but that the head has been a good deal repainted. In other respects it is quite characteristic. It has all the grandeur of his style and his rich glow of subdued colour. The sleeve which has not been repainted is a masterpiece of technique, and, putting the execution aside, the head displays all that feeling for human beauty that distinguishes the Italian school.

Velasquez and Rembrandt were nearly contemporary. They both devoted the greater part of their activity to portrait painting pure and simple, and they both passed through an early period of precise and highly finished work to the masterly sketchiness of their later style. They also both suffered from a serious artistic defect to which I have alluded elsewhere. They had very little feeling for human beauty.

Their appreciation of the beauty of light and shade, of colour, and of texture, and their power of rendering these beauties, are miraculous, but an ugly human being seems to have been much the same to them as a handsome one. Velasquez could not only complacently multiply his portraits of his unwholesome-looking patron, but he even revelled in painting the unfortunate divarfs and idiots that, to the disgrace of Spanish civilisation, were the chief sources of amusement at the dismal court of Philip the Fourth. And Rembrandt, too. How few good-looking people there seem to have been amongst his numerous sitters-a fine man's head here and there, and very occasionally a passable Dutch maiden with a pleasant face. But that is all. 



\section{Plate 24.}

ARIOSTO.

BY TITIAN, IN THE NATIONAL GALLERY, LONDON. 


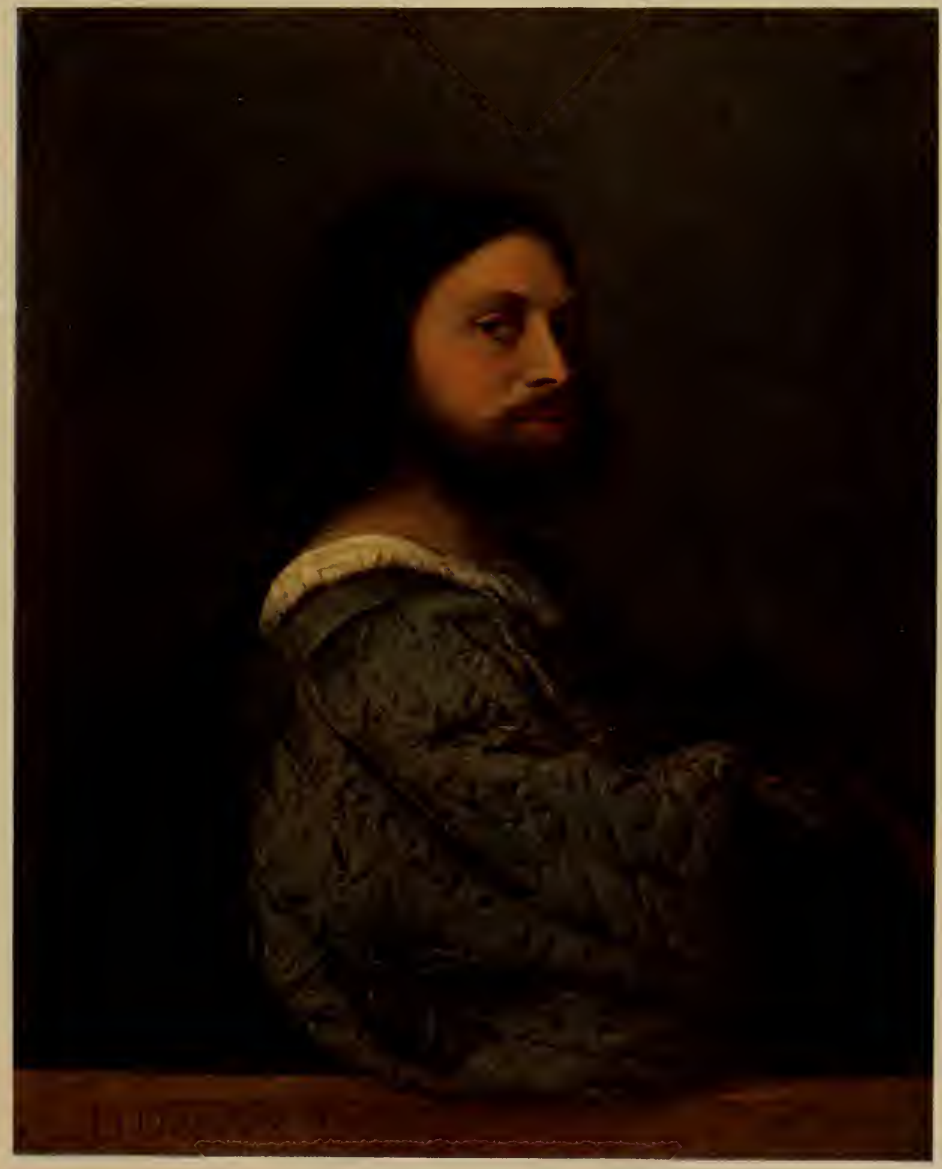



It is unfortunate that a sturdy realism, although it is so valuable in art, does tend to the neglect of beauty. I think that if Titian had had the same sitters as these two great masters he would have made them look far more attractive-though he might not have painted them so well.

And now comes a question of surpassing technical interest: How did Velasquez paint?

As usual, contemporary records are provokingly silent on this point, but we have one invaluable document. In "Las Meninas," a work of his finest period, we have from the painter's own hand a realistic view of his studio, with himself at work in it on a large canvas. The room is big, very lofty, and rather bare. It is lighted by high windows at the side, apparently blocked up below as the light comes a good deal from above, but not from a skylight. Velasquez is standing to his work, and he uses an ordinary palette and brushes. The colours on the palette are few in number. To judge from the reflection of his sitters in a mirror at his back they are standing some way off the painter, but nearly in a line with the canvas; that is, the painter can see both his work and his sitters with a very slight movement of the head.

It is interesting that the brushes are of the ordinary length, for Palomino, who wrote only sixty-four years after the death of Velasquez, states that he painted the portrait of Admiral Pulido y Pareja with exceptionally long brushes in order to get more vigour and relief. If this is true he must have abandoned the practice when he painted "Las Meninas"-a much later picture, and the high-water mark of his technical achievement. (Plate 25.)

To me there is no doubt that this portrait of the Admiral is the one that is now in our National Gallery, though its authenticity has been questioned by no less an authority than Señor de Beruete. It is a wonderfully direct and vigorous 
example of the painter's middle period-a little brutal in comparison with the exquisite subtlety of his later work.

To return to "Las Meninas." There is one very striking novelty in it which marks an epoch in the history of art. For the first time an effort has been made to give absolute truth of light and shade, and, more than that, to give the effect of atmosphere that pervades all natural scenes. In all preceding painting the lighting has been that of a picture rather than that of Nature; the figures may look real in themselves, but they never bear an absolutely real relation to one another and to their surroundings. For the first time in art a room has been made to look like a real room, with the figures in it bathed in a real atmosphere, and lit up with the light and shade of Nature.

This is a very extraordinary achievement, and although the lesson of it has been but imperfectly learnt, yet it has had a lasting effect on modern art. We know, at any rate, that truth of this kind is possible, and here and there we attempt it with some small measure of success.

In comparison with this atmospheric realism, the forced chiaroscuro of Rembrandt seems very crude and artificial.

In all technical matters "Las Meninas" represents the highest point that painting has ever reached, but at the risk of tedious repetition I must point out how ugly the picture is from the human point of view. The foreground is occupied by a misshapen dwarf kicking a dog with a most ungainly gesture, and the waiting-maids, from whom the picture derives its name, with the little princess that they are grouped around, are singularly graceless and ill-favoured. The only pleasant-looking figure in the picture is that of the painter himself, and he is, with becoming modesty, placed in the background.

I have referred to Señor de Beruete, whose work on Velasquez 


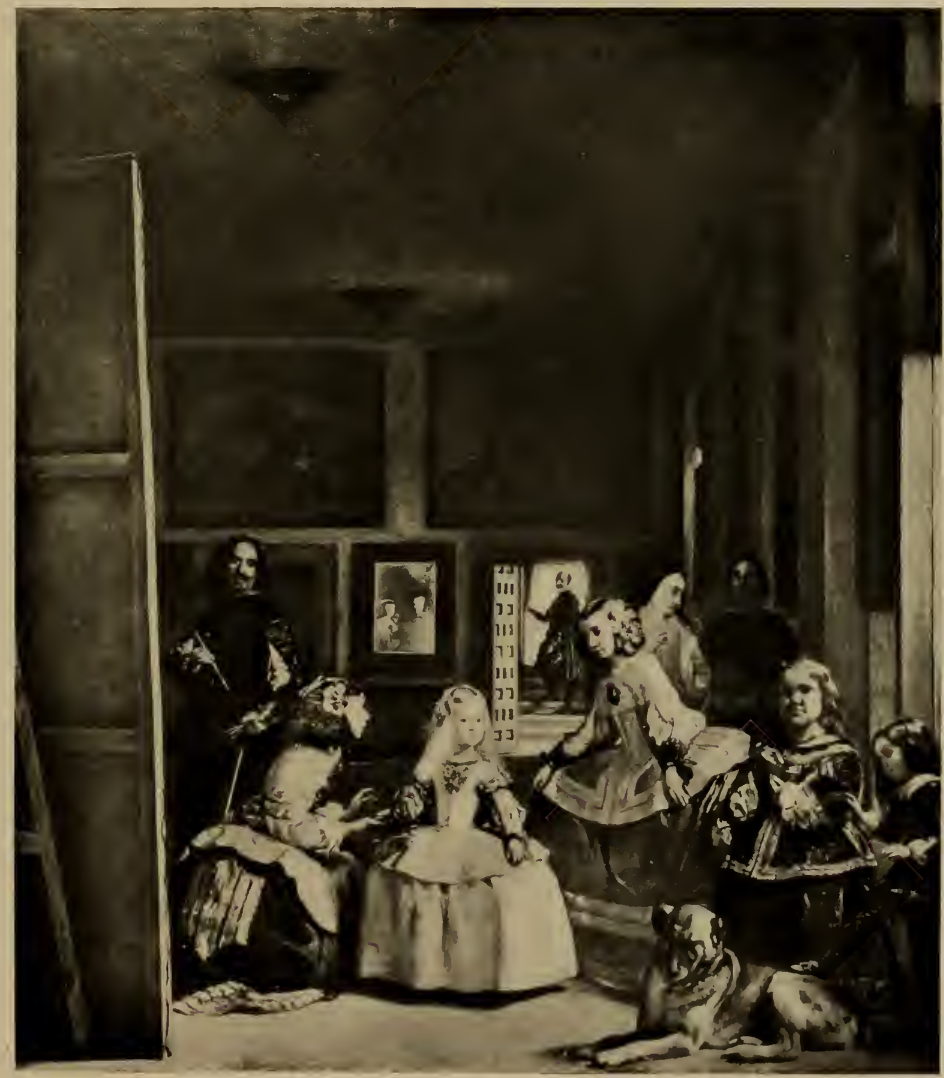

LAS MENINAS,

BY VELASQUEZ.

Plate 25.

in THE PRADO, MADRID

From a I'hotograph by Brawn, Paris. 

is probably the most authoritative on the technical side.* His judgment seems to me occasionally at fault, as in the case of the portrait of the Admiral; but as a painter himself, and one who has devoted his life to the study of the master, his conclusions as to the technique of Velasquez should be treated with great respect. He gives the colours on the palette in "Las Meninas" as vermilion, white, "terre de Seville," and carmine. There are indications of three or four sombre tones which may be black and various browns, but there is no trace of the blue and yellow that were certainly used. He mentions that the brushes in the same picture are mounted on goose-quills with wooden handles (I confess that when I examined the picture this detail escaped my attention). De Beruete goes on to say that Velasquez always used round brushes, and that there is nothing in his pictures to indicate that he ever used flat ones. This is one of the arbitrary assertions that make me somewhat distrust our author's judgment. I am equally convinced that there are many broad, sweeping passages in the master's work which could only be rendered by broad, flat brushes.

De Beruete also rejects the testimony of Palomino as to the occasional use of long brushes. For this rejection he seems to have no valid reason.

With regard to the preparation of the canvas, I think we can follow our author with more confidence. According to him, the ground was red in the early work, gradually changing to the neutral grey of the later style. The impasto of this preparation becomes less and less; towards the end it only just covers the canvas, the grain of which is generally fine, even in big pictures.

In the "Bacchus" the priming was reddish. There are places (especially round the figures and accessories) where this priming

\footnotetext{
-A. de Bcruete: "Velasquez," Paris, 1898.
} 
has never been covered, so instead of working his figures into the background each part was painted separately, carefully following the drawing.

In his later work he became presbyopic, so, not being able to see close, he had to get further and further away from his canvas, which made his execution more summary. In his latest pictures he used very fluid colours, in some places only floated on, as in water-colours, and there is no impasto save in the head and hands. This method enabled him to paint very rapidly. There is no technique so simple as that of Velasquez. To each of his manners correspond special methods. The difference is chiefly that the thick pigment of his first pictures becomes more and more liquid as his skill increases.

So far Señor de Beruete.

I may add on my own account that Velasquez hardly ever made drawings or studies for his pictures. There is a small version of "Las Meninas" which may have been a preliminary study, but is more probably a replica, and there are one or two oil sketches for other pictures; but on the whole there is scarcely another artist of distinction by whom there are so few studies extant.

In the early and middle period he probably drew in his work with a painted outline. In the portrait of a sculptor at Madrid, the bust that he is working on, which has been left unpainted, is outlined in this way. In the later period this painted outline is apparently abandoned, although, of course, the work may have been drawn in with charcoal.

He did not lay in his picture in monochrome, as was the practice of Leonardo, and probably of Holbein. Nor did he adopt the method of Frans Hals-and of Mr. Sargent in our days-what the French call the "peinture à premier coup," in which each part of the picture is the result of one painting only. 
If it is wrong it is not modified by subsequent work, but it is taken out and completely repainted.

The first painting of Velasquez was like the subsequent ones, only perhaps the colour was a little greyer and weaker. In the early and middle periods it was put on with a full brush. In the details of the dress the impasto was often fairly thick, but much less so than in Rembrandt's later style. Parts of the dress were often finished at one painting. The subsequent paintings were merely modifications and improvements of the first laying in. The colour was opaque, both in the lights and shades, with a very scrupulous attention to truth of tone. The execution in the early period was precise and rather hard-in the middle period very solid and simple, but with much greater freedom-in the third period it was freer still, rather vaguer and softer, and much more subtle. In this later period the paint was put on less thickly. He was not afraid of making alterations when necessary, but one of the characteristics of his work is the sureness of his intention. His pictures seem conceived as a whole from the very beginning; and in his later style the interest is focussed on the really important parts-the unimportant details being either suppressed or treated somewhat vaguely. Through all the three periods the colouring remains simple and subdued. The grey tones of which it is mostly composed are extraordinarily harmonious, so that Velasquez is almost as great a colourist as Titian, though their schemes of colour are as the poles asunder. In truth of tone he is immensely superior to Titian-indeed, to any of the Italians; in this his only rivals are some of the Dutch painters, such as Terborg, Vermeer, or de Hoog.

I think this is all that can be said with any safety as to the methods of Velasquez. The case of Rembrandt is still more difficult.

He also dispensed with preliminary studies in his portrait 
work; of all the numerous drawings that have come down to us hardly any refer to portraits.

There are one or two etchings which reproduce his portraits, but these were probably done from the paintings, and not as studies for them.

He seems to have worked in a studio with a very small window, so as to get the powerful effects of shadow in which he delighted. I have already pointed out that his chiaroscuro is far more artificial than that of Velasquez. It is of course extraordinarily skilful, and the shadows are so arranged as to give the utmost value to the important parts, but it is too arbitrary to be quite satisfactory. Again, the warmth of his colouring is unnatural, although very pleasing. His feeling for colour is allied to that of the Venetians, although it is much more limited, and plays almost exclusively amongst the browns, reds, and yellows; but within this limited range its quality is supreme. This extraordinary success of Rembrandt in the key of brown has led many people to imitate him in their colour schemes, but nearly always with disastrous results. For the ordinary painter the greys of Velasquez are much safer, besides having the advantage of being distinctly truer to Nature.

Like that of Velasquez, Rembrandt's early style is careful and precise-for instance, in his own portrait in our National Gallery, painted at the age of thirty-three, there are little hairs at the end of the moustache, painted with a fine brush, and drawn with the utmost delicacy. The execution is smooth, and there is scarcely any attempt to render texture by brushwork.

It is in his later style that the handling becomes so extraordinarily vigorous, and that the thick paint is brushed to represent texture in a way that seems almost miraculous. In this quality of brushwork no one has ever equalled Rembrandt. In his latest manner it becomes rather coarse, but it is always masterly. 
In grouping and arrangement he was also very skilful, especially in his middle and later periods. In "The Lesson in Anatomy" the composition is too obviously arranged, and some of the heads repeat themselves in a monotonous manner, but the richness and freedom of the grouping in the so-called "Night Watch," and the perfect naturalness of "The Syndics," have never been surpassed.

With all his immense gifts Rembrandt was a very unequal painter. Some undoubtedly genuine works of his are almost bad, especially amongst the subject pictures.

His drawing is often careless-the hands are quite commonly very clumsy-and he had even less than Velasquez the feeling for the beauty and dignity of the human form. The one nude female figure painted by Velasquez, although commonplace enough in form and feature, is an angel of beauty in comparison with the squalid Bathshebas and Susannas in whom Rembrandt delighted.

To me this point is of great importance, but I feel that I must apologise for recurring to it so frequently. Were it not for this defect I should esteem these two masters the greatest painters in the world; as it is, I think them the greatest portrait painters, and undoubtedly the greatest exponents of the technique of oil-painting. Both of them in their later styles made use of the full capacity of paint for the rendering of texture-the brush-marks were so directed as to express with the least amount of labour the wrinkles of the skin or the peculiarities of any surface that they wished to portray. Rembrandt carried this much further than Velasquez; his portraits of old men are the most skilful examples of brushwork in the world, but his execution sometimes degenerates into needless coarseness. Velasquez is always more restrained, but hardly less masterly. 
Of course this kind of work must not be looked at too closely; it has to be seen at some distance to produce its proper effect. (Some of the moderns have improved on this so much that it is impossible to see their pictures at all within the compass of an ordinary room-they require the whole length of a big picture gallery, and even then it is difficult.) It is evident that we have departed far from the principles of Holbein, of whose work one of the great charms is that it looks right quite close, and from far off as well-but of course this is only to be obtained by great and perhaps unnecessary labour. It is enough if a large portrait looks right at a distance of some ten or twelve feet, and this is usually the case with our great impressionist masters. There is no doubt, too, that there is an appeal in the very magic with which this free work is done. The skill is so much more obvious than with the careful workit is sometimes so great as to be quite uncanny. Also the saving of time, if it be not carried to the point of slipshodness, is an undoubted gain; with any other method we should not have had nearly so many masterpieces from these great painters, and we have all too few as it is.

There is one other point: these summary methods involve much less strain on the sitter, and very often enable the whole picture to be painted straight from the original. With Court pictures, indeed, the dresses have generally to be painted from a model or a lay figure, for the sitters are so much occupied with lengthy futilities that they have not much time left for sitting for their numerous portraits; but these dresses are mostly so stiff that it doesn't much matter. Excluding the Royalties, I believe that most of Velasquez's portraits were painted straight from the sitters, clothes and all, and practically all of Rembrandt's. This is an undoubted gain for the rapid painters-a gain that was deliberately thrown away by Sir Joshua and the other painters of his time, who to 
give less trouble to themselves and to their lazy patrons, were in the habit not only of painting the costumes from models, but even of getting them painted by their pupils.

To sum up, other things being equal, rapidity is a great gain for the portrait painter. By the methods of Rembrandt and Velasquez, this rapidity can be achieved without the sacrifice of any quality of great importance. But in my opinion they carried this rapidity of execution as far as it can safely be carried. Any further advance in that direction degenerates into coarseness or emptiness. Even they sacrificed something; there are certain qualities in Holbein that they do not touch, but perhaps the greatest example of the contrary method is the "Monna Lisa" of Leonardo. This is, of course, akin to Holbein in its execution, but it has a delicacy and subtlety that not even he approached. But this portrait is the work of years; it is the result of an elaboration that would certainly be thrown away on most sitters, and is a quite impossible method for the workaday world in which most portrait painters move.

Amongst the Italian masters, the one who came nearest to the impressionistic style was Tintoretto. His procedure was undoubtedly very summary-in fact, he was essentially a glorified sketcher, but his portraits, although vigorous, are by no means his best work. For the perfection of the purely sketchy style, we must go north again, and study the work of Frans Hals, perhaps the most skilful exponent of direct painting that the world has seen-although Raeburn and Mr. Sargent run him close. As we have said, the essential of Hals's method is that each part should be done at one sitting, consequently it has all the freshness and vivacity of a sketch. If any part of it be wrong it must be entirely repaintedthe method does not admit of modifications. To this freshness, other very important qualities have to be sacrificed. It is hardly compatible with any great subtlety of modelling, nor does it lend 
itself to delicate varieties of texture. The paint is put on with a full, wet brush, the touches being kept distinct and very little blended. To get the proper effect the spectator must stand some way off and let distance do the blending.

There is undoubtedly something very fascinating about this method of painting. It looks, and is, so masterly. But unlike the very finest work, it rather flaunts its cleverness-there is nothing of the art of concealing art about it.

As regards the texture and modelling of flesh, Hals is not on the same plane with Velasquez and Rembrandt, but he has one virtue which is supremely his own. No one has ever given such natural vivacity of expression, though here again Mr. Sargent runs him close.

As I have said before, Hals is in some ways more a draughtsman than a painter. His shadows are put in with clear, decided touches, and modelling is less thought of than the accurate placing of the accents that mark the features. There is no fleshiness, no distinction between the bony parts and the softer ones, no delicate rounding of the surfaces. The hair is put in with great coarse strokes like an enlarged drawing. Then the colour of the heads is poor, hardly more than one even tone with coarse brown shadows. He seems to have kept all his fine colouring (and it was sometimes very fine) for his costumes and accessories. (Plate 26.)

But when all exceptions have been taken to Hals's method it must be allowed that it has one great advantage. It is an admirable training for the painter in sureness of hand and eye. We are all inclined to put on wrong tones and careless touches in the comfortable assurance that subsequent work will put them right; but with prima painting there is no such hope. If the work is not right it must all come out and be done over again, so that the natural laziness of the artist helps to correct his carelessness and slackness. It is easier to make an effort 
Plate 26.

DR. ALBERT VAN NIEROP. BY FRANS HALS, IN THE HAARLEM MUSEUM. 


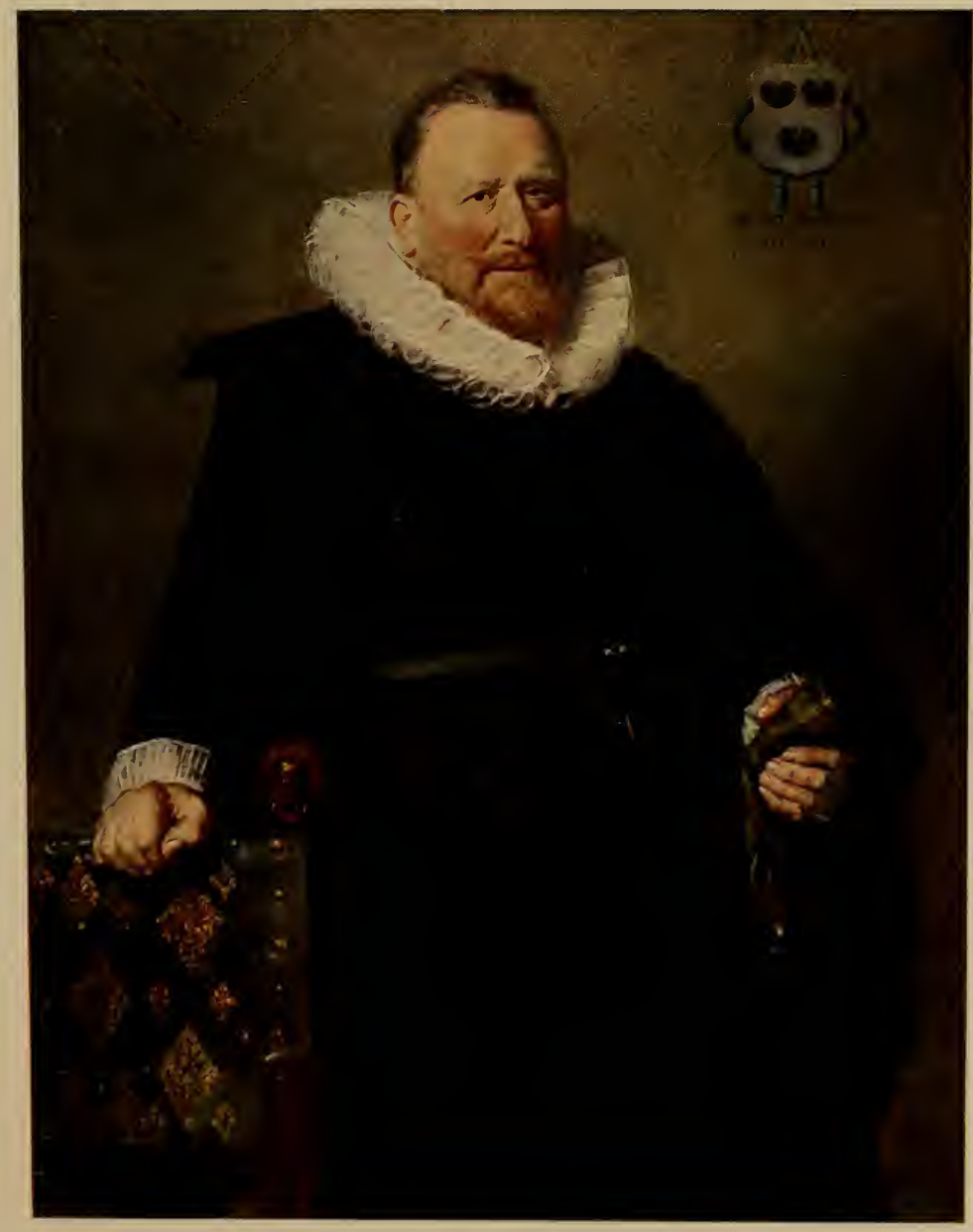



to get the work right at once than to go on taking out and repainting.

As a contrast to Hals we may take the courtly Vandykealso a man of extraordinary talent, but also not quite in the front rank.

Vandyke was spoilt by success, and degraded his own art and that of many subsequent painters by establishing a sort of manufactory of fashionable portraits. $\mathrm{He}$ and his master Rubens were the first to employ assistants on a very great scale. Of course the pupils of the Italian painters did help them in their work, but the assistance was not given on nearly such a wholesale scale as in the case of the two northern painters.

Here is an account given by one of his friends of Vandyke's method of work.

" $\mathrm{He}$ never worked longer than one hour at a time on each portrait. When his clock told the hour he rose and made a bow to the sitter, as much as to say that enough was done for that day, after which his servant came to prepare fresh brushes and palette, while he received another person to whom he had given an appointment.

"After having lightly sketched the face, he put the sitter in an attitude that he had previously meditated, and with grey paper and black and white crayons he drew in a quarter of an hour the figure and drapery, which he arranged in a grand manner and with exquisite taste. He then handed over the drawing to skilful persons whom he had about him, to paint it from the sitter's own clothes, which were sent on purpose at Vandyke's request. The assistants having done their best with the draperies from nature, he went lightly over them, and soon produced by his genius the art and truth which we there admire. As for the hands, he had in his employment persons of both sexes who served as models." 
This is a manufactory with a vengeance. It is quite unlike the atelier of Velasquez, where the assistants were only employed in copying the master's work.

It will be noted that Vandyke put the sitter into an attitude that he had previously meditated. That is to say, he made his subjects fit into his own notions of what was graceful and artistic without apparently taking the least trouble to find out their peculiarities. Then he never painted their bodies-a sketch drawn in a quarter of an hour was enough guidance for that. He had their clothes, but he didn't even paint them himself, and the hands were always done from other people. I need hardly point out how fatal this procedure is to all true portraiture.

The models who served for the hands are perhaps the most fatal feature. I believe Vandyke was the first portrait painter to discard all individuality in the hands. Unfortunately his example has been widely followed, with the worst consequences to our art.

It will be observed that, like Holbein, he began with a separate drawing, from which the picture was subsequently laid in-but, unlike Holbein's careful work, this drawing was a mere sketch, and was handed over to Vandyke's assistants to be painted on to the canvas. In the case of the inferior portraits, of which there are a good many in England, no doubt most of the painting is the work of these assistants.

Vandyke's own handling is facile, but not sketchy; his work never looks unfinished. At the worst it is a little tame and mannered; at the best it is never as forcible and masterly as that of Velasquez or of Rembrandt, but it is good sound painting, well drawn, well coloured, and well modelled.

Perhaps the finest of all his English portraits is that of Lord Wharton, now at St. Petersburg, which created such a sensation when it was exhibited at Burlington House in the Vandyke exhibition of a few years ago. (Plate 27.) Here there is no 


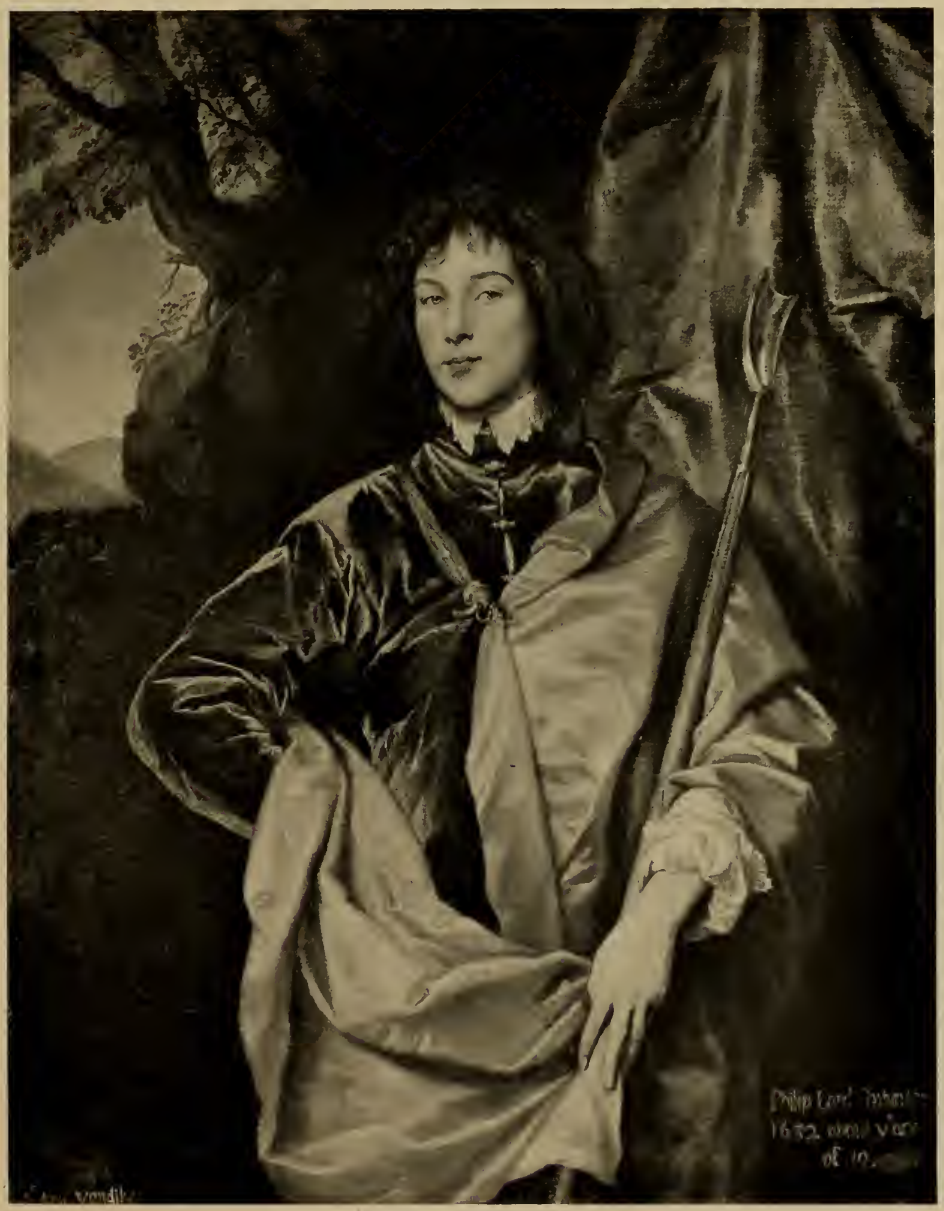

PHILIP LORD WHARTON.

BY VANDYKE.

Plate 27.

in the hehMitaog galleray, St, petehsburo

From a I'hotograph by livans Ilan/staengl. 


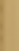


trace of the manufactory. It was doubtless the work of the master's hand throughout.

We now come to the great English school of the eighteenth century.

Sir Joshua Reynolds in his merits and defects is a lineal descendant of Vandyke. He had even greater charm, at any rate in his female portraits, but he was also more given to scamping his work, and had almost less conscience in employing assistants. We have an account from his pupil Northcote of Sir Joshua's house in Leicester Square, where he painted from 1760 to the end of his life.

His own studio was a small one, about 20 feet long by I6 feet in breadth, but there was a long gallery in which were exhibited the principal pictures he had in hand, and there were numerous rooms for his pupils, copyists, and drapery men, of whom he had a considerable staff. His pupils served also as models for hands and draperies.

As in the case of Vandyke, there was a constant stream of sitters through the studio. They nearly all sat in the same chair, in the same light. The Master painted their heads very methodically, laying them in with a very simple palette consisting of three or four colours only, and then glazing them with tivo or three more. After this they were handed on to the drapery men and the other assistants to put in the clothes and the backgrounds. Then the pictures came back to the Master, who worked all over them a little (apparently without the sitters), mostly in the direction of giving a broader and more general effect, for Sir Joshua was great on generalisation.

As for the details of his technique, we have various accounts from his own note-books and from contemporary records.

Here is a description of his early practice by an amateur painter who was admitted to his studio. 
"On his light-coloured canvas he had already laid a ground of white where he meant to place the head, and which was still wet. He had nothing on his palette but flake-white, lake, and black, and, without making any previous sketch or outline, he began with much celerity to scumble these pigments together till he had produced in less than an hour a likeness sufficiently intelligible, yet withal, as might be expected, cold and pallid to the last degree; at the second sitting he added, I believe, to the three other colours a little Naples yellow."

He must have used a somewhat fuller palette for the subsequent sittings, but that is not mentioned. It is mentioned that this particular picture "very soon faded, and soon after the forehead particularly cracked, almost to peeling off, which it would have done long since had not a pupil repaired it."

This was in 1754. There is a letter of Sir Joshua's in 1770 describing his practice then, when he was forty-seven years old.

"I am established in my method of painting. The first and second paintings are with oil of copaiva (for a medium), the colours being only black, ultramarine, and white." "The second painting is the same." "The last painting is with yellow ochre, lake, black, and ultramarine, and without white, retouched with a little white and the other colours."

This may be supplemented by what his pupil, Beechey, says of his master's method at about the same date:

"His vehicle was oil of balsam of copaiba. His colours were only black, ultramarine, and white, so that he finished his picture entirely in black and white, all but glazing; no red or yellow till the last, which was used in glazing, and that was mixed with Venice turpentine and wax as a varnish."

Later he seems to have adopted Venice turpentine and wax almost exclusively as a medium for the heads, whilst the draperies 


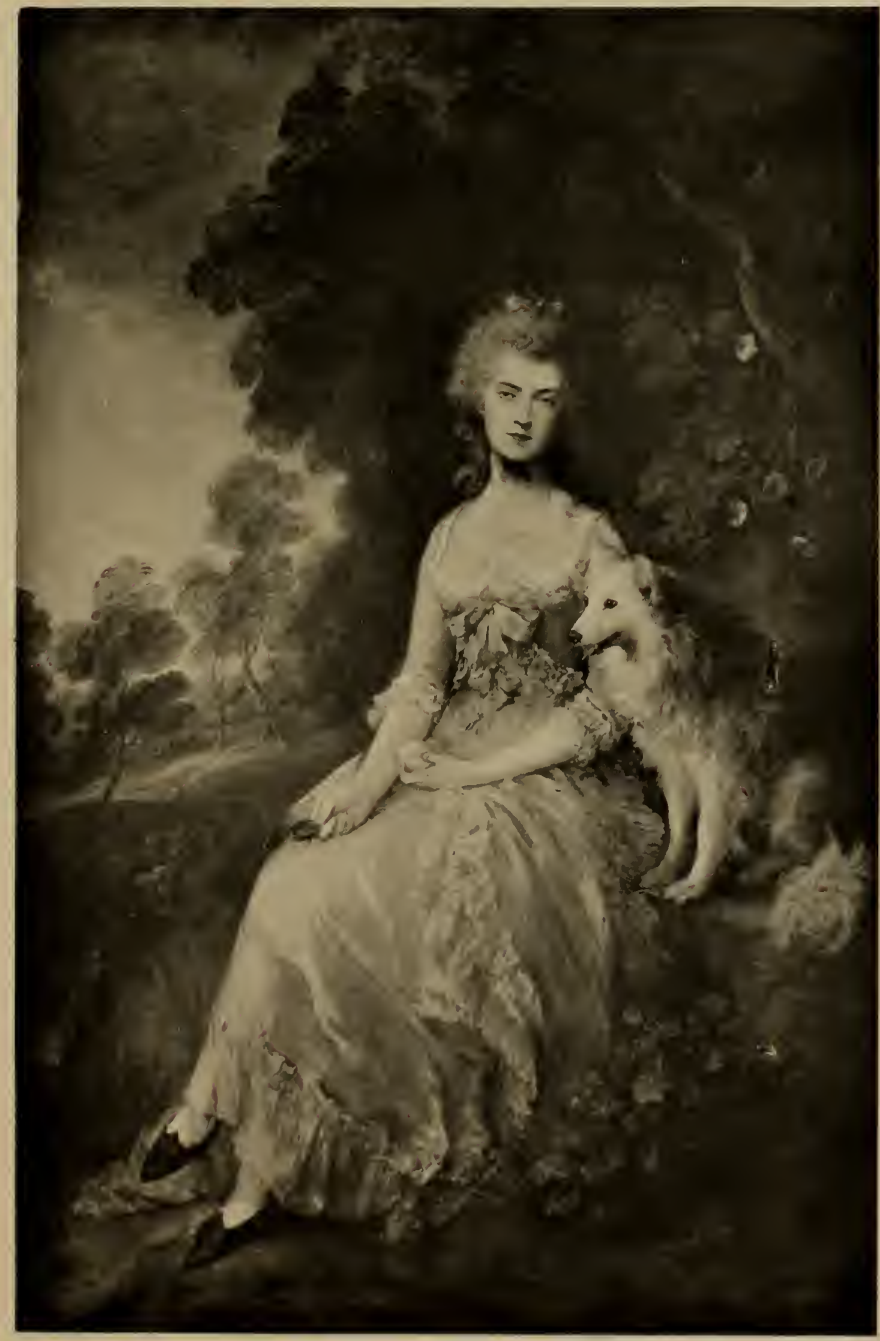

- - MRS. ROBINSON ("PERDITA").

BY THOMAs gaINSBOROUGH, R.A.

Plate 28.

IN THE WALLACE OOLLEOTION, LONOON, 

were painted with wax without the turpentine, thus getting a richer impasto.

In spite of this pretended carefulness and simplicity of method his experiments with pigments were reckless in the extreme. $\mathrm{He}$ used such colours as gamboge, orpiment, and the cochineal lakes, all well known now to be fugitive, and many of his pictures have suffered accordingly.

Altogether Sir Joshua is a very unsafe guide for technique.

The most interesting detail that has come to light about Gainsborough's methods is that he used very long brushes. Here is an account by an eye-witness: "I was much surprised to see him sometimes paint portraits with pencils on sticks full six feet in length, and his method of using them was this. He placed himself and his canvas at a right angle with the sitter, so that he stood still and touched the features of his picture exactly at the same distance at which he viewed his sitter."

From this we gather that his sitters, even allowing for his arm being outstretched, cannot have been more than eight feet away from him. This is inconveniently close, and may account for the serious errors of proportion that are to be found in so many of his pictures.

It will be remembered that Velasquez is said to have tried this method of long brushes, but he seems to have given it up, whereas Gainsborough probably adopted it more and more, until it becomes habitual in his later work.

This method with Velasquez seemed to be compatible with great firmness and solidity of touch. With Gainsborough it seems to produce what, in his best work, is a delightful lightness of execution, but in his worst is an abominable scratchiness.

For full-length portraits it was Gainsborough's habit to make a small sketch of the figure before beginning to work on the full sized canvas. On this he would lay in the head, the figure, the 
drapery, and other accessories from the sketch, and then finish from the model.

As an example of Gainsborough's treatment of a full length portrait when he was in the plenitude of his powers I have reproduced the "Mrs. Robinson ('Perdita')" in the Wallace Gallery. (Plate 28.) I have never seen a finer Gainsborough than this.

I have not been able to discover any authentic details about Romney's practice. It was probably akin to Sir Joshua's, but simpler and less experimental.

Fortunately we have a fairly definite account of the methods of the great Scotch master, Raeburn, which are more likely to appeal to modern artists than the roundabout ways of Sir Joshua or the flimsiness of Gainsborough.

Raeburn was an exponent of what may be called the direct method of painting; that is, he aimed at putting every touch on the canvas as nearly right in tone and drawing as he could get it. If he were successful in this it remained unmodified-it was right at once and for ever. If he were unsuccessful it had to be re-done, but it was never put on with a view to being subsequently modified. So that the finished picture is a sort of mosaic of definite touches, each of them apparently put on the canvas with one siveep of the brush.

In his earlier works he carries this method so far that his faces look too hard; as if, indeed, they are cut out with a hatchet. They are also, to my mind, unduly simplified. They are wonderfully true as far as they go, but they do not tell one enough about the sitters; in short, they lack subtlety.

Oddly enough, Raeburn's work did not become more summary as he grew older, as is the case with most artists. On the contrary, in his later manner he modified the extreme breadth of his modelling, and gave a much more complete suggestion of the real texture of flesh. The square touch of his earlier style 


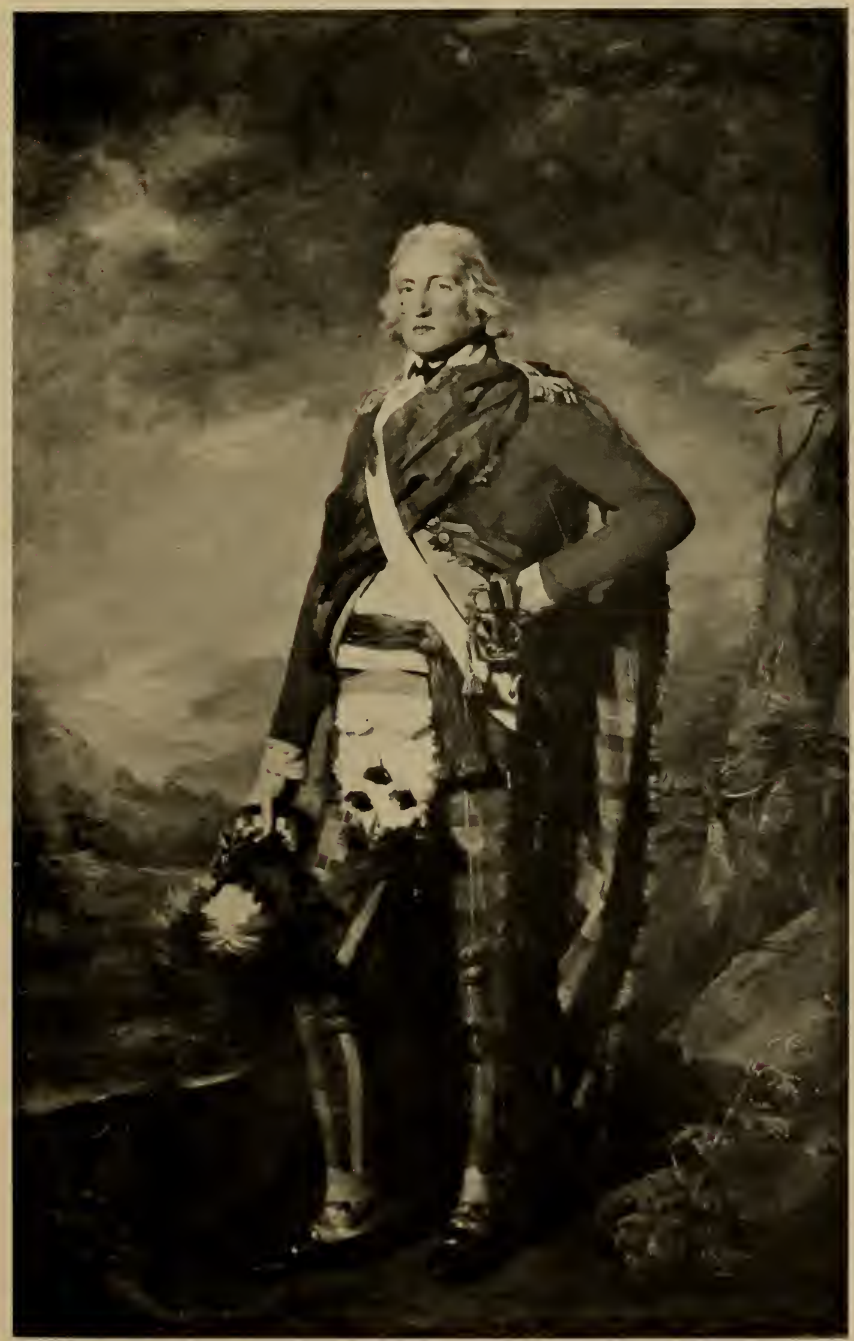

SIR JOHN SINCLAIR OF ULBSTER.

BY SIR HENGY RAEBURN R.A.

Plate 29.

aY PERMISSION OF SIR J. G. TOLLEMACHE SINOLAIR, DART, OF ULBSTER.

from a Photograph by $T$, \& $R$. Annan of Sons. 
(2.

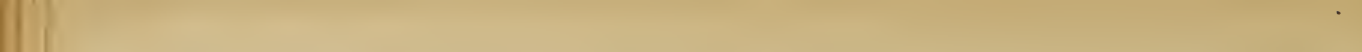


becomes a singularly skilful and suggestive smear. In the last years of his life his handling is almost as fused as that of a late Velasquez.

Here are some notes of his practice (as handed down by various sitters) given by Mr. R. A. M. Stevenson in his excellent introduction to Sir Walter Armstrong's great work on Raeburn :

I. He seldom kept a sitter more than an hour and a half or two hours.

2. He never gave more than four or five sittings to a head or bust portrait.

3. He did not draw in his subject first with chalk or charcoal, but directly with the brush on the blank canvas.

4. Forehead, chin, and mouth were his first touches.

5. He placed the easel behind the sitter and went away to look at the picture and sitter together.

6. A fold of drapery often caused him more trouble than the build or expression of a head.

7. He never used a maulstick.

As Stevenson remarks, "If any painter in the eighteenth century in these Isles used paint after the sanest and most enduring traditions, it was Raeburn. The excellence of his straightforward method has caused his colour to stand much better than that of Reynolds." Unfortunately this colour which has stood so well is not of the best quality. His colouring was often harsh and cold. This, indeed, is his chief defect as a painter.

$\mathrm{He}$ was fond of simple backgrounds. These were usually of a well-chosen tone of grey, with a certain play of light and shade in them. His more elaborate backgrounds, especially the landscape backgrounds, were frankly conventional.

Perhaps the finest of all Raeburn's portraits is the one I here reproduce (Plate 29) of Sir John Sinclair of Ulbster. It is a miracle of direct and vigorous painting. 
To come to the moderns, it was my good fortune to be on intimate terms with Millais, and I have had the great privilege of watching him at work.

In life-sized portraits he always put the canvas side by side with the sitter, and walked backwards and forwards for a considerable distance-putting on a touch and then going back to look at the effect. If it was not right he would come forward again to modify it. This modification he often did with his finger. I may add-though this hardly applies to his portraiture, which was nearly always the size of life-that with figures under life size he placed the canvas so much in front of the model that the painting, when looked at from the furthest distance of his walk, appeared precisely of the same size as the model.

Of course, all painters try to get away from their work from time to time, in order to judge of the general effect. But Millais carried this principle very far. As he told me once, "I like to get far enough away from my portrait to see it the size of a postage stamp; I then know if it is right or not."

It is also unusual to keep the canvas during the whole operation side by side with the sitter. For one thing, it restricts the choice of lighting, as the best light for the sitter might not be a possible light for the canvas. As a matter of fact, most of Millais's portraits are lit from the side, probably for this very reason.

His studio, during his later period, was a very long room with lofty side windows but with no regular top-light such as was almost universally employed by the older portrait painters, with the exception of Velasquez, whose studio at the time that he painted "Las Meninas" seems to have been much like that of Millais.

Probably for such a convinced realist as Millais, a top-light would have been too conventional, too unlike the conditions under which people are usually seen. 
At the same time, with that inconsistency that often goes with genius, when his sitters were supposed to be out of doors, he seldom troubled about getting a true out-of-door effect. In this again he resembled Velasquez, and, indeed, all the older painters.

To return to Millais's technique, his method of putting the sitter side by side with the canvas has the undoubted advantage of giving an immediate comparison between the picture and the model under the most favourable conditions, and so conduces to the vividness and life-likeness of the portraiture. But it is troublesome to carry out, and there is a great temptation not to go far enough back. Also the execution suffers; hurried dabs put on at the end of a walk, and afterwards corrected with the finger, can hardly have the masterly technique of paint deliberately applied by an artist standing quietly at his canvas.

Nevertheless, Millais's technique was extraordinarily vigorous and expressive, although it did lack the deliberate precision of the old masters.

It was one of Millais's essential principles that the picture had to be right-that is, true in drawing and colour-and although in his later period he was one of the most rapid of painters, he would spare no time or trouble to get it right.

For instance, for the portrait of Miss Eveleen Tennant (now Mrs. Frederic Myers) he had some eighty or ninety sittings. This was because something went wrong with it, and it took him all that time to get it right-and this labour was not thrown away, for in the end it turned out one of the most brilliant of his numerous representations of beautiful women.

It will be seen from the reproduction (see Frontispiece) that the colouring is very rich, and that the pose and expression have a straightforward simplicity which, to me, are quite as charming as the somewhat mannered grace of the earlier English masters. 
To take another instance, in Mrs. Grote's life of her husband she complains bitterly of the number of sittings that Millais insisted on for his portrait of the great historian.

I remember talking to Millais about this. "Oh, yes," he replied. "She says I killed him. It was all because I got the car too high, and couldn't find out what was the matter for a long time."

There is an excellent saying of his, to Mr. Stuart Wortley as quoted in the "Life and Letters"-

"It doesn't matter how beautifully a thing is painted, it is no good if it isn't right-it's got to come out"; and again, "What does it matter how you do it? Paint it with the shovel if you can't get your effect any other way."

On the other hand, if the work went right from the beginning, Millais was a very rapid painter.

He never did anything better than the portrait of Mr. Gladstone, which was done in some five or six hours. (Plate 30.) The distinguished French painter, Monsieur Benjamin-Constant, described it in the Magazine of Art as "the finest portrait of the time." He says "This painting can hold its own as a work of art by the side of the greatest masters of the past; Rembrandt himself could not injure it by juxtaposition. . . . Never has life been set on canvas with greater power, nor so large an existence been presented with a touch, a sweep of the brush."*

Millais very seldom made any preliminary sketches for his portraits. After very roughly indicating the position of the figure, he would paint the head straight on to the white canvas, just smudging a tone round it, to represent the background. The first painting was with the full vigour of the palette, the subsequent ones merely modifications of it. There is one other point with regard to Millais's procedure that I should like to

-Magazine of Art, 1900, p. 152. 


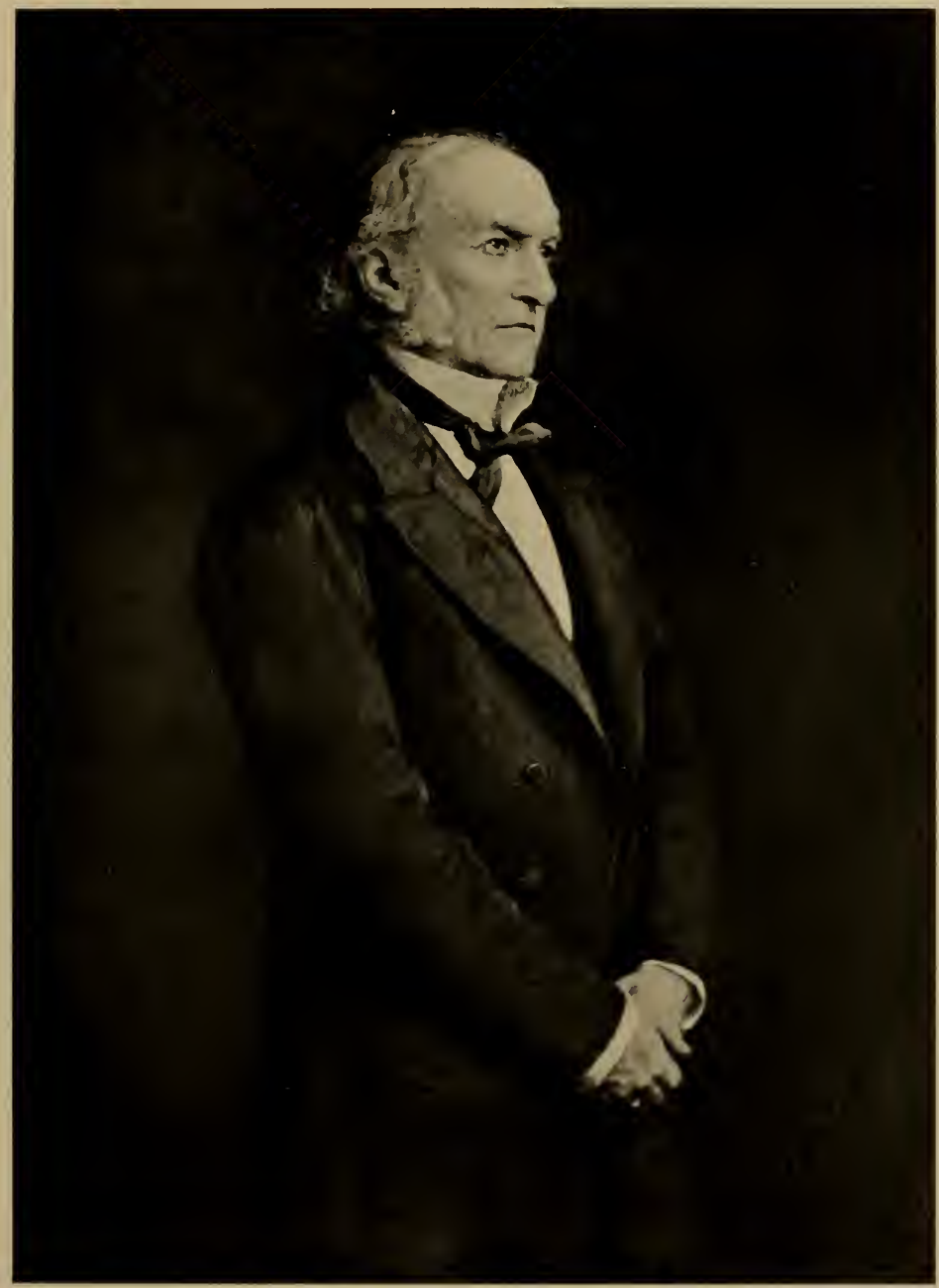

THE RT. HON. W. E. GLADSTONE,

BY SIR J. E. MILLAIS, BART, P.R.A.

Plate 30.

in the national oallery, LLONOON. 

emphasise. In a letter from $\mathrm{Mr}$. Gladstone, no doubt referring to the very portrait just reproduced, occurs this passage: "I was at once struck with a characteristic which seemed to me to mark him off from all other artists (and they have in my long life been many) to whom I have sat. It was the intensity with which he worked, and which, so far as I may judge, I have never seen equalled."

I am convinced that this intensity is very essential to the portrait painter. Whether the sittings be few or many the work should always be done under high pressure; only in this way can that vitality be achieved which is so important for his art.

I now turn to a very different painter. There is no doubt that the influence of Whistler on modern art has been very great, much greater than that of Millais. He was essentially a fighter, and in a time of artistic revolt all the turbulent spirits amongst the younger painters gathered round his standard, so that his influence was out of proportion to his actual pictorial achievement.

That he was a very original painter no one will deny. Nor that he was an artist to his finger-tips. But to class hin with the great masters is, to me, an absurdity.

I am only now concerned with him as a portraitist. As such, his reputation is chiefly based on two or three works-the portrait of his mother, that of Carlyle, and that of Miss Alexander. I here reproduce the last of the three as giving, on the whole, the finest example of his peculiar merits.

Most of his other portraits are very inferior. Some are almost grotesque, like the one of poor Monsieur Theodore Duret, who deserved better at his hands, as being one of the first art critics to appreciate his talents, and who has written an excellent, if over-eulogistic book about him-a very striking example of magnanimity after such a portrait. 
To take really fine examples like the ones I have mentioned, we find a very subtle harmony of tone, an original pose, and great simplicity of treatment. The tones are in very admirable relation one to the other, but they are so subdued that the picture does not look like nature. Miss Alexander is not like a real child standing against a wall. She is essentially an arrangement in low tones of grey-more harmonious, doubtless, than the real child would be, but entirely lacking in vitality. (Plate 3I.) His admirers always compare Whistler with Velasquez, and as I have before acknowledged, the subtlety of his grey tones and the admirable simplicity of his arrangements do recall the greater painter; but the essential difference is that the portraits of Velasquez look extraordinarily like real people, those of Whistler extraordinarily unlike.

As to Whistler's technical methods, I have been given some very interesting notes of his practice by a person who worked for some years in his studio. "He put the picture side by side with the sitter. He objected to figures actually life-sized; by as much floor as was in front of the feet, by so much did he suppose his sitter retired from the frame, and to that amount he made him smaller. The canvas had a grey preparation made with black and white mixed with turpentine. He did not use a palette, but had a table near him on which he mixed the tones he was going to use. This was a very important part of his practice; before actually painting his picture he mixed with great care a quantity of the tones he would require-such as background-colour, floorcolour, coat-colour in the light, ditto in the half-tone, ditto in the shadow; flesh-colour in the light, in the half-tone, and in the shadow; hair-colour in the same way, ctc. He had a mixture of oil and turpentine in a saucer standing on the table. Using this as a medium, he covered thinly the whole canvas with these prepared tones, using house-painters' brushes for the surfaces, 

Plate 31.

\section{MISS ALEXANDER.}

BY J. McNEILL WHISTLER,

By permission of W. C. Alexander, Esq. 


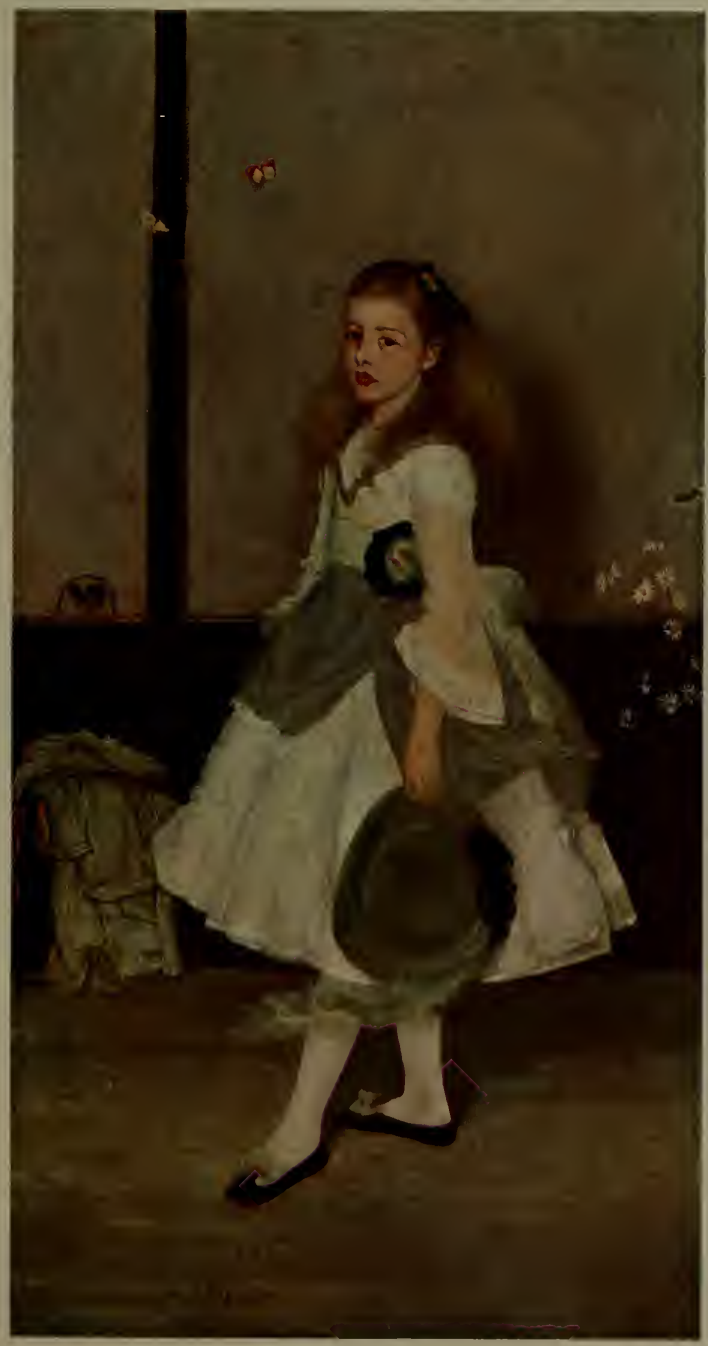



and drawing lines with round hogshair brushes nearly a yard long (he said that Carlyle was much struck by these big brushes, and laughingly approved of them as well fitted for their purpose). His object was to cover the whole canvas at one paintingeither the first or the hundredth. I remember his pulling up Lady Archibald Campbell for saying that, at the last sitting, he would 'touch up' her portrait. Not 'touch it up,' he said, 'give it another beautiful skin.' This contains a complete statement of the quality that he aimed at.

"When a thing was incomplete he did not try to patch it; he did it all over again and again and again-till it was finished-or wrecked, as often happened, from the sitter getting tired, or growing up or growing old.

"It was certainly not a recipe for one-down-t'other-come-on portrait painting, to be delivered in time and depended on.

"He would put the mixtures in little gallipots of water round the table that served as a palette, so that he could depend upon taking up the same tone another day.

"During most of his life his palette consisted of white, yellow ochre, raw sienna, raw umber, Venetian red, Indian red, vermilion, cobalt, ultramarine, Antwerp blue, ivory black, with the chromes or cadmiums, I think the latter (Pissarro, who was Whistler's pupil all his life, used the chromes, and said they were safer). For fleshcolour he used white, yellow ochre, Venetian red, and chiefly Indian red, and added for the shadows ivory black and raw sienna.

"For many of his portraits he used a quite black background; he told me that he took to it by accident. In the studio where he painted Miss Rosa Corder there was a black door, and happening to see her against it, he liked the effect. Afterwards he had a square of black velvet nailed on to an easel which he wheeled about.

"The lighting was always subdued; his sitter posed far away 
in the penumbra of the studio and never under a direct light. I remember he said he hated 'high lights' in a picture.

"About I880, when I knew him first, he had quite got out of the stiff poses of his earlier portraits. He loved Grévin, and wished to give to his sitters a dashing, coquettish pose. 'Swagger' was a favourite word, and a quality he loved and sought in the pose."

So far my informant. I may add on my own account that however much he aimed at dash and coquetry in the pose, he certainly never achieved it. His later portraits are very nearly as stiff as his earlier ones, only they are stiff in a different way.

Mr. Mortimer Menpes, in his interesting book, "Whistler as I Knew Him," rather differs from my informant as to the pigments used by Whistler, which shows how difficult it is to rely even on first-hand information as to details of artistic practice. After mentioning that he used a table with a polished top as a palette, he goes on to say that on this table he arranged his colours in a manner which he maintained to be highly scientific. "Beginning with flake white in the middle, on the left he placed lemon yellow, cadmium, yellow ochre, raw sienna, burnt umber, burnt sienna, and ivory black; on the right, vermilion, Venetian red, rose madder, cobalt blue, and Antwerp blue." It will be observed that there are four colours on this list which are not mentioned by my informant, who gives, on the other hand, three colours (rav umber, Indian red, and ultramarine) which are not mentioned by $\mathrm{Mr}$. Menpes. No doubt Whistler altered his practice at different times.

Mr. Menpes goes on to describe the actual method of painting in the following words: "When painting a life-size portrait the master began on a canvas previously prepared with flake white and ivory black, forming a neutral grey. He then spread on his palette with a large brush a great patch of the general flesh-colour, and scrubbed that flesh tone on the canvas in one 
patch. Thereupon he began to work the violets and the rose carnation and pearly tints of the flesh into the local colours spread upon the palette. Every detail of the flesh was amalgamated and incorporated in the great mass to preserve a oneness; and his picture was more than half painted on the palette.

"Having charged his brush with the colour, he put it on the canvas evenly and in one sweep. There was no attempt at what is called broken colour, which results in a series of accidents, causing the picture to represent a Persian carpet rather than a face."

Then we get further details as to Whistler's procedure, from the account given by Monsieur Theodore Duret of the innumerable sittings for his own portrait.

It was first of all decided that he was to be painted in evening dress, at that time a startling innovation. It was to be lifesize, full-length, and with a light background. Some accessory had to be found which would render the black clothes less severefinally M. Duret was told to bring a rose-coloured domino.

He was posed standing in front of a piece of stuff of a greyish rose colour, with the domino over his left arm. The portrait was started without any preliminary drawing; he merely marked in charcoal on the white canvas a few points to indicate the position of the top of the head, of the feet, and the limits of the figure at the sides. Then he at once put on to the canvas the colours and the tones, such as they were to be in the finished picture. At the end of the first sitting the whole canvas was covered, and one could judge what the picture was going to be.

But this rapid start did not mean a rapid completion. Monsieur Duret had many long sittings, during which the picture did not become more finished; instead of adding details he rather suppressed them as the work went on, striving always to maintain the aspect of a sketch done without effort. 
He paid great attention to the tones; if the slightest error -of tone appeared either in the black of the coat or the rose of the domino or the grey of the background, he passed a coat of paint over the whole picture, in order to bring all the parts into that precise relation which constituted the harmony that he was seeking. He entirely repainted the figure and the background at least ten times. The portrait took several months to paint.*

It may be observed what immense trouble Whistler took, and also how concerned he was to efface all traces of this labour. His great aim was to make a portrait even at the hundreth sitting look as if it had been painted at one. This, no doubt, he achieved, but it is really quite a small quality in art, and to it he sacrificed many other things of much greater importance.

What was really valuable in his procedure was the intense preoccupation with the tones; and be it observed that these very delicate tones, that in his best work are so beautifully harmonious, are put on in the simplest possible way-just ordinary paints carefully mixed and then put on thinly with a big brush. To the painters who think that "quality" can only be obtained by broken colour or by glazing or scumbling or other bedevilments, this triumph of the simplest form of painting may be recommended as requiring some modification of their theories.

There are, however, certain drawbacks to Whistler's method, however much one may admire its simplicity. These drawbacks mostly come from that unfortunate desire of his to make a finished picture look like a hasty sketch. There is no real advantage in repainting a whole picture at each sitting. Indeed, with a picture of any size it is impossible to do it properly.

There are all sorts of delicacies and refinements of drawing and modelling, which demand more time than can possibly be given to them by this method. This is no doubt the reason that 
Whistler's portraits are so very empty, and that the heads in particular are often mere expressionless masks, with none of the infinite subtlety and complexity of the human visage.

I must now turn to a very different artist. The differences between Watts and Whistler are fundamental. They were both quite single-minded in their devotion to art, but their aims were entirely different. To Watts the emotional and intellectual side of art was supreme; he wished to express feelings and ideas; he dealt largely in allegory, despised realism, and was but little concerned with technique. He was a poet and a dreamer who chose to express himself in paint rather than in words. His art was, indeed, closely allied to literature. I do not hold with the critics who condemn any approach to literature in art, and who say that a picture should never tell a story and should never express an idea. This unduly narrows the field. One of the most interesting and one of the most difficult problems in painting is the expression of emotion, and unless a picture tells a story it is difficult to see how emotions can be depicted. It is absurd to represent people as sad or angry unless the spectator has some notion of what they are sad or angry about. Again, allegorical ideas, if they have to be expressed at all ( $\mathrm{I}$ confess I am not very fond of them), can be expressed as well by painting as by literature-perhaps better-and Watts was great in allegory. So I have no quarrel with the intellectual side of Watts's art. If an artist can be a poet and a thinker so much the better; but he must be something else as well. It is of small use to have fine ideas unless one is able to express them adequately. There is one side of painting which is purely a handicraft, and no painter can afford to neglect this side. Now Watts was not enough of a craftsman. He had great natural gifts even for the handicraft, but he did not develop them sufficiently. At his best he was a very fine colourist, but he was seldom at his best- 
he had an eye for grandeur and distinction of form, but his drawing was often painfully defective. In his later years he seldom used a model, and the result was that his figures got further and further away from Nature. And his method of putting on paint was never satisfactory; instead of "the beautiful new skin" that Whistler was always endeavouring to give to his figures, Watts seemed satisfied with a sort of messy surface that was neither good paint nor good realism-neither pleasant in itself nor good as a representation of nature.

On the whole, I consider Watts's early work a good deal superior to his later. The portrait that I here reproduce (Plate 32) of Miss Alice Prinsep (now Mrs. Stracey-Clitherow) is a very good example of this early work. The technique, although not precisely masterly, is adequate and quite free from the unpleasant texture of his later work. The pose and expression are simple and dignified, and the colour is singularly rich and harmonious, and, indeed, quite worthy of one of those Italian masters whom Watts was always emulating. It is one of the finest examples of rich and full colouring to be found in modern art.

As my views on the inadequacy of Watts's technique are not generally shared, I consider myself very fortunate in being able to give a definite account of his earlier and better methods from notes taken by an eye-witness some forty years ago. My informant, Mr. John Griffiths, is an artist who, as a young man, paid three visits to Mr. Watts on purpose to learn his methods.

I cannot do better than quote his own words: "The first visit records the talk Mr. Watts and I had together. He showed me several of his works in various stages of progression upon which he was then working, commenting on each one.

"The other two visits record his method of working on the two heads which I have. He talked the whole time, the purport of which I have endeavoured to put down in the notes. 


\section{.}


Plate 82.

MISS ALICE PRINSEP (MRS. STRACEY-CLITHEROW).

BY G. F. WATTS, O.M., R.A.

By permission of the Hon. Sir Henry T. Prinsep. 


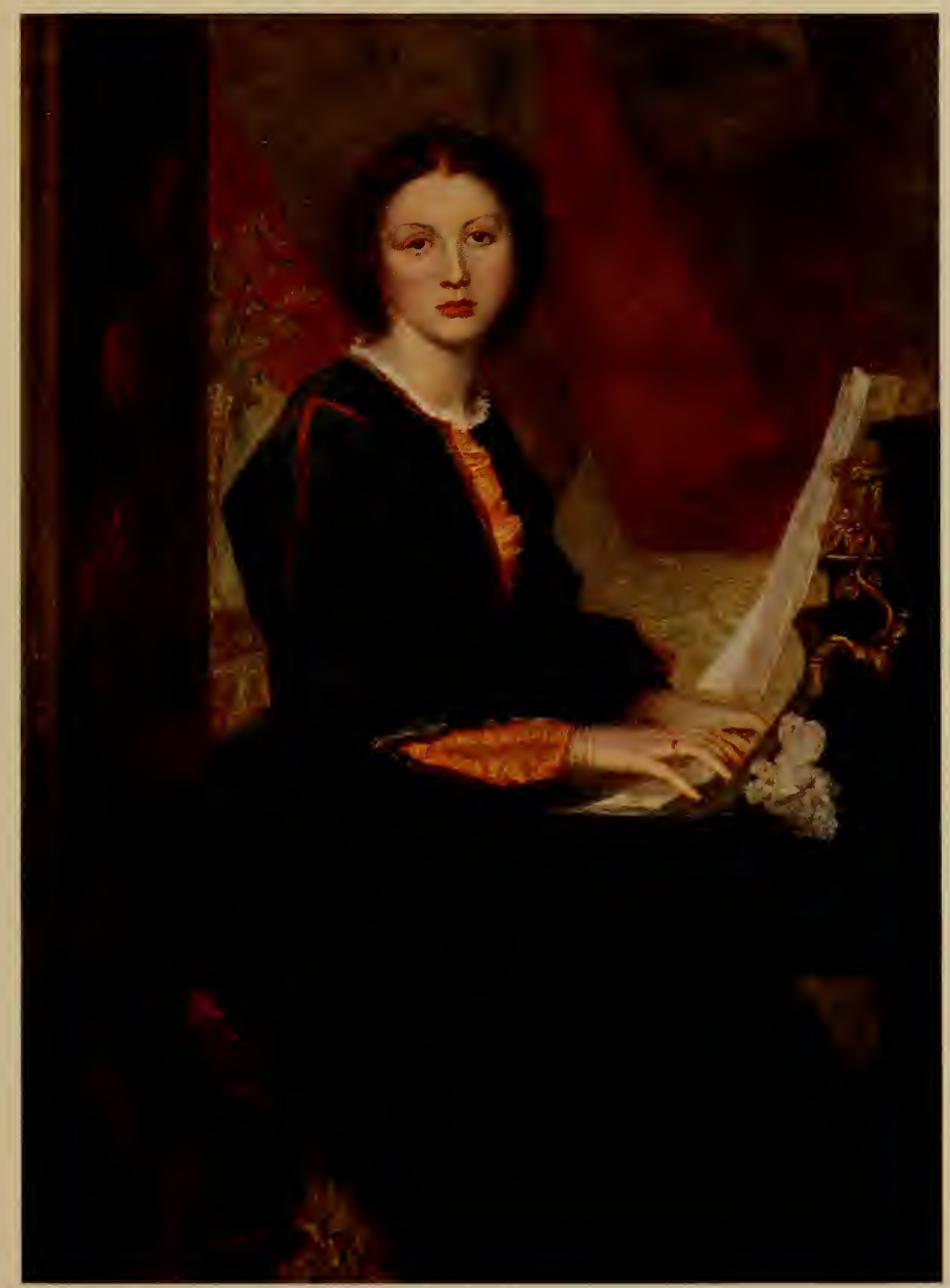



"I well remember that he blended his tints more on the canvas than on his palette by a series of very rapid dabs, producing in the painting a sort of buttery effect. As stated in the notes, he used large brushes (hog-hair), which were worn to a point, so that if he wanted to make a sharp line he did it most dexterously with diluted colour and the point of a large brush-a line as fine as any artist could make with a small sable brush."

I will now give the notes just as they were written down at the time.

" Ist August, I865. Went to Mr. Watts's studio at Little Holland House. After some talk about art Mr. Watts said that the great want in the English school was some definite method of teaching. He doubted if he could be of any assistance to me, as he was always experimenting, and his painting a series of tricks. His method is to paint thickly at first, and get a hardness in the work and lighter in tone than the finished work, and then to slobber it all over, probably before it is quite dry, with thin colour and a quantity of linseed oil (not boiled). Before this he uses in the work, when required, Roberson's medium or something of the kind-for greys, ultramarine ash. I observed that in the early stages of the paintings a quantity of Naples yellow was used. The colour was laid on exceedingly thick, great masses of white lying in pellets on the work. He said he always strove to get the quality of Titian, and this method he found was the nearest approach to it. He said the after-glazing was not like the ordinary glaze-that he thought very objectionable-but being done (which must be very judiciously) while the under-painting is not quite dry, so that it becomes incorporated with the painting, and gives that luminous quality, and forms a whole as seen in nature.

"He told me to come the following Sunday morning, and bring a canvas with me.

"8th August. Got there by 9 a.m. Mr. Watts took my canvas 
and painted a head before me, taking as his motive the painting of a woman which was hanging on the studio wall. He commenced by covering the canvas over with burnt umber, diluted with Roberson's medium and spirit of petroleum, using round brushes. From this brown wash he gradually worked out the form of the head, having no previous outline. Into this he worked his tints. A little light red and white and raw sienna or yellow ochre, and white in broken touches-the burnt umber mixing with them, and partly showing through, forming lovely greys. As the work got dryer he worked more solidly on the face, using the brush first in a series of dabs, but when the work got stiffer more like drawing with a crayon. For the darker touches, as in the nostrils, mouth, eyes, etc., he used Indian red, burnt and rav umber. But I noticed he had on his palette a colour of the quality of burnt lake, which he introduced with raw and burnt umber. He said the simpler the colours were the better. His palette then consisting of white, raw and burnt sienna, light and Indian red, raw and burnt umber, and the colour resembling burnt lake were all he used for the face and hair, and for the headdress a little black with Naples yellow, forming grey.

"The whole was done in an hour, he painting very leisurely, holding the brush at arm's length, at the extreme end of the handle. The effect produced with such simple means was wonderful, the whole head glowing with colour-the greys lovely, although not a bit of grey pigment was used.

"He recommended squeezing the white and other colours on blotting paper before using, in order to absorb the oil out of them. He said it was better to paint the background thickly and decidedly, and the object might be painted thinly rather than the reverse, because there were enough decided forms in the object which would tell.

"He kept white diluted with turpentine in a small pot. Although 
his heads, he said, looked dry and hard before varnishing, but after two or three coats of varnish they were greatly improved.

"He preferred spirit of petroleum to turpentine, because the former does not wear out the brushes. In laying on the colour he rolled his brush about, which left the pigment in crisp little ridges. If he wanted more grey in the head, he commenced by rubbing the ground over with raw instead of burnt umber, and so working into it. He then told me to take the head home, and copy it in the way that I had seen him work, and to bring the two to him again.

"August 12. Arrived at the studio by 7 a.m. Mr. Watts took my copy (his own he left untouched), which appeared dirty in the flesh tints as compared with his, and rubbed with his fingers a little rose madder on the cheek, nose and ear, and then put on in little touches, but thinly, tints composed of Naples yellow and white with rose madder. A thin scumble of Naples yellow and white over the brown gives a fine pearly grey. He drew parts, such as the nostril, mouth, etc., with raw umber, and the colour that looked like burnt lake. If a touch was too strong, he would touch it with his fingers. If purer grey were wanted, he rubbed on with his finger a little blue, which looked like cobalt. He said the work would look spotty, but be all right when varnished. 'Try and put your touches in the right place with as little work as possible, and let each operation carry on the work further towards completion. If you make a mess, better begin another rather than to continue. Finish the dresses as perfectly as you can, because they give interest. Avoid slobbering your colour about. Do not imitate Reynolds. If you do, it is hopeless. But imitate Titian, for his work is like looking at a bit of nature."

I confess that the impression produced on me by these notes is that Watts's precept was better than his practice. The actual 
method seems distinctly messy, and very different from the theoretical "put your touches in the right place with as little work as possible." But to any admirer of Watts's technique (and there are many), I am sure that this detailed account of his earlier practice will prove interesting and instructive.

I feel naturally great diffidence in dealing with the work of living artists. In the first place the field is so vast that I have had to confine myself to the British school, and even then the number of our portrait painters of real talent is so great that I have thought it best to restrict my choice to three artists, who I think are representative in their various ways of the best work in portraiture that is being done at present in the British Isles.

Mr. Orchardson represents the older school, and carries on the brilliant tradition of Millais without being an imitator of his methods.

I have already referred to the chief characteristics of his work in the historical section of my book. I am now by his courtesy, and by that of Viscount Peel, enabled to reproduce the fine portrait of the latter as Speaker, that is one of the chief ornaments of the Speaker's House. (Plate 33.) I hope that the reproduction gives a not inadequate idea of the skill with which an admirable colour harmony has been evoked out of the simple elements of the black robes and of the brown woodwork and green leather of the chair. This must have been a very difficult portrait to paint, owing to the uncompromising character of the surroundings, and yet they have been perfectly harmonised with the figure.

The composition, in spite of the difficulties, is singularly happy. The pose is easy, and the kecnness and vigour of the head are admirably rendered.

I have already referred to the commanding position held by Mr. Sargent, and have discussed the peculiarities of his style. I wish I could give definite details of his masterly technique, as there is no artist in the world whose work is discussed with 
Plate 88.

VISCOUNT PEEL.

BY W. Q. ORCHARDSON, R.A., IN THE SPEAKER'S HOUSE, WESTMINSTER.

By permission of the Artist and Viscount Pecl. 


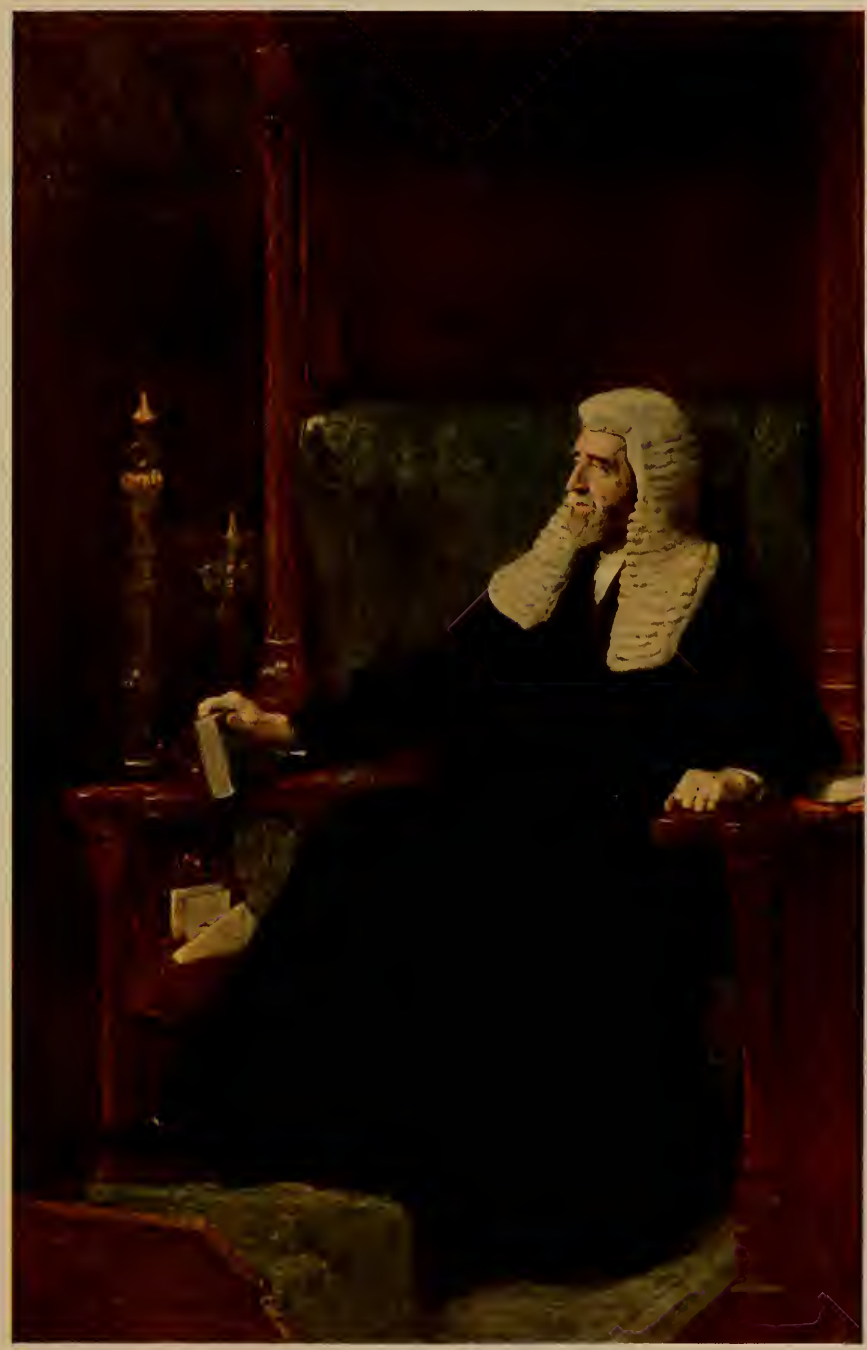





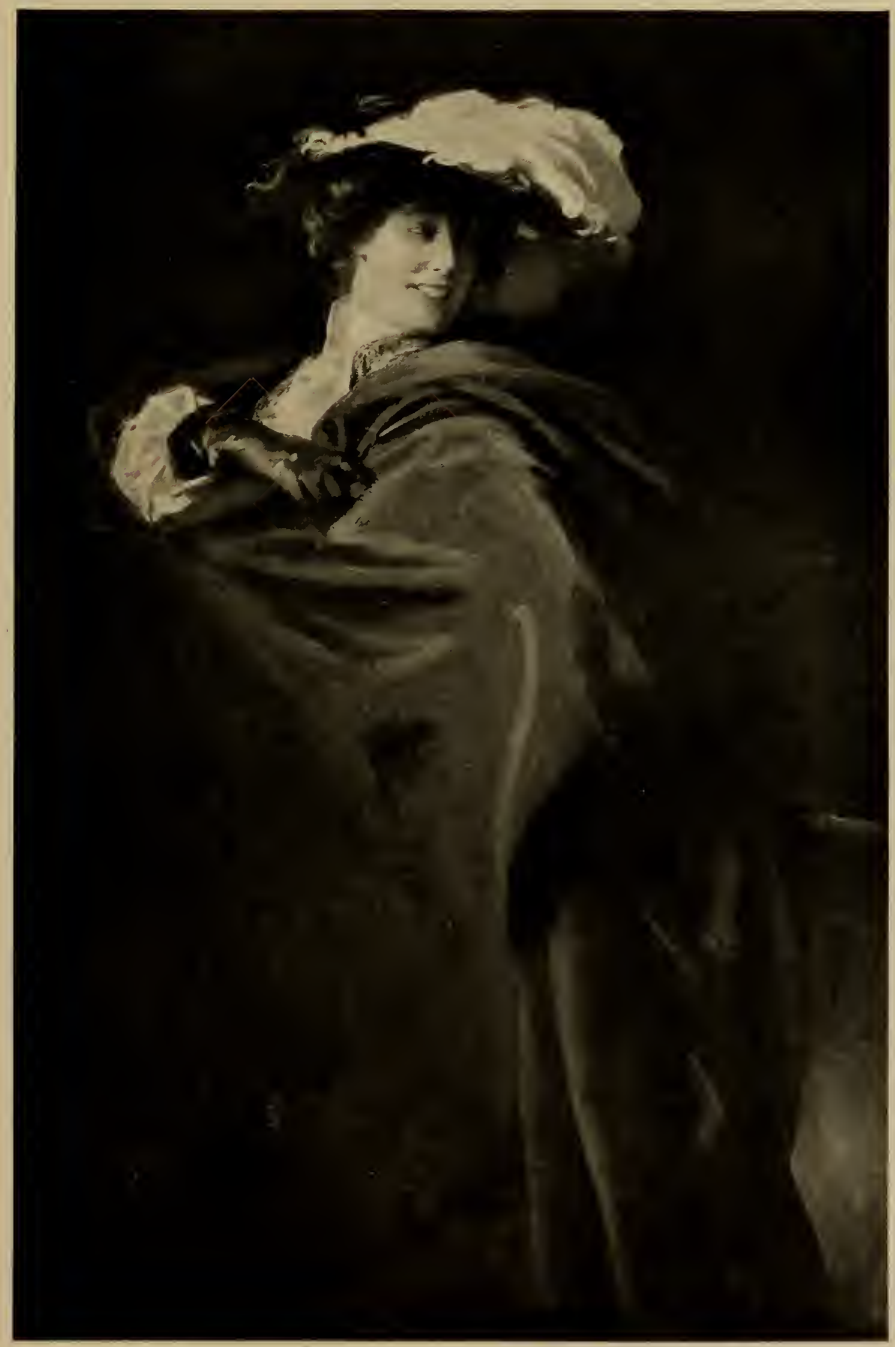

A VELE GONFIE.

BY J. S. SARGENT, IR.A.

Plate 34.

BY PERMISSION OF ASHEA WERTHEIMER, EBQ

From a Photograph by $F$ Hollyer, I'cmbroke Squarc, London, IV. 

such keen interest by his brother artists, nor who has an equal influence on the rising generation of painters. Fortunately in many ways it is quite simple and hardly requires explanation. Anyone can see the directness with which the paint is applied, and the strenuous endeavour that each touch shall be as true, and shall express as much as one touch can possibly express. But, of course, there is much more in it than that, and here, alas! I am at a loss.

I have applied to Mr. Sargent, who is kindness itself in these matters, but he says, "As to describing my procedure I find the greatest difficulty in making it clear to pupils even with the palette and brushes in hand, and with the model before one, and to serve it up in the abstract seems to me hopeless." So I must not attempt what the master himself is unable to do. I can only advise students to look at Mr. Sargent's work. There is much to be learnt from merely looking at it. I am fortunately enabled by his courtesy, and by that of Mr. Asher Wertheimer, to reproduce the portrait called "A Vele Gonfie," that was one of the chief ornaments of the Academy of 1905. (Plate 34.) The sweep of the drapery, the swing of the figure, and the extraordinary animation of the expression make this portrait one of Mr. Sargent's masterpieces. Its vitality is astounding.

With Mr. Lavery, who is my third representative painter, I have been more fortunate. I have to thank a lady who is herself an artist, and who has sat to Mr. Lavery two or three times, for a very valuable account of his procedure. Here are some extracts: "He has great consideration for the sitter-he arranges a large mirror which reflects him at work on the canvas so that the sitter may be interested. He spends a great deal of time and trouble to find a pose that in its simplicity is dignified, and in its originality surprises and refreshes the eye. Two days I spent in his studio trying to take an unaffected pose. Mr. Lavery did sketch after sketch of me, till once he found what he wanted. 
"Then discarding the sketches he takes a canvas the size he requires, and within two hours he has the entire canvas coveredthe texture of the frock and the drawing of the features and pose of the figure almost complete; the following day the greater part of this paint is removed from the canvas and the picture again gone over from head to toe. This was repeated every day for almost two weeks, each afternoon the picture looking more complete, till finally he decides that he has reached his limit.

"Nearly all his drawing is done with the brush. He uses charcoal merely to map out or space his composition. His palette is very simple, the primaries, black, white, and burnt sienna-in all, six pigments."

It will be noticed that Mr. Lavery's procedure is much akin to Whistler's, although he was never a pupil of the latter and never even saw him paint. But there is one important difference. Whistler entirely repainted his picture every time, making no use of the previous work, so that at the fiftieth sitting it was no further advanced than at the first. But Mr. Lavery, although he goes all over the work, makes use of the previous painting, so that there is a gradual progress towards completion. This to me is a much sounder method.

It will be noted what great trouble is taken with the arrangement. And this trouble is certainly not thrown away. I know of no one who arranges a portrait better, both in colour and form. As a colourist, Mr. Lavery is distinctly ahead of any portrait painter of the day. I am fortunate to be able to reproduce in colour one of his finest works, which I think will give some idea of the extraordinarily decorative qualities of his portraits. (Plate 34.) But, as I have said before, I think he sometimes pushes these qualities a little too far, so that he seems less interested in his sitter as a human being than as a decorative arrangement, and to me the ideal portrait painter should be immensely human. 


\section{Plate 36}

PORTRAIT IN GREY AND BLUE.

BY JOHN LAVERY, R.S.A., IN THE LEIPZIG GALLERY. 


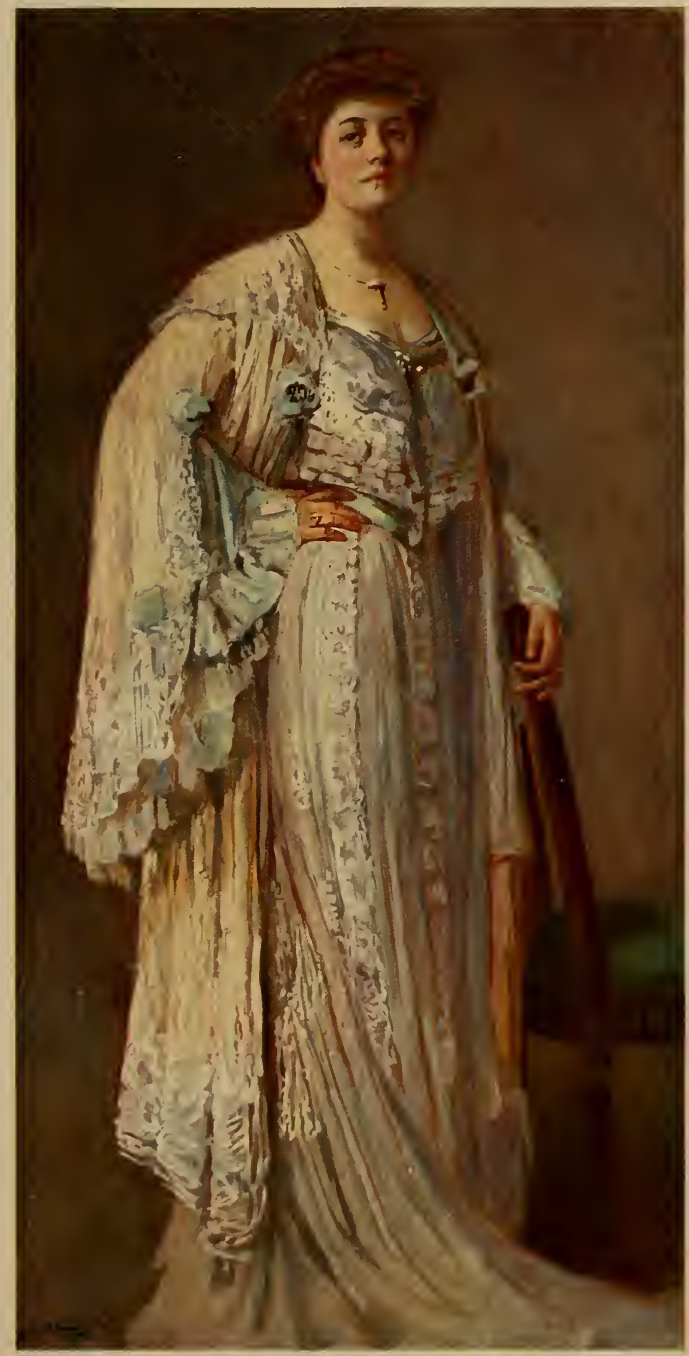





\section{Part III. \\ THE PRACTICE OF PORTRAIT PAINTING.}

THE practical question now arises, how should the beginner set about this difficult art? I have endeavoured to set before him what little is known about the methods of the great masters. Unfortunately, they are so various and so contradictory that it is very difficult to model one's own practice upon them. The only thing that is certain is that very fine portraits have been produced by all these different methods.

But I can hardly leave the matter there: of course I have certain views of my own as to the best way of setting to work, and with all diffidence I must put these before my readers for whatever they are worth.

To begin with, I am a realist. I hold that the first object of the artist should be to give faithful likenesses of his sitters, and these likenesses should be characteristic; that is, the sitters should be wearing the sort of clothes that they wear in real life, and should be in the sort of attitude that they are wont to assume. If there be any accessories, they should at the least be not incongruous. The background should represent a fairly likely place for them to be in-if it represent a place at all.

Now and again an advowedly fancy portrait is permissible. Pettie painted some very interesting portraits of his friends in old costumes which undoubtedly made them much more picturesque if less like themselves; but I think this treatment should be exceptional.

Here comes a very important question. If accuracy of charac- 
terisation be the one thing to be aimed at, the sitters should not be represented at their best-only at their average; that is as they look most often.

This, I think, is pushing the principle too far. As long as we do not represent them as they never are, it is quite permissible to paint them when they look their best, and in their most becoming clothes, and in as little awkward an attitude as their habits enable them naturally to assume. In the same way the background and accessories, as long as they are not incongruous, may fairly help to make the picture a pleasing one.

There are some painters to whom this rendering of character is so supremely important that they like to over-emphasise it-that is, to give a touch of caricature. When skilfully done this is very effective, and quite dispels that danger of the tame and the commonplace that haunts the painters of commonplace people. But personally, I do not regard it as legitimate, and it does not seem to have been the method of the greatest masters.

I have so far said nothing about the purely artistic qualities of the picture-the harmony of colour, the play of light and shade, the pleasant rhythm of line and the skilful arrangement of masses. I do not forget that these are an essential part of every really fine painting, but in portraiture the other must come firstthat is, the more purely artistic qualities must be subject to the primary requirements of an accurate likeness.

Undoubtedly the restrictions are severe, but it is precisely these restrictions that make the problem so interesting. I think with some few sitters it is practically insoluble, but in nearly every case the solution is possible without infringing the conditions of legitimate portraiture.

If we wish to see how a great master can move freely within the most rigid barriers, we have only to consider the portrait groups of Frans Hals. 
In these he had to represent a definite number of people in definite costumes. All the faces had to be well seen, and probably he had not even the choice as to which of the persons had to be put in the most conspicuous places; and yet how free and harmonious are the resultant compositions!

It must be borne in mind that the colour-scheme of a portrait can with advantage be very simple.

Many of the finest works of Velasquez and of Rembrandt are merely harmonies in grey and in golden-brown respectively. Most of the Dutch painters made great use of black. Even Titian's colouring is in his portraits generally quiet and simple. But these subtle variations of one dominant tone are extraordinarily difficult.

An agreeable play of line can generally be achieved in women's portraits by the arrangement of the drapery. But with men it is more difficult, as modern male costume is singularly graceless.

This question of costume is one of our greatest trials, and the temptation to clothe our sitters in some fanciful and picturesque garb that they would never wear is often hard to resist; but I think, as a rule, it should be very sternly resisted. Fortunately, in modern female dress there is a good deal of flexibility.

There are very few women who have not some nice gowns - generally the ones they think least of themselves-and if they have none it is still possible to have one made that will not be very different from what they actually wear, but will yet be artistically harmless.

Indeed, I would even stretch a point. It is perhaps admissible, if a lady's dress be habitually horrible (which sometimes occurs), to make her get one which will not be characteristic of her past, but may be of her future, if she profit by the lesson; but I admit that this is a departure from the purity of my first principles.

As for men's dress, the artist must do the best he can. 
Șhooting clothes are often inoffensive; some uniforms are not impossibly gaudy. At the worst a black coat, though mostly bad in shape, can be made fine in colour.

Furs are quite pictorial, but they must not be worn in defiance of all probability. It always gives me a shock to see a gentleman sitting down complacently in his drawing-room in a heavy fur coat that he would certainly have taken off as soon as he came indoors. If he be so attired he had better be nowhere in particular, or else out of doors.

In the same way it hurts my feelings to see a lady portrayed in evening dress with a large hat on. It may be picturesque, but it certainly is not natural.

And here we must wrestle with that difficult question, the open-air portrait. The outdoor dress is often so much better than the indoor that it would be a pity to neglect it. But the treatment of the background requires anxious consideration. The old masters had a very definite principle, and acted up to it in the frankest and most courageous manner. The sitter was painted as usual in the studio without any attempt to modify the indoor lighting, and the landscape background was used as a decorative screen, mostly quite unlike nature in itself, and always without the slightest approach to the true relations between the figure and the landscape. In fact, the general effect was that of a person standing in the studio against a wall on which a very conventional landscape was painted. It was never in the very least like a person standing in the open-air with real sky and real trees behind him.

I think it was the very frankness of this convention that saved it; the landscape was accepted as a mere decorative screen, and the eye was satisfied.

This is really better than the compromise adopted by Millais, who kept the indoor lighting on his figures, whilst the landscape was more or less realistic. 


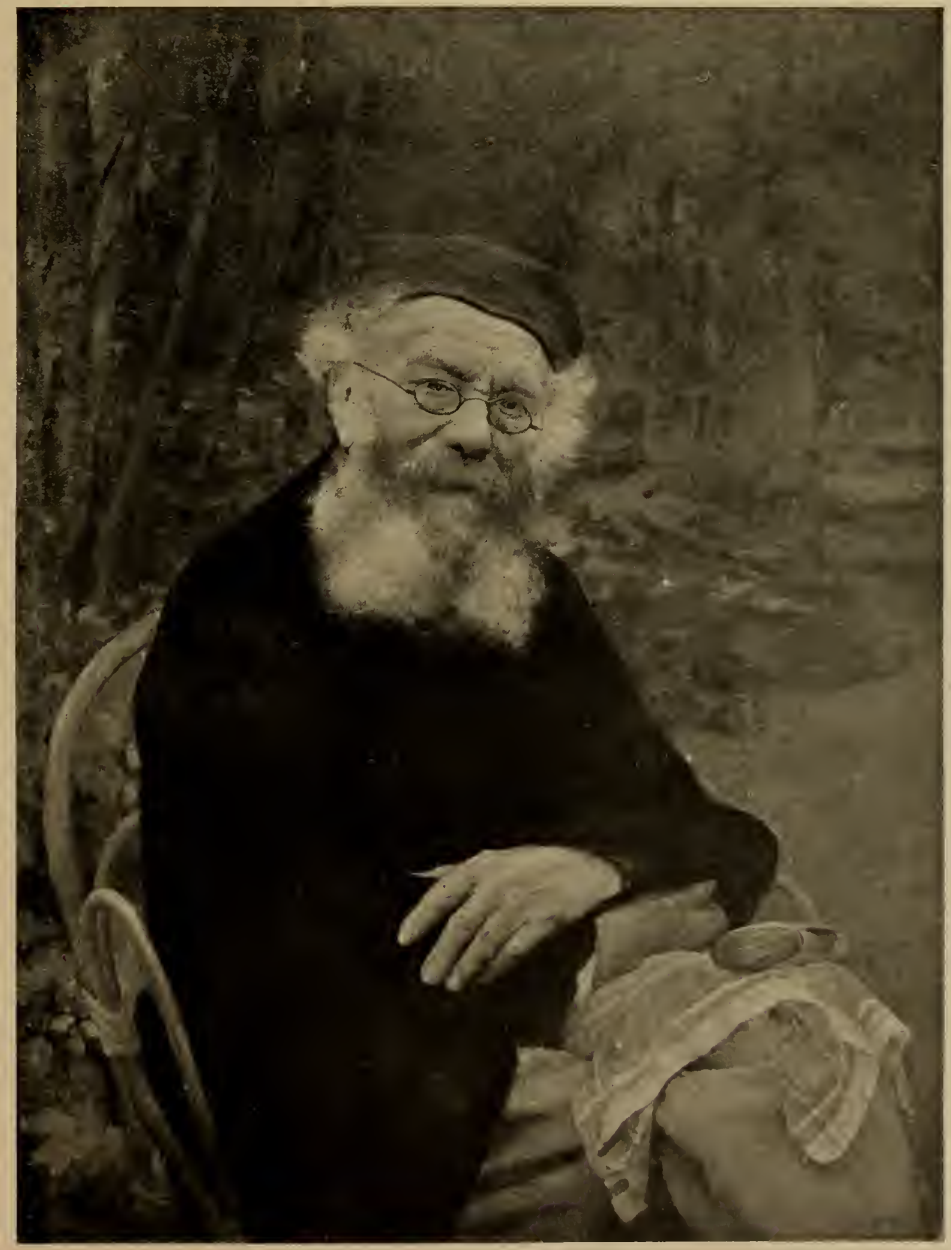

"MY GRANDFATHER."

BY BASTIEN-LEPAGE.

Plate 36.

BY P:HMISSION OF MONEIEUH EMILE BASTIEN-LEPAGE, 

Of course there is another way, and I believe it is the right one -at any rate for us moderns.

Bastien-Lepage, in his celebrated portrait of his grandfather, painted the old gentleman in the open-air, and took the utmost pains to get the real relation between his sitter and the admirably true background. (Plate 36 .)

In its way I regard this as an advance on anything done by the old masters. Of course it has been tried fairly often since Bastien-Lepage showed the way, but to me not often enough.

It is unfortunately a very inconvenient way of painting a portrait, but the inconvenience can be diminished by making use of a glass-roofed studio, which gives under favourable circumstances a very near approach to the real out-of-door lighting. But most people will say that what was good enough for the old masters is good enough for us. I confess I do not think so. In many ways they are supreme and likely to remain so, but in other ways painting has made a distinct advance. This advance has been mostly in the domain of landscape, and here I believe the improvement to be immense. I have no great love for the highly artificial landscapes that delighted our forefathers, and which still delight ourselves, if we are sufficiently sophisticated.

How any real lover of nature can be content with the extraordinary travesties of it that used to pass for landscape I cannot conceive-or, rather, I can conceive of it in our forefathers, for when realistic landscape had not been invented any approach to it was better than nothing. But now, when there are so many painstaking students of nature who collectively have given so many truthful representations of the varied aspects of the world, I cannot understand the taste for artificial landscape still surviving. And if unreality and convention are bad in pure landscape, as I firmly believe, they are also bad in landscape used as a background to figures. 
Therefore, if we are to put figures in the open-air, let us endeavour to do so truthfully. It is very difficult, and the temptation to shirk the difficulty is great. I have often yielded to it myself, but I have no doubt as to the right principle, however I may have fallen off in practice.

But we do not get rid of all difficulties by putting our figures indoors-far from it.

In the first place there is the studio light. There is no doubt that a light more from the top than is to be found in most rooms is not only a becoming light which defines the features pleasantly without distorting them, but is also very convenient to work by, for with a high light the canvas can be turned in various positions without getting a shine on it. Also this light fatigues the eyes of the sitters less; they can look in its direction but somewhat under it without being dazzled, as they would be if they looked towards the window in an ordinary room. For these reasons most portrait painters adopt it; nor do I see any valid reason against it as long as it does not obviously clash with the lighting of the background and accessories. But here lies the difficulty. Theoretically, I should like my sitters to be placed in an ordinary room; if possible, one of their own rooms, so that they should be portrayed as their friends see them. But no ordinary rooms are lit from the top, and most ordinary rooms are very difficult to paint in. This difficulty partly arises from the imperfect lighting, but there is another which is not so obvious.

All portrait painters, as far as I know, like to stand up to their work. If they adopt the Millais method this is essential, but in any case it gives much greater freedom and allows them to get away from their canvas from time to time.

Now if they stand up in an ordinary room they look down too much on it. They get a quite impossible view of anyone sitting down, and even if their sitter be standing up the perspective of 


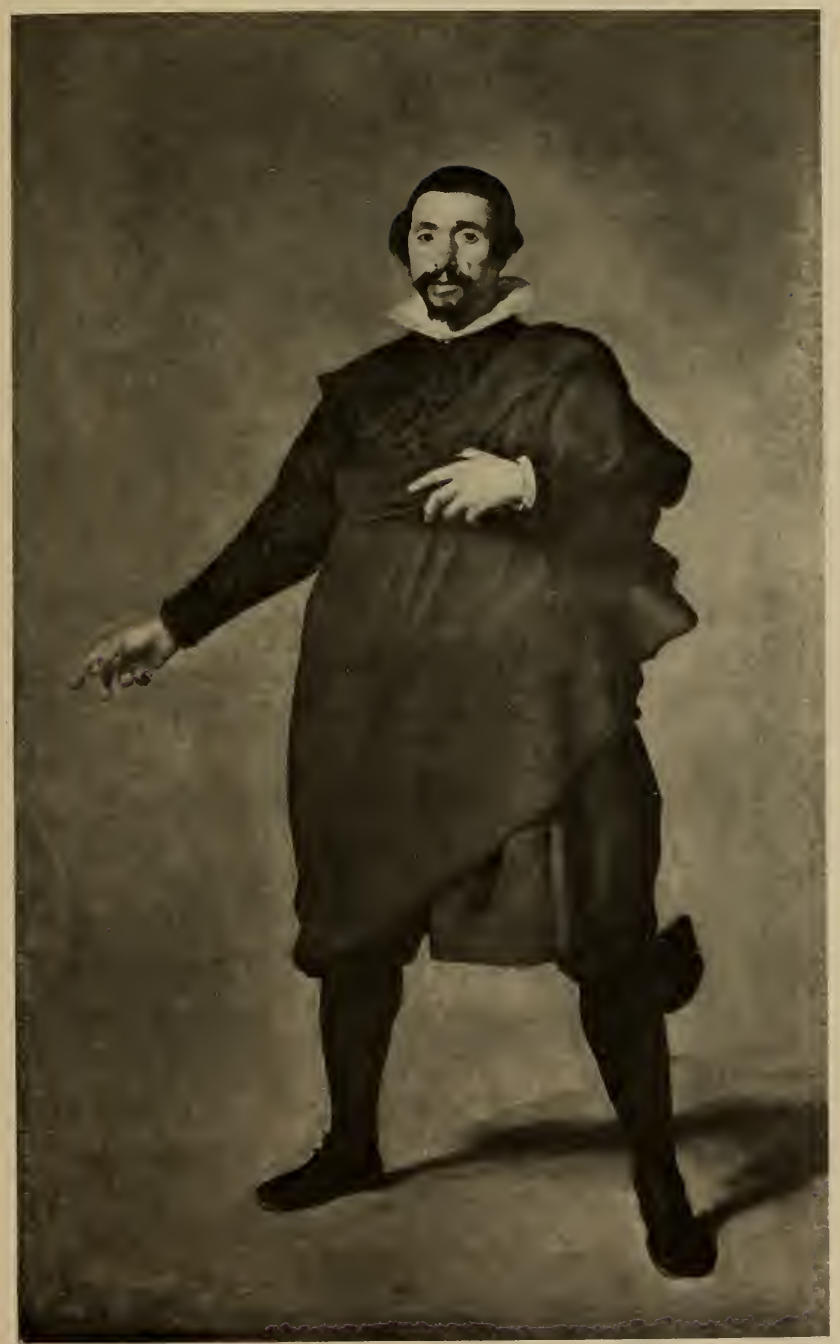

THE JESTER (PABLILLOS OF VALLADOLID).

BY VELASQUEZ

Plate 37.

From a Photograph by Braun, l'aris. 

the floor and of the furniture seems absurdly steep. (Some modern artists have risked this absurdity, but to my mind, with bad results.)

So in a studio the sitter is put up on a stage, and any furniture or accessories are, if possible, put up on the stage too, but this is quite incompatible with representing him in his true relation to an ordinary room.

I know an artist who had a little room built which could be moved about in the studio like an exaggerated model stage. The principle was excellent, but I fancy it was inconvenient in practice.

All these considerations make it very difficult to represent the sitter in his own room with all the surroundings as they are in real life. So the attempt is mostly abandoned, and on the whole I think rightly, though this may seem to abandon the position of rigid realism that $I$ took up with regard to landscape backgrounds.

The difference is this: I have no objection to leaving out; my objection is to putting in anything that is false. I admit a background that represents nothing in particular-a plain tone is to me, quite harmless. I have more scruples about a curtain or a screen, but I think they may pass as long as they bear a natural relation to the sitter. With the smaller sizes there is no great difficulty. Just a head can have almost anything behind it without raising awkward questions as to what the room is like in which the sitter is placed.

It is when we come to full-lengths that the difficulty is acute. There must then be a floor, and the floor seems to demand walls, and the walls look very bare without some furniture, so that we are almost driven into constructing at least a plausible room.

I have said "almost," for it is possible to represent a floor that fades off into space without seeming absurd, as witness Velasquez's "Admiral" in our National Gallery and the "Pablillos" in the Prado (Plate 37), or certain portraits of Whistler's. Why it 
does not seem absurd I do not know. But it does not, so on the principle that there is no harm in omissions, I think this is a quite legitimate treatment of the background of even a full-length portrait.

But very often accessories are required either to balance the figure or to improve the line of it, or to harmonise the colour. This will increase the difficulty of suppressing the background, but in most cases the less attention is called to the room itself the better. Of all backgrounds the most convenient is a curtain. It can be of any colour and of any tone, and can be so arranged as to give almost any line required, but its very convenience has made it so hackneyed that it has now to be used with great discretion.

Tapestry has also been unfortunately popular. It has such possibilities of quiet broken tones and indefinite forms that it would be an ideal background were it not so common.

Oak panelling, too, is very useful. Too useful, alas! I, myself, have had a hankering after screens. They shut off the rest of the room so nicely that no one need enquire what it looks like, and they can be placed with sufficient naturalness wherever the artist happens to want them. Also, they are capable of a good deal of variety, though their main forms are somewhat uncompromising.

But when all is said and done perhaps the best background is a tone that represents nothing in particular-only it must be just the right tone, and I, for one, have the greatest difficulty in inventing this right tone.

But whatever background we adopt, it ought to be there in nature behind the sitter whilst he is being painted, or as near an approximation to it as can be got.

The simple tone can always be painted on another canvas and then put behind him. This sounds easy enough, but first catch your tone.

Then comes the question, shall this tone be even or broken 
up? I am inclined, myself, to have it fairly even, with a certain gradation of light and dark. But there is no objection to broken tones as long as they do not catch the eye too much, and raise the fatal enquiry as to what they represent.

As for accessories, there are no general principles to be laid down, except that they must be natural. If they can also be characteristic, so much the better. I am always glad if I can put a sitter in his own chair; if not I try to provide him with one in which he feels and looks at home. I do not think a book should be introduced if the sitter is notoriously averse from reading anything except the daily paper. If a book be introduced, it should be a probable book for him to have by him, and so on throughout the whole range of possible accessories, which, by the way, is artistically rather limited.

Of course, everything in the picture must be lit by the same light (anything may have a cast shadow over it) and be in the same perspective as the sitter. If there is any attempt to represent a real room, I think the top-light should be abandoned.

Groups require special consideration. They are the most difficult problems of portraiture, but when happily solved they are immensely effective, and give a welcome opportunity of escaping from the monotony which is almost unavoidable in the presentation of single figures.

Here again I have no general principles to offer. Harmony of line and mass and colour, which are of the essentials of our art, unfortunately cannot be defined. Most people have some feeling for them, and artists ought to, and generally do, possess this feeling in a specially high degree. It can undoubtedly be improved by practice, and by the study of fine examples: as to what are these fine examples, there is a fair consensus of opinion. Certainly portrait groups afford a fine opportunity for the practice of these various harmonies. 
The most maddening, but also one of the most fascinating branches of our art is the painting of young children. It is of the essence of childhood never to be still. This gives them a delightful animation in real life, but naturally enhances very much the difficulty of painting them.

It is, of course, quite necessary to keep them amused, for they show their emotions with a painful lack of reticence, and when a child is sulky it can hardly be said to be looking its best.

Something can be done by getting a third person to read to them, or, still better, to tell them stories, if the person has the right inventive power. For the artist to endeavour to amuse them himself is, I think, too great a strain.

A musical box is useful at times. When Millais was painting one of his daughters at a very early stage in her life, I had the privilege of working the musical box for him. I learnt then that one tune would amuse a child for a long time if constantly repeated. It is less amusing for grown-up people, but that is not the point.

Perhaps the best way of keeping children quiet is to get a talented friend to make drawings for them. This can be effectively done on a spare canvas with charcoal, and will interest them for some time if they are allowed to suggest the subjects of the drawings. I recollect that a spirited drawing of a tiger eating strawberries (by special request) was an immense success with one very small girl that I painted.

With all possible alleviations it is a heartbreaking business, but if the portrait turns out well there is a corresponding reward. There is something quite unique in the charm of childhood, and it is an eminently pictorial charm.

I distinctly advise the budding portrait painter not to confine himself to any one class of subject; that is, he should not paint men, women, or children exclusively. The danger of monotony 
that haunts such a restricted art is much increased for the specialist in only one branch of it. I am convinced that Frank Holl, for instance, would have been a much more interesting and, indeed, a better painter if he had not practically confined himself to men's portraits.

It may be objected that the artist has not a free choice in this matter. He makes a hit with one kind of portrait, and for the rest of his career he gets commissions from the same class of sitter and from no other.

Well, if he does it is his own fault. Has he no friends that he can paint in order to show the public his versatility?

Indeed, as a general rule, I should advise that a certain number of portraits should always be painted to please the artist, and not for gain. He can then choose subjects that inspire him, and he will have the enormous advantage of a free hand. When people are painted for nothing they cannot, for very shame, worry the artist with the suggestions and restrictions that are, after all, legitimate enough in the case of a commission.

In the height of Millais's popularity he recommended me to paint my friends even if commissions had to be put aside for the purpose, and said that he did so himself from time to time. And Sir Lawrence Alma-Tadema went further: he told me when I first took up portraiture never to leave off painting subject-pictures. "Your portraits will be all the better for it," he said.

And this, I think, is profoundly true. All the great portraitists, except perhaps Frans Hals, have painted subject-pictures with an immense gain to the freshness and variety of their art.

We must now leave these generalities and discuss the technical details that are likely to embarrass the beginner.

In the first place he must have a studio. I have already explained why it is so difficult to paint in an ordinary room. After all, the first essential in painting is that the artist should be 
able to see his work. Great experience may enable him to paint with a bad light on his canvas, but the beginner had certainly better not attempt it.

The studio should be large enough to enable him to get well away from the picture. If questions of expense did not come inas, alas! they mostly do-I should say the larger the better. A high light is unquestionably the easiest to paint by. If there be no actual skylight, the room should be lofty and the windows should reach up high. The main window should face the norththis is necessary to ensure steadiness of illumination. It is a pity that we have to rely on the north light, as it is apt to be cold and often dull, but it is almost impossible to work by a light that is always changing, as it does when it comes from any other aspect.

There should be a sufficiently elaborate arrangement of blinds or curtains to enable the light to be varied at will.

Then comes another important question. Most studios are oblong. If the beginner has a choice of studios, or is able to build one, should the north window be at the side or at an end? In the case of Millais, and apparently of Velasquez also, the room was a long one with windows on one side. But then these rooms were large, so that they had not to work too near to the windows. If the room is not very large it is perhaps better to have the chief light at one end, for then the other end is plunged into an agreeable and convenient gloom, in which backgrounds and accessories can be placed when they have to be subdued in tone. A sitter also often gains by not being placed in too strong a light.

I think an actual top-light is very useful, but it certainly should not be the only light in a studio. Indeed, I should have windows wherever practicable. They can always be covered up when not wanted, and they can do so much to alleviate the inevitable monotony of portraiture. 
A second studio with a glass roof for open-air work is of enormous help.

In the studio there should be a large model stage of such a height that the head of a person sitting on it in an ordinary chair is just a little above the head of the painter when he is standing up. I say a little above, as nothing is more unbecoming to a sitter than to look down on him. This shortens the apparent length of the neck, and makes the head sink into the shoulders.

The stage should be large enough to admit of a table or a screen or any other portable accessory being grouped on it with the sitter.

The ideal model stage would have a platform that could be moved up and down. I have such a one, but it is unsteady and otherwise inconvenient, so I seldom use it. But it ought not to surpass the wit of man to devise a satisfactory one.

To come to a small practical detail, I recommend that the stage should run on invalid-chair castors. They work smoothly and they never wear out. (Most castors become impossible after a short period of use.) It is very important that the stage, even with a heavy sitter on it, should be readily moved into any position in the room. For this, good castors are essential, and a parquet floor is also of great help. Carpets are an abomination in a studio, except loose ones to be used for purely pictorial purposes.

If the stage will not move up and down it is well to have another lower one for people standing up, especially for full-length portraits. For these a great difficulty is that the floor has to be shown, and if the artist is on a level with his subject it is apt to appear absurdly steep. This can be partly obviated by going a long way off, but it is better to assist this flattening of the perspective by placing the standing figure somewhat above the artist. As a rule about a foot in height is enough. 
It is always difficult to make the floor in a picture look flat, and with very steep perspective it is impossible. I know one distinguished artist who habitually adopts a lower horizon for his floor than for the rest of the picture.

I do not agree with this device, as it is a pity to play any tricks with nature if it can be avoided. The best solvent of these difficulties of too violent a perspective is to go far enough off.

I need not enlarge on the necessity of providing a variety of backgrounds. The most useful are pieces of stuff of all sorts of colours. These can serve as plain tones or as curtains, and are invaluable to try behind the figure. Even if none of them give the required tone one can generally be found that will suggest it. Of course, there are many ways of hanging them up. The simplest is over a spare canvas on a spare easel.

Another property which personally I find indispensable is a large looking-glass, mounted on good castors, so that it can be readily moved about the room. I will explain later why I find it indispensable.

I need not dilate on the implements of the trade; the portrait painter has presumedly passed his art-student stage. If any reader wishes for my views on the subject, I must refer him to my manual of oil-painting.

But there is a little dodge of my own which I have not mentioned there, which I think may be specially useful to the portrait painter. As our work is mostly life-size, there is an obvious advantage in placing the canvas side by side with the sitter, and looking at them both from some way off. The picture and the sitter are then seen of the same size and in the same light, so that this method is a great preventative of errors in tone and proportion. As I have explained, however, in treating of Millais's work, it has great drawbacks, owing to the artist having 


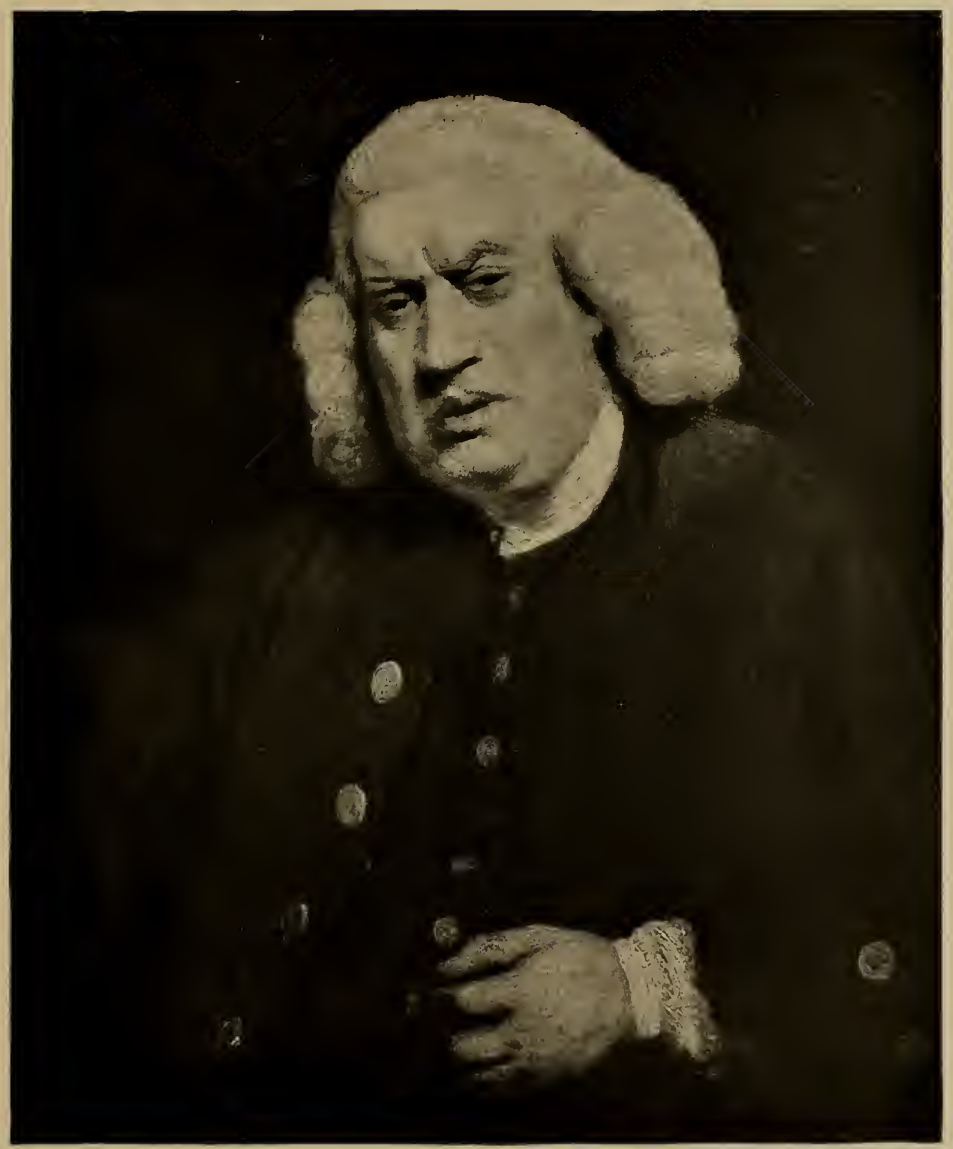

DR. SAMUEL JOHNSON.

BY SIR JOSHUA REYNOLOS, P.RA.

Plate 38.

IN THE NATIONAL QALLEAY, LONDON 

to walk backwards and forwards between the touches. These drawbacks would disappear if he could keep at a distance and still work on the canvas. In painting, this is hardly possible. Gainsborough tried it with six-foot brushes, but this does not put the painter far enough away, and these brushes are extremely inconvenient to paint with. Velasquez appears also to have tried it, but he certainly abandoned the method. So we may take it as impracticable, at any rate in painting; but for drawing it is not so impracticable.

I place a piece of soft charcoal at the end of a Japanese fishingrod, made of bamboo, which is fairly stiff and quite light. With the arm extended it is possible to draw with this whilst standing more than ten feet off the canvas. It is troublesome to draw in this way, and only the roughest outlines can be attempted, but I find it very useful in placing the picture on the canvas, and in getting the main lines right in direction and proportion. It would be better if one could stand further off still, but this would be very difficult.

The question of the canvas is worthy of discussion-it is not quite so simple as it seems at first sight.

Whether it is to be rough or smooth must be left to the taste of the artist. Of course, smooth is best for highly finished work, and rough for more vigorous treatment; but if the canvas is very rough it is difficult to vary the texture, and to make the brush-work tell sufficiently. The question of colour is more difficult. Most modern painters use a white canvas, and for some kinds of work this has a great advantage.

Oil-painting becomes slightly more transparent with age, so that the ground has a tendency to come through. It also becomes slightly darker, so that if the ground is light the one tendency counteracts the other.

But we must not make too much of this. With vigorous 
solid painting and sound colours, the ground does not come through to any appreciable extent, so that the colour of it does not affect the finished picture. Nevertheless, the colour is important, as it certainly affects the work during its progress. There is a tendency to paint light on a light ground, dark on a dark ground, warm on a warm ground, cold on a cold ground. The reason of this is not that the ground shows through, but that until the canvas is quite covered the ground contrasts with the painting - a touch of paint on a light ground looks darker than it really is, and in the same way a touch on a warm ground looks colder than it really is. So that the painter in the one case is painting lighter, and in the other case warmer than he seems to be painting. It is in this way that the ground colour of the canvas tends to make the painting like itself.

I think this principle may be usefully borne in mind, should the painter wish to correct some prevailing tendency. For instance, if his work be too pale and flimsy he should try a dark canvas. If it be too dark and heavy he should try a very light one.

I may add that without altering the colour of the canvas a somewhat similar effect may be produced by altering the lighting of it. If you wish your picture to be in a very light key you should turn your canvas away from the light, as then your painting, whilst you are doing it, will seem darker to you than it really is. In the same way, if you wish to produce a very dark effect place your canvas in the fullest light available. You will then be painting much darker than you think, and you will unconsciously force the shadows and tone down the lights. At first sight this may seem to contradict the rule about the colour of the canvas, but a little reflection will show that the principle is precisely the same.

IVe now come to the procedure to be adopted in the actual painting of the portrait.

The first sitting should be devoted to finding the best pose 
and to settling, if possible, all questions of costume and background. The most favourable light and shade should be very carefully studied, and generally the whole arrangement of the picture thought out. It is often as well to make a small sketch of this arrangement, but I do not think that this sketch need be at all elaborate. There is always a danger, if an artist works too much at the preliminaries, that he may lose the freshness of his first impression.

When the arrangement is settled, a very careful drawing should be made with charcoal on the canvas. This drawing again should not be elaborate; only the really important lines should be given, but these should be as well given as the painter knows how. Some people consider that this careful drawing cramps the freedom of the subsequent painting. I hold precisely the opposite opinion. Nothing is so fatal to freedom of execution as the continual correction of errors, and nothing saves one more from the necessity of such correction than a careful preliminary drawing.

The charcoal may either be fixed or preferably gone over with some dark paint, such as raw umber, made fluid with turpentine. This gives a line which is less likely to be completely lost before it has served its purpose.

The first painting should be with a big brush and full paint. The way of putting on the paint should be very carefully attended to, as the texture of the finished work will, to a great extent, depend on this first painting.

That is to say, rough surfaces should be painted roughly and smooth surfaces smoothly, and the brush-marks should be directed in the way which best expresses the modelling of the original.

If a head can be finished at this one sitting, there is an immense gain in vivacity of touch and freedom of execution, but this is a very difficult business for anybody but Mr. Sargent, and even he has very often to take his work out and do it again 
and again before he gets it to his satisfaction. Lesser men, if they try for this freshness, are apt to get it at the expense of much more valuable qualities. It is not difficult to finish a head at a sitting if one is content to leave it ill-drawn, ill-coloured, and a bad likeness.

To any beginner I should say: Do not attempt the impossible; get your first painting as right as you can, but it is sure to be wrong in many particulars. Leave it to dry, and then take it up again; you will find plenty to improve in it.

But unless radical alterations are required, the subsequent painting need not be very robust. The necessary impasto and the suggestion of texture can very well be got at the first painting. All that is necessary afterwards is to correct and refine. Some vigour will probably be lost in the process, so it is better to have the foundation rather too rough than too smooth.

Draperies have mostly to be done at once. There is no getting a fold into the same place again when once disturbed. A certain refinement and some modification of tone can be added afterwards, but if the drapery is wrong, it simply has to be repainted. Some sitters are so fidgety that it is almost impossible to paint their clothes from them; in this case recourse must be had to the professional model, but this is always a pity.

It is still more of a pity if a lay figure has to be used, but where a very elaborate pattern occurs it is difficult to avoid so doing. This difficulty hardly arises except in the skirt of a lady's dress. In the bodice it is generally possible to do a piece at a time, whereas a skirt must be treated as a whole. In any case, the general form of the drapery must be carefully sketched in from life, and it must then be arranged on the lay figure in the same general lines.

One of the most difficult things in portraiture is the proper 
painting of hands; indeed, as we have seen, some of the great painters have failed in this respect.

The reason for this is that it is quite unnatural for anyone but the trained model to keep his hands still for any length of time, and there is so much independent movement of the fingers that it is extraordinarily difficult to replace $a$ hand in precisely the same position that it had before. Also, many sitters are very awkward in the posing of their hands, and if the artist tries to pose them himself, the position is apt to seem unnatural. In spite of these difficulties, the temptation to follow the practice set by Vandyke, of employing professional models for the hands, should be strenuously resisted. A hand is as much an essential part of the sitter as his nose, and there is no more justification in using a model for one than for the other.

The problem is difficult, but it can be solved-mainly by the commonplace method of devoting a good deal of time and trouble to it.

A hand is in some ways more difficult to paint than a head, and the artist should be prepared, if necessary, to give more time to painting the former than he gives to the latter.

This question of time, however, is an important one. Other things being equal, it is far better that a portrait should be done quickly. It is very disastrous if the sitter gets bored; and if the artist gets bored too, it is simply fatal. At the same time, it is of no use to scamp one's work, nor to be content with obvious errors, because correcting them would take too long. Therefore, the portrait painter must do his work at high pressure, must never waste his time, and must, if possible, prevent his sitter from getting bored. To achieve this latter object it is essential to engage the victim in conversation, not necessarily all the time, but at judicious intervals.

This is one of the problems of my profession. When the 
artist is absorbed in his work, the last thing he wants to do is to talk. But the sitter has nothing to absorb him, so the time that flies so rapidly with the artist, crawls very slowly with his unfortunate patient, and soon that dull and hopeless expression creeps over him which is so fatal to the success of any portrait. This must be conjured away at any cost, and undoubtedly the best way is to get the sitter to talk. The less talking the artist does the better, but he should cultivate the gift of drawing out his sitter.

Personally I supplement this fitful conversation by placing a large looking-glass behind me, so that the sitter can see the progress of the picture in it. (This also is the practice of $\mathrm{Mr}$. Lavery, and doubtless of other artists.) Some painters are very chary of showing their pictures until they are finished, but I cannot for the life of me see that there is any harm in letting other people see the steps by which our results are achieved. This watching of the progress of the picture has naturally a great interest for the subjects of it, and has the incidental advantage that they can see, more or less, when they are out of the pose, and can correct it for themselves.

The looking-glass serves a double purpose. I never paint without having one behind $m e$, as it is so invaluable in correcting errors of drawing. The most usual error is that of distortion-that is, a head is drawn with the features all crooked; for instance, one eye higher than the other, the mouth all awry, and the nose on one side. If not corrected at once, the artist soon gets accustomed to this distortion, but if he looks in the glass he sees it precisely reversed, and the crookedness seems even worse to him than it really is. The glass also puts the picture further off, and enables him to judge of the effect at a distance without having the trouble of going so far away. This is particularly valuable in a small studio. 


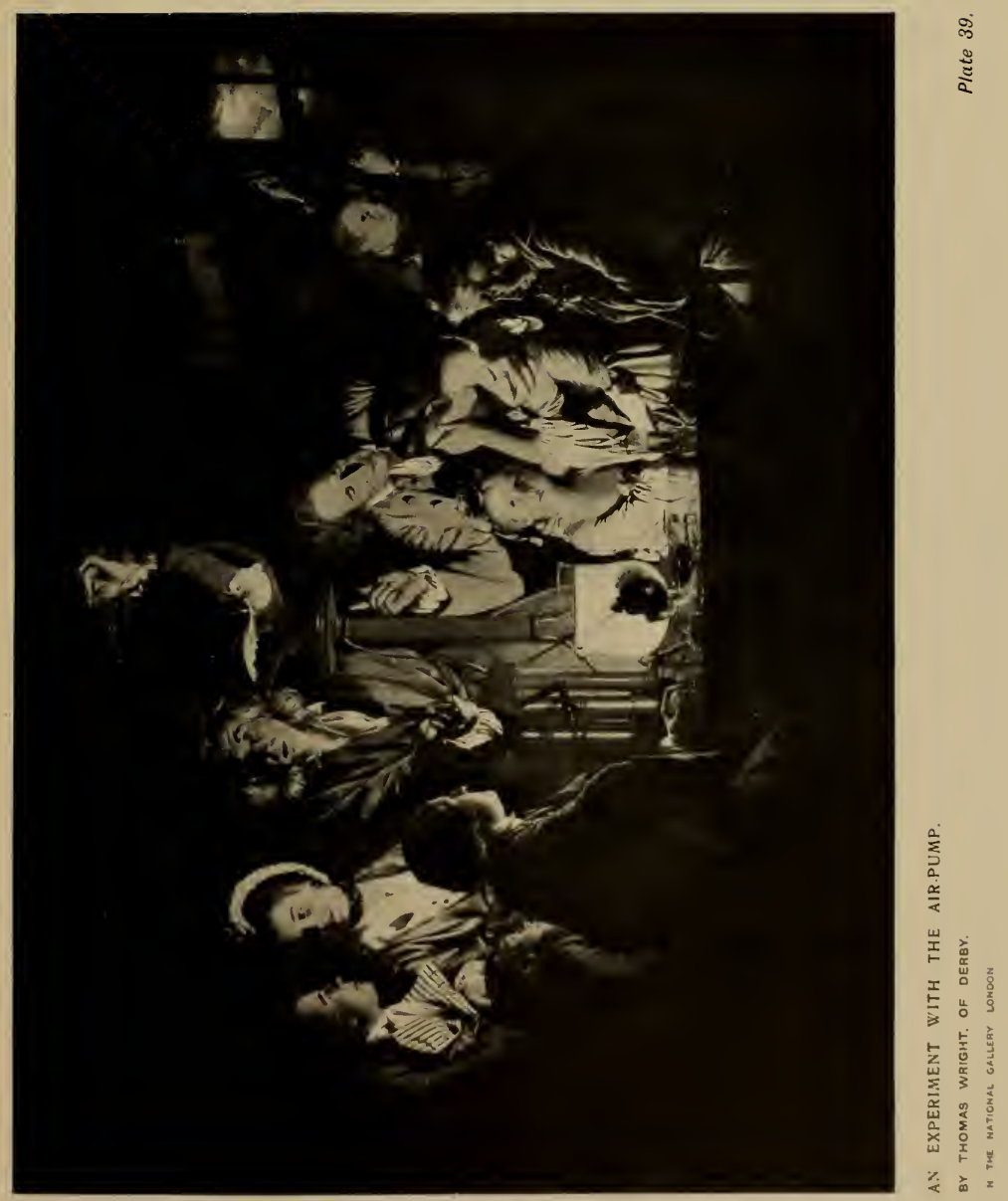



Is it possible to lay down any rules about the arrangement of light and shade? I think no definite rules can be given, but there are one or two hints that may be of service to the beginner. I have already mentioned that a high light is generally more becoming than one from the side. A strong side light often has a somewhat distorting effect upon the features.

A rugged and forcible head is, of course, made still more forcible by strong shadows. The delicacy of a child's or of a young woman's head is best preserved by a rather full light without strong shadows.

There is one curious distinction that I have noticed in the practice of the great masters with regard to male and female portraits. They were very fond of representing heads in the threequarter view (unduly so to my mind); with male portraits the head was nearly always turned away from the light, so that the smaller side of the face was in shade, or at any rate so that the nose was outlined by shadow. In the female portraits the light comes very often from the side to which the head is turned. This certainly gives more softness to the features, and has a slight tendency to diminish the apparent size of the nose.

It is odd that artificial light is so little used in portraiture, and yet Schalken and Honthorst have shown by their excellent studies of heads lit up by candlelight how much can be done in this style; and, later, Wright of Derby carried the method to great perfection in his portrait groups, of which "The Experiment with an Air-pump," in our National Gallery, is an admirable example. (Plate 39.)

But with the exception of a few theatrical portraits, such as the one of Mrs. Patrick Campbell by Mr. Solomon, where the effect of the footlights is well given, there is very little use of artificial light in modern work. I think it is unduly neglected; we have many advantages over the older painters in the greatly improved means of illumination that we possess. The great difficulty 
used to be that all the colours are falsified by candlelight, which is so yellow that it practically cuts out all the blues; the result being that the whites and yellows become almost indistinguishable, and the blues merge into the greens, the reds and pinks becoming more orange, so that a picture painted by candlelight looks quite false in colour when seen by daylight.

But now we have the incandescent gaslight, which shows colours very well. It is a good deal greener than daylight, but much nearer to it than the orange light of lamps or candles. The arc electric light is nearer still. Indeed, all colours are seen by it with practically no alteration, but it is an inconvenient light to use. The ordinary or incandescent electric light is, on the other hand, very convenient, but it is nearly as yellow as candlelight, and consequently treacherous. The Nernst lamp, which can be used with the ordinary electric fittings, is much whiter, and, I think, will be found very useful.

There are many advantages in the use of artificial light. For one thing, to the artist who uses it, fogs and dark winter days have lost their terrors. Also, there are many sitters who can come in the late afternoon and evening more easily than in the daytime. Again, very strong and interesting effects can be obtained by this means. A rugged head often looks magnificent by artificial light. Nor is there anything unnatural in its use: the modern man is as well known to his friends by artificial light as by daylight. There is no reason that his portrait should always represent the daylight aspect of him.

Altogether I think much can be gained by greater freedom and variety of lighting, and in this direction we have great advantages over our forerunners.

Before leaving this intricate question of the proper illumination of a portrait, I must say a few words about the toning down of subordinate parts, and the consequent emphasising of the 
important features. Rembrandt carried this very far, and his example has been followed by many modern artists.

I think that when plausibly done this toning is quite legitimate, and is specially serviceable in disguising the ugliness of modern costume. A pair of trousers is perhaps the most hopelessly unpictorial article of clothing that has ever been invented; so any means of distracting the eye from it is most welcome. The simplest means is to cast it into shadow-an expedient that can be adopted with any other part of the picture that it is advisable to suppress. The only stipulation I should make is that this toning down should bear some relation to natural effects, and not appear an entirely arbitrary arrangement of light and shade. I have already mentioned that Rembrandt often errs in this respect, and I feel sure that here his example should be avoided. With care and some little ingenuity the required effect can be produced quite naturally. The background may be much further away from the source of light than the sitter, and therefore more faintly illuminated. Again, it is quite legitimate to suppose that shadows are cast upon the sitter and his surroundings by objects of some kind in front of him. Indeed, these shadows can be actually produced in the studio by spare canvases, which may be taken to represent articles of furniture that are in front of the picture, and consequently not seen. As a rule, these shadows should be painted frankly as cast shadows-that is, with more or less of an edge, and with some definite form. But however the effect is produced it should look natural.

Then comes the question of size. It has long been a convention that portraits should be of the size of life or else very small indeed, in which case they are called miniatures. There is no reason in the nature of things why they should not be painted of some intermediate size; and, of course, they sometimes are, but on the whole it is not usual. This is a pity, for anything that gives 
variety in portraiture, if only in size, should be cultivated, but the fact remains that most portraits are of what is called life-size. In looking round an exhibition, however, it will at once strike the observer that the term admits of very different interpretations. What it generally means is that the head on the canvas measures about the same in length and breadth as the head of a real person - that is, about nine inches high for a man, and about eight inches for a woman. In other words, the painting looks the size the sitter would look if he were standing in the frame with his head on a level with it.

Some artists, however, maintain that the sitter's head should always be considered to be some way behind the frame, and, according to this principle, they make the painted head decidedly less in measurement than the real one-still declaring that it represents the size of life. This contention is logically unassailable if there is any part of the picture that projects in front of the head. For instance, in a sitting position the knees are often a good deal in advance. If they are painted of the actual dimensions of life, it is obvious that the head, which is further back, should be on a somewhat smaller scale. This holds still more if there is a table or any other piece of furniture in front of the sitter. As I have said, this is undoubtedly logical, but the practice has its drawbacks. People are so accustomed to look chiefly at the heads of portraits-indeed, artists often force them to do so by toning down everything else-that they seldom stop to consider whether or not these heads are supposed to be further back than other parts of the picture. They do not recognise the reason for the alteration of scale, and merely see that the reduced heads look small and consequently weak in comparison with those in which this reduction has not taken place.

Other things being equal, the larger the size the more vigorous and striking is the portrait. This is so well recognised that many 
artists deliberately paint a little over life-size. Rembrandt did this very markedly in his later work. With Frank Holl it was habitual, and Professor von Herkomer and many lesser men carry it rather far in our day. Personally, I consider this practice illegitimate. I daresay we should all be more impressive if we were a good deal bigger. But being the size we are, I think our portraits ought to represent us as of that size and of no other.

It is obvious that a portrait can be as much smaller than life as the artist likes without sacrificing truth; it merely represents the sitter as so much further behind the frame. But it cannot truthfully be larger than life, unless the figure is supposed to be in front of the frame, which is absurd. I see no reason, however, in those cases where there is nothing that comes further forward than the head, why it should not be of the precise dimensions of life; it can be supposed to be on the level of the frame. In those cases where the head must, in the nature of things, be further back than other parts of the picture, my reason entirely agrees with those artists who paint it under life-size, but $I$ have to confess that my practice does not always follow my reason. I am so much impressed by the meagre and skimpy appearance of a head just under life-size as compared with other portraits of the full dimensions (and in exhibitions these latter will be sure to predominate) that, although I never paint my heads bigger than life, yet I often paint them as big when, in strict logic, they ought to be reduced. It is wrong, I know, but I err in very great company. It is especially in full-lengths that the difficulty arises. The figures are mostly represented with a good deal of floor space in front of their feet, so as not to bring the feet too near the edge of the frame. Unless the perspective is uncomfortably steep, this strip of floor means that the figures are a yard or so behind the frame and ought to be small in proportion; but they are not usually so painted. 
Personally, I make a compromise. I generally show very little floor in front of the figure, and so get rid of most of the apparent diminution.

It must also be recollected with regard to full-lengths that these large pictures should be looked at from some way off, and the further away the spectator stands the less necessity is there for a diminution of the figure.

All these difficulties are got rid of by painting the sitters quite frankly of a much smaller size than life. There is then no competition with life-sized work, and all questions of perspective can be much more easily arranged. Also, there is more scope for the representation of the actual surroundings: if the figures are on a small scale there is less difficulty in showing the room they are in.

Fine examples of this can be seen at our National Gallery in the wonderful group by Van Eyck of the Italian merchant and his wife that is reproduced in an earlier chapter, and in the very fine Terborg that hangs in an adjoining room.

It is hopeless to recommend the example of Van Eyck as one to be followed by modern painters, as they none of them seem to have the time and patience to emulate him in his exquisite rendering of minute detail. But it is more possible to follow Terborg-at any rate, it would be very well worth trying, and a great relief in the midst of the acres of sloppy canvases that sprawl at large over the walls of our exhibitions. So there are more reasons than that of mere variety for experimenting with portraiture on a reduced scale.

There has been a revival of late of actual miniature painting, but this is so special an art that it hardly comes into the scope of a book on ordinary portraiture. At any rate, I must confess that I know too little of the technique of miniature work to be able to discuss it with any advantage. Nor, indeed, have I sufficient 


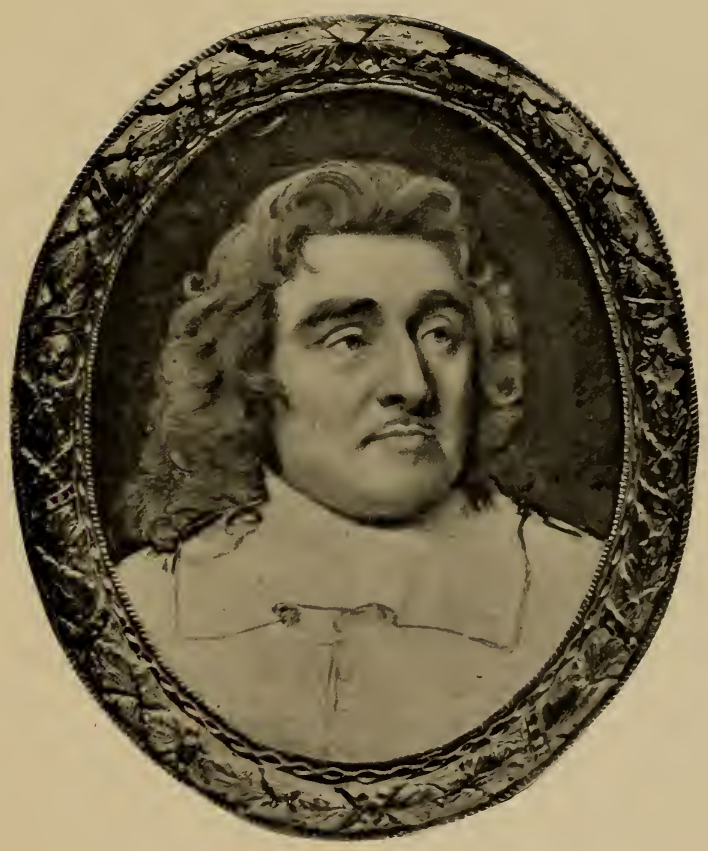

DUKE OF ALBEMARLE (GENERAL MONK).

From the MiNiaTURE BY SAMUEL COOPER.

Plate 40. 

sympathy with the art; it has always been, except in its earlier days, such a highly artificial form of portraiture; and the modern revival seems to be mostly in the hands of the amateur, aided by the photographer. There are some genuine artists who practise it, but they are all too few. I should like, however, to counsel the young miniaturist to seek inspiration from the more virile phase of his art, to go back to Samuel Cooper (Plate 40), or even earlier, to the Clouets, rather than to attempt the elusive charm of Cosway and his successors-and, if possible, to avoid the painted photograph.

I must now end these very fragmentary hints, which are, of course only intended for beginners. They may, perhaps, help these beginners to avoid some of the pitfalls that beset their path. For the rest, I must refer to the account I have given of the methods of the great painters, but it is so difficult to get really trustworthy information as to these methods, and at the best they are so diverse that it is cruel to turn the student loose amongst them and to tell him to choose for himself without any further guidance.

My own view is that the greatest of all the portrait painters is the one whose aims and methods are the best, and also the easiest to follow. For what it achieves there is no simpler technique than that of Velasquez. His aim was to take a man as he found him, and to represent him truthfully and naturally; he also sought for harmony of line and colour, but never at the expense of truth.

His technique was devoted to the attainment of this aim in the simplest and most direct manner. Unlike many other painters, he was never the slave of his technique; he had no hard-and-fast rules, such as that the painting had to go through certain stages, or that each part of the picture should be painted at one sitting, or that certain parts should be painted thickly and others thinly, etc. If the painting came right at first he left it-if not, he modified it until it did. 
The picture was well thought out beforehand, so that little actual correction was needed; but when it was needed he gave it without hesitation and without any fad as to repainting the whole picture when only a part of it was wrong. If thin painting was sufficient to give the effect he painted thinly. If a suggestion of texture was required he painted thickly and roughly enough to give it with the least labour. He could suggest a surface by brushwork in a way that has only been excelled by Rembrandt, but he never paraded this brushwork. The last thing that Velasquez ever seemed to think of was the cleverness of his technique.

And his was an example that in a humble way we can all of us follow. The simpler the technique, the easier it is to learn: once it is learnt the less it is thought of the better. When actually painting we should be absorbed in the one aim of adequately representing what we see. We should be thinking of nature and of harmony of line and colour, not of technique. As Millais said, "Get the thing right, no matter how you do it."

If we have learnt too elaborate a method we have to be always thinking of it; if we have learnt no method at all, or learnt one inadequately, our representation will be fumbling and defective.

If we resolutely pursue this aim of getting the thing right (in the artistic sense) in the simplest possible way, we shall be improving our technique all the while, as Velasquez did-till in our old age even the clumsiest of us may have achieved some method of masterliness.

But if we are always trying to be clever instead of endeavouring to represent more and more truthfully what we see, we shall most assuredly degenerate into mannerism-which is the Grave of Art. 


\section{N D E X}

$A$

Accessories in portraiture, 85

Alexander, Miss, Portrait by Whistler of, 63,64

Alexander the Great, Portrait of, 2

Alma-Tadema, Sir L., R.A., Advice to portrait painters by, 87

Anne of Cleves, Portrait by Holbein of, II

Ariosto, Portrait by Titian of, 42

Artificial light, Use in portraiture of, 97

"A Vele Gonfie," by J. S. Sargent, R.A., 75

\section{B}

" Bacchus," by Velasquez, 45

Background, Realism in, 77, 80, 84, 90

"Banquet of the Civic Guard," by Van der Helst, 13 ; Sir J. Reynolds on, 14

Bastien-Lepage, J., Portrait of his grandfather by, $8 \mathrm{I}$

Benci, Ginevra de', Portrait by Ghirlandajo of, 5

Bordone, Portrait of a Lady by, 8

Byzantine portraiture, 4

\section{C}

Campbell, Lady Archibald, Portrait by Whistler of, 65

Campbell, Mrs. Patrick, Portrait by S. J. Solomon, A.R.A., of, 97

Canvas, Question of, $9^{1}$

Caricature in modern portraiture, $3,32,78$

Carlyle, T., Portrait by Whistler of, 63

Characterisation in portraiture, 77

Children, Difficulties in painting of, 86

Classic portraiture, 1,2
Clothes, Tyranny of, in portraiture, 8; methods of painting, by great artists, 50 ; influence of, in portraits of women, 79

Cooper, Samuel, ro 3

Corder, Miss Rosa, Portrait by Whistler of, 65

D

Dante, Portrait by Giotto of, 5

Duret, M. Theodore, Portrait by Whistler of, 63,67 ; on Whistler's methods, 67

Dutch School of Portraitists, Greatness of, I2

\section{E}

English School of Portraitists, Grace and charm of 18 th Century, 9; decadence of, 20; chief painters of, 20 ; modern members and work, of, 26, 34

Eyck, Van, family, 1o

Eyck, Jan Van, as inventor of oil painting, so ;

"Flemish Merchant and Lady," ugliness of, 10

\section{F}

Fayoum, Funeral portraits of, 2, 4

Filippo, Fra, as painter of portraits, 5

"Flemish Merchant and Lady," by Van Eyck, Ugliness of, 10 ; size of, 102

Flemish School of Portraitists, Interest of, to France, Portraiture in, 25

\section{G}

Gainsborough, T., R.A., as a painter of hands, 14 ; productiveness of, 21,23 ; inequality 
of work of, 21 ; as colourist, 22 ; "The Linley Sisters," 21 ; methods of, 57 ; "Mrs. Robinson ('Perdita ')," 58 ; use of long brushes by, 9I

Ghirlandajo, as portraitist, 5

Giotto, Influence of, 4 ; as realist, 5 ; portrait of Dante by, 5

Gisse, George, Portrait by Holbein of, 39 Gladstone, W. E., Portrait by Millais of, 62

Goya, 33

Gozzoli, Benozzo, as portraitist, 5

Greek portraiture, 2

Griffiths, John, on Mr. Watts's methods, 70

Grote, Mr., Portrait by Millais of, 62

Guthrie, Sir J., P.R.S.A., Work of, 34

$\mathrm{H}$

Hals, Frans, Work at Haarlem by, 12 ; fleshpainting of, 13 ; technique of, $25 ; \mathrm{Mr}$. Sargent compared with, 32, 33; methods of, $51,5^{2}$; success with portrait groups of, 79

Hamilton, Lady, Portraits of, by Romney, 22

Hands, Importance in portraiture of, I3, I4, 95; neglect by English artists of, 21 ; neglect by Vandyke of, 53,54

Holbein, Hans : appointed Court Painter to Henry VIII., II ; portrait of Anne of Cleves, 11 ; as realist, II ; methods of, 36 ; "Pre-Rafaelite" methods of, 37 ; drawings of, 37,38 ; " George Gisse," 39 ; care for outline of, 39 ; principles of, 50

Holl, Frank, R.A., as rival to Millais, 28 ; characteristics of work of, 28

Honthorst, Use of artificial light by, 97

Hoppner, J., 25

\section{I}

Impressionism, Tintoretto founder of, 37 Intensity, an essential of portraiture, 63

Italy, Portraiture in, in Middle Ages, 4 ; in I6th century, 6 ; fine ideal of portraiture in, Io

$$
\text { J }
$$

Johnson, Dr., Portrait of, by Reynolds, 23

\section{K}

Kneller, Sir Godfrey, 20

\section{L}

"La Bella," by Titian, Stiffness of pose of, 8 Landscape in portraiture, $80,8 \mathrm{I}$

"'Las Meninas," by Velasquez, 18, 43, 44, 45, 46,60

Lavery, John, R.S.A., Style of, 34 ; methods of, $75,76,96$

Lawrence, Sir T., P.R.A., "Artificiality" of work of, 25

Lely, Sir Peter, 20

Leonardo, as portrait painter, 6 ; as innovator in methods of chiaroscuro, 6 ; unproductiveness of, 7 ; "Monna Lisa," 7 ; methods of, $37,5^{\text {I }}$

"Lessons in Anatomy," by Rembrandt, 14, 49 Light, Questions in portraiture of, 82,85 Linley, The Misses (Mrs. Sheridan and Mrs. Tickell), Portrait by Gainsborough of, 22 Lippi, Filippino, as portraitist, 5

\section{$\mathrm{M}$}

Mannerisms-" the grave of art," ro 4

" Maria Luisa de Tassis," by Vandyke, 19

Masaccio, as painter of portraits, 5

Menpes, Mr. Mortimer, on IVhistler's methods, 66

Michel-Angelo, as portraitist, 6

Millais, Sir J. E. P.R.A., as the founder of modern British portraiture, 27 ; as realist, 27 ; originality of, 27 ; "John Ruskin," 27 ; characteristics of portrait works of, 28 ; lack of simplicity in colour of, 29 ; methods of, 6o, 6r ; "Miss Eveleen Tennant," 61 ; "Mr. Grote," 62 ; " Gladstone," 62 ; method in painting children of, 86 ; arrangement of studio of, 88

Miniature painting, 99, 102, 103

"Monna Lisa," by Leonardo, $7,5^{1}$

Moroni, Portrait of a Lady by, 8 ; as specialised portraitist, 9 ; "The Tailor," 9

" My Mother," by IVhistler, 63

\section{$\mathrm{N}$}

Nero, Colossal Portrait of, 3

"Night IVatch, The," by Rembrandt, Misnaming of, 15; Van Hoogstraten on, 16,49

Northcote, J., R.A., as portraitist, 25 
O

Oil-painting, Invention of, 6, I0, II

Open-air portraiture, $80,81,82$

Orchardson, W. Q., R.A., Style of, 3I, 72 ; portrait of Viscount Peel, $7^{2}$

Outline, Holbein's use of, 39 ; in art and nature, 40 ; use of, by Velasquez, 46

\section{P}

" Parson's Daughter, The," by Romney, 22 Peel, Viscount, Portrait by Orchardson of, 74 Pompeii, Paintings at, I, 3

" Pope Leo X.,", by Rafael, 7

Portraiture, Sincerity an essential of, 25 ; demand for verisimilitude in, 26,30 ; " outline" in, 40 ; proportion in, 40 ; advantage of rapidity in, $5 \mathrm{I}$; position of canvas and sitter in, 60 ; intensity an essential of, 63 ; realism in, 77 ; characterisation in, 77 ; colour and light in, 78 ; clothes in, 79 ; open-air, 80 ; questions of light in, 82,85 ; studio arrangements for, 83 ; accessories in, $85 ;$ groups in, 85 ; children in, 86 ; studio for, $87,88,89$; question of canvas, 91 ; procedure in, $9^{2}$, $93,94,95,96,97$; artificial light in, 97 ; "toning down " in, 99 ; size in, 99

Pre-Rafaelite Brotherhood, Millais and, 27, 29

Pre-Rafaelites (1 $5^{\text {th }}$ century), Style of, 37

Prinsep, Miss Alice (Mrs.' Stracey Clitherow), Portrait by Watts of, 70

Pulido y Pareja, Admiral, Portrait by Velasquez of, 43,83

\section{$\mathrm{R}$}

Raeburn, Sir H., R.A., Originality of, 25 ; methods of, 58,59 ; "Sir John Sinclair," 59

Rafael, as portrait painter, 6 ; "Pope Leo X.," 7 ; methods of, 37

Ravenna, Mosaics at, 4

Realism in portraiture, 77

Rembrandt, Boldness and resourcefulness of, 2 ; vitality of work of, 7 ; greatness of, as portraitist, 12, 14, 49; born at Leyden, 14; style of, 14, 15; "Lesson in Anatomy," 15, 49; " The Night Watch," 15; "The Syndics of the Clothworkers' Guild," 16 ; colour of, 17,48 ; breadth of treatment of, $4 \mathrm{I}$; defects of, 42 ; methods of work of, 47,48 ; portrait of himself, 48 ; inequality of, 49 ; as colourist, 79

Reynolds, Sir J., P.R.A., as a painter of hands, I4; on Van der Helst's "Banquet of the Civic Guard," 14 ; dates of, 20 ; productiveness of, $2 \mathrm{I}, 23$, "Mrs. Siddons as 'The Tragic Muse,'" 22 ; colour of, 22 ; "Dr. Johnson," 23 ; lack of "likeness" in portraits of, 39 ; merits and defects of, 55 ; methods of, $55,56,57$

"Robinson, Mrs. ("Perdita ')," by Gainsborough, $5^{8}$

Roman portraiture, 3

Romney, George, Period of, 20 ; productiveness of, 2I, 23 ; "Lady Hamilton" and "The Parson's Daughter," 22 ; methods of, $5^{8}$

Ruskin, John, Portrait by Millais of, 27

\section{S}

Sargent, J. S., R.A., Comparison of his work with Velasquez's and Hals's, 32 ; "Master of Portraiture," 33 ; methods of, 75 ; " Ả Vele Gonfie," 75

Schalken, Use of artificial light by, 97

Scottish School of Portraiture, Style of modern, 34

“Siddons, Mrs., as 'The Tragic Muse,' " by Reynolds, 22

Sincerity, an essential of portraiture, 25

Sinclair, Sir John, of Ulbster, Portrait by Raeburn of, 59

Solomon, S. J., A.R.A., Portrait of Mrs. Patrick Campbell by, 97

Spanish School of Portraitists, 17

Studio, Arrangement for portraiture of, 87 , 88,89

" Surrender of Breda, The," by Velasquez, 18 "Syndics of the Clothworkers' Guild," by Rembrandt, 16, 49

\section{T}

Tennant, Miss Eveleen (Mrs. Frederic Myers), Portrait by Millais of, $6 \mathrm{I}$

Terborg, Small portrait by, 102

Tintoretto, as founder of "Impressionism," 37 ; motto of, 40 ; breadth of treatment of, $4^{1}$; methods of, $5^{1}$ 
Titian, as portraitist, 6 ; position of as painter, 7 ; " stiffness" of female portraits of, 7 ; "La Bella," 8 ; "L'Homme au Gant," 8 ; breadth of treatment of, 40 ; methods of, $4 \mathrm{I}$; portrait of Ariosto, $4^{2}$; as colourist, 79

\section{V}

Van der Helst, "Banquet of the Civic Guard " of, 13

Vandyke, Portraits of women by, and their "stiffness" of pose, 8; characteristics of, 9 ; as a painter of hands, 14 ; as pupil of Rubens, 19 ; facility of, 19 ; female portraits by, 19 ; knighted, 19 ; productiveness of, 19; methods of, 53 ; "Lord Wharton," 54

Varro, Portrait Gallery of, 3

Vasari, on Giotto, 4 ; on invention of oil painting, ro

Velasquez, Boldness and resourcefulness of, 2 ; vitality of work of, 7 ; portraits of women by, 8 ; position of, as portraitist, 14, 17 , 49 ; stiffness of work of, 17 ; style of, 17 ; "manufactory " of, 18 ; "Las Meninas," $18,43,44,45,46,60$; "The Surrender of Breda," I8; Whistler compared with, 29, 64; naturalness of, 30 ; Sargent compared with, 32 ; hardness in early work of, 33 ; breadth of treatment of, $4 \mathrm{I}$; defects of, $4^{2}$; methods of work of, 43,44 ,
45,47 ; becomes presbyopic, 46 ; use of outline by, 46 ; compared with Titian, 47 ; inequality of, 49 ; use of long brushes by, 57,91 ; as colourist, 79 ; arrangement of studio of, 88 ; simplicity of technique of, 103

Venetian School of Portraitists, Characteristic of, 9

\section{IV}

IVatts, G. F., R.A., "Over-ratedness " of, as portraitist, 30 ; as colourist, 31 ; as poet and dreamer, 69 ; faulty drawing of, 70 ; portrait of Miss Prinsep, 70 ; methods of, $70,71,72,73$

Wharton, Lord, Portrait by Vandyke of, 54

Whistler, J. McN., Influence of, 29, 63 ; compared to Velasquez, 29, 64; lack of " lifelikeness " in work of, 30 ; originality of, 63 ; portraits of his mother, Carlyle, Miss Alexander, and M. Theodore Duret by, 63 ; decorative treatment of, 64 ; methods of, 64,$65 ; \mathrm{Mr}$. Menpes on methods of, 66 ; M. Duret on methods of, 68 ; "emptiness" of portraits by, 69

Women, Influence of costume on portraits of, 8,79 ; portraits by 18 th century artists of, 20,24 ; in French art, 25

Wright, of Derby, "The Experiment with an Air-Pump " by, 97 




\section{A PORTRAIT PAINTER ON PORTRAIT PAINTING.}

(By A. G. Gardiner.) "The Art of Portrait Painting." By the Hon. John
Collier. Casselt, 108. 6d.

There is a pleasant unpretentiousness about this book that makes amends for the absence of literary workmanship or a deeply-considered study of the subject. Mr. Collier would more truly describe his work as "Notes on the Art of Portrait Painting." He puts down as he goes along in an easy, conversational way, his ideas and experiences in reference to an art about which he writes as an expert. He says much that is illuminating to the mere lover of por traiture, and still more that is helpful to the student. His subject is divided into three sec tions-an historical summary, a chapter on the aims and methods of the great masters, and a chapter on the practice of portraiture.

The attempt to render the human face in line or colour is as old as civilization, and Mr. Collier considers that in one particular, that of rendering the essential dignity of the human face and figure, it is likely the Greeks have never been equalled. In painting as in sculpture the art of ancient Rome was a debased rendering of the art of Greece. Then with the development of Byzantine formalism in the sixth century the night of the Middle Ages settled down upon art. Portraiture emerged with Giotto, who; as Vasari says, introduced "the custom of accurately drawing living persong from nature, which had not been used for more than 200 years." "Nor, Two centuries much longer," adds Mr.. Collier, as in Reynolds' " Johnson," or of convincing and Gain in Reynolds" "Nelly O'Brien" and I and Leonardo had probed, with his miraculous the "Morning Walk." But Reynolds, with his combinatioiz of art and science, all the mysteries 150 portraits in a single year, suffered from over of light and shade, leaving in "Monna Lisa "one production, and Gainsborough, wilh his prefe. of the sunreme examples of the world's por rence for landscape, adopted in his portraiture traiture. Titian, Raphael, and Mroni sounded a cavalier summariness which, splendid in its in their several manners nearly al the denths of highest efforts, easily passed into sketchiness the art, and meanwhile, in north, Europe, Jan and thence to unpardonable shallowness. In Van Eyck and Holbein had, in the wore Gothio many respects Raeburn, who has.come to full spirit, realied the possibilities of portraitu:c. recognition late, had most affinity both in tcehTruth and beauty are one according to the poet, nique and aim with the supreme masters, though but in portraiture they are divisible, and througl, he offers the singular example of one who began out grace and iseauty havebeen the chalacteristics with the broad, summary method and passed of the south; truth, acornful of mere charm, the later to a more detailed manner, thus reversing characteristic of the north. Mr. Collier does not the normal experience just as Bacon reverser exaggerate the place of Holbein in portraiture the normal course in writing prose.

He had the sincerest vision, the most unfaltering Again portraiture plunged downward with the truth of any painter in history, and if his method flsshy brilliance of Lawrence, to return to is hard it is magnificent as the negation of that nature and truth under the inspiration of the passion for sketchiness which has in moderm Pre-Raphaelite movement and the vigorous, art so often degenerated into sloply shallow wholesome genius of Millais. With Whistler ness. Mr. C'ollier would like to see a reaction in nortraiture became a decorative selieme and the direction of this genius for taking pains, Mr. Collier rightly ridicules the compariaon of this linear truth and definiteneas, this antithesis Whistler's flat and unsubsl-oxit sl figuros with of the sin of scanning.

portraiture reached its zenith : o contem- We do not agree with his depreciation of Watts porary art of Rembrandt and Velasquez. Mr. as a portraitist. His failureg were nany; bat Collier rightly gives the preference to the at his best he got at the heart of the liunan Spaniard. Velasquez had the objective truth of mystery with incomparable insight and cerHolbein. He saw with that large, comprehen. tainty. His art too has a sarger measure solbein. He saw with that large, comprehen. of that Rembrandt quality of subjective emotion sive, pasaion the art of any other English purtraitist, spesrean. There was nothing mean to his royal more indeed than that of any other artist except Boul, aud the dwarf, the jester, and the mendi more indeed than that of any other artist except eant are dowered, equally with l'one and King, Carriere, whose noble work finds no mention in with the majesty of humanity. Rembrsudt, on this book. English portraiture to-day is tomi. the other hand, expresses in all his portraiture who ls the embodiment in ari of the eosmopoli the Inmer drama of his own soul. Velagquez tan spirit of the time and whose gpecial contri. mees into the heart of the mystery before him; hution to portiaiture is tho infusion into it of a but lie tells us nothing of the greater mystery nute of sardouic satire, as clever as it is unplea. within him. Kvery stroke of Rembrandt's brush, on the other hand, is charged with his own deep broo is male in regard to him; but it is nut very true broodings and aombre umrest. We think only of of his methoil snd it is wholly mutrue of lis l'hilip, or Inncent, or Arlmiral P'sreja before the spirit. Even where Velasqueg pictured unplua eanvanen of Velasquez: in the canvases of Rom. sant persons, as Insovent X., he way enncerned brandt it is the painter who is ever hefore us. only with the truth. His okil eommeut is nevor The grest lutchuse is to the spaniard what intruiled.

Beethoven is to Bach. 
SMITHSONIAN INSTTUTION LIBRARIES

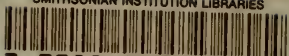

39088 00216910 The arf of portrait painting 